Ergün Lafl1

Jutta Meischner

\title{
Hellenistische und römische Grabstelen im Archäologischen Museum von Hatay in Antakya
}

\section{Einleitung}

Das Archäologische Museum von Hatay in Antakya ${ }^{1}$ verwahrt 32 teilweise gut erhaltene Grabstelen hellenistischer bis kaiserzeitlicher Entstehung. Sie sind nicht ausgestellt, sondern befinden sich ungereinigt auf einer Galerie gestapelt der Stadtluft ausgesetzt. Im Corpus der ostgriechischen Grabreliefs von E. Pfuhl und H. Möbius (1977) wurden sie nicht erfasst, weil die meisten erst in jüngerer Zeit angekauft oder vom örtlichen Straßenbauamt übernommen wurden. Präzise Fundortangaben stehen nicht zur Verfügung. Bis auf Kat. 4 sind die Stelen auch unpubliziert ${ }^{2}$. Die breite Skala der vertretenen Bildtypen bereichert die Kenntnis des ostgriechischen Grabreliefs jedoch nicht unerheblich. Ihre Diversität und schließlich die unterschiedliche Qualität, von spröder Einfallslosigkeit bis zu stimmungsvoller Charakterisierung, gibt Zeugnis von einer großstädtischen Klientel, die von verschiedenen Werkstätten zu verschiedenen Bedingungen von Anspruch und Einflussnahme bedient wurde. In ihnen spiegelt sich der Lebensstandard der syrischen Metropole seit dem Hellenismus bis zur mittleren Kaiserzeit. Eine Vorlage der im Galeriedepot verwahrten Stelen ist daher, in Fortsetzung des Katalogs für die Rundplastik im Museum von Antakya ${ }^{3}$, angezeigt.

\section{Katalog der Stelen}

\section{Naiskosstele mit Einlasszapfen}

Inv. 2388. - H $76 \mathrm{~cm}$; B $41 \mathrm{~cm}$. - Abb. 1.

Giebel mit Rosette, Seitenakrotere. Zurückspringendes Gesims, mehrfach gegliedert. Vorspringende Pilaster mit profilierten Kapitellen; darüber >Architrav . Eine Standleiste korrespondiert mit dem 〉Architrav . Im Feld darunter mehrzei-

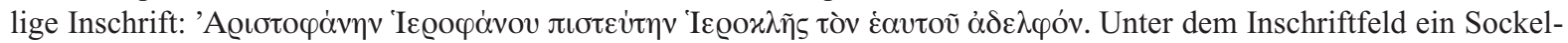
profil und niedriger Einlasszapfen. Die Pilaster bilden nicht die seitliche Begrenzung der Stele; neben ihnen verbleibt ein schmaler Streifen frei.

Den Hintergrund des Naiskos von Pilaster zu Pilaster decken die weichen Falten eines vertikal fallenden Parapetasma vollständig. In der Mitte davor steht die frontale, nach links blickende Panzerstatue eines Kriegers auf rechtem Standbein und leicht schräg gestelltem Spielbein. Chiton, Panzer mit Lederlaschen, Schulterklappen und cingulum sind fein unterschieden. Der Krieger trägt wadenhohe Lederstiefel. In der Linken hält er einen kleinen Rundschild, in der gesenkten Rechten eine vom Boden bis an den oberen Bildrand reichende Lanze. Die schlichte Komposition bei sorgfältig ausgearbeiteten Details, dem Standmotiv

\footnotetext{
${ }^{1}$ Unser Dank gilt der Generladirektion für Kulturgüter und Museen, Ankara, für die Publikationsgenehmigungen 1999 (J. Meischner) und 2005 (E. Lafl1) sowie insbesondere der Kooperationsbereitschaft von Faruk Kilinç und Erdal Y1lmaz, Museum Antakya. - Zitate und Abkürzungen folgen den Richtlinien des Österreichischen Archäologischen Instituts, s. <http:// www.oeai.at>.

${ }^{2}$ Die von A. Saraçoğlu 1997 angefertigte Dissertation wurde nicht publiziert.

3 J. Meischner, Die Skulpturen des Hatay Museums von Antakya, JdI 118, 2003, 285-394.
} 


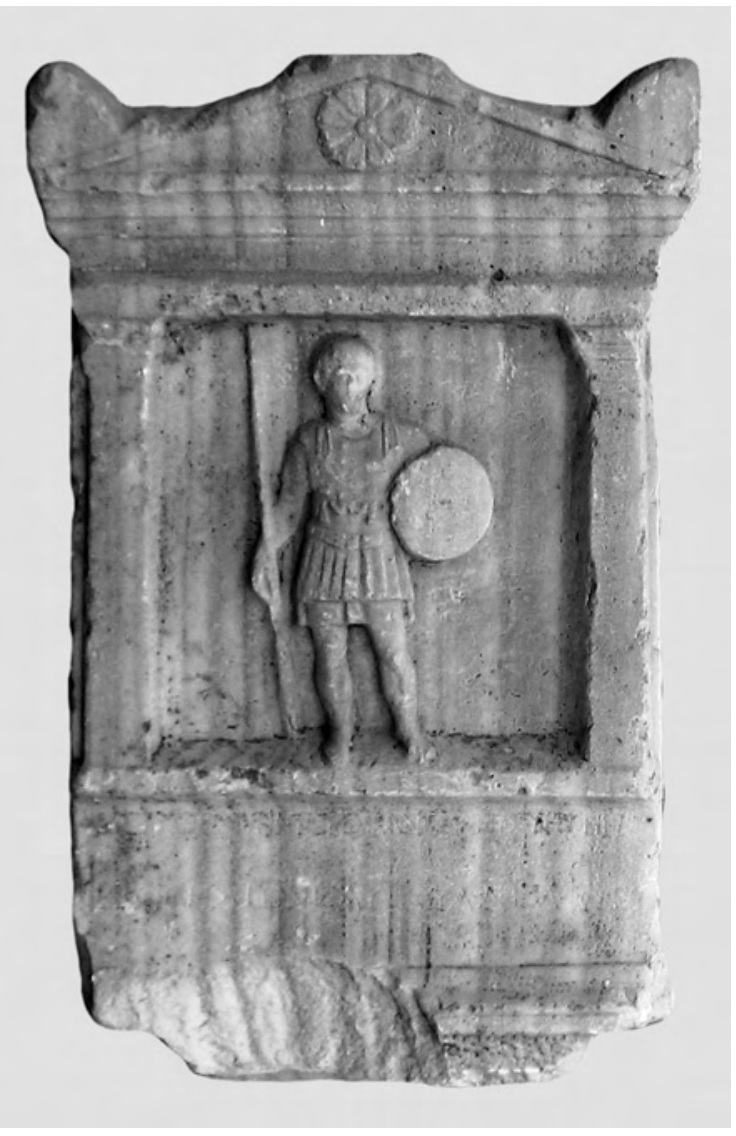

1 Kat. 1: Naiskosstele mit Einlasszapfen Inv. 2388

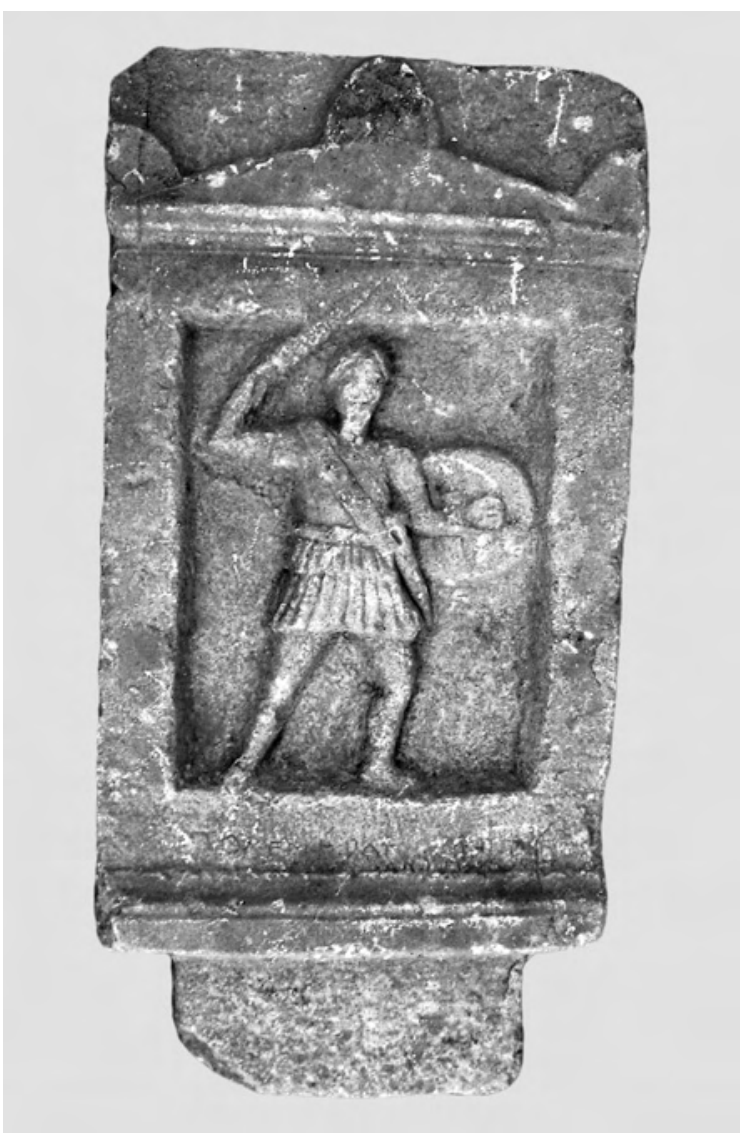

2 Kat. 2: Giebelstele mit Einlasszapfen Inv. 17843

im Kontrapost und dem stoffreichem Parapetasma, ist keine Massenarbeit und bleibt ohne Parallele. Die im klassischen Kontrapost dargestellte Statue des Kriegers mit Schild und Lanze steht wirkungsvoll vor dem stoffreichen Parapetasma, das in Breite und Höhe den gesamten Hintergrund ausfüllt. Auf zusätzliche Ausstattungselemente und Personen wird verzichtet. Der Typus des Grabreliefs strahlt klassische Ruhe aus, eine dekorative Monumentalität, die dem bescheidenen Format hohe künstlerische Würde verleiht. Die mehrzeilige, unakkurate Inschrift, nach der ein Hierokles seinem treuen Bruder Aristophanes, Sohn des Hierophanes, das Monument weiht, ist möglicherweise nicht zugehörig.

Eine Datierung der Stele kann sich nur auf Form und Ausdruck der Grabfigur stützen und die Feinheit der Ausführung berücksichtigen. Antiochia wurde 300 v. Chr. von Seleukos I. gegründet, kaum später muss die Stele entstanden sein. Die künstlerische Bezugnahme von Hintergrund und Hauptmotiv ergibt jenen »dezenten Stimmungsgehalt», der die Stele als eines der »qualitativen Spitzenstücke« kennzeichnet, die K. Parlasca als möglichen griechischen Import klassifiziert ${ }^{4}$.

\section{Giebelstele mit Einlasszapfen}

Inv. 17843. - H $72 \mathrm{~cm}$; B $36 \mathrm{~cm} .-$ Abb. 2.

Glatter Giebel, drei unausgearbeitete Akrotere, nicht freigeschlagen. Gesims und Fuß profiliert.

In hochrechteckiger Bildnische steht ein behelmter Krieger, frontal in Ausfallstellung. Er trägt einen Lederpanzer mit doppelter Laschenreihe und cingulum sowie ein breites Schwertgehänge mit Schwertscheide.

\footnotetext{
${ }^{4}$ Parlasca $1982,6$.
} 
Das Schwert in der erhobenen Rechten überschneidet den oberen Nischenrand. Der linke Unterarm ist durch ein Schildband gesteckt, sodass der Rundschild von innen zu sehen ist. Auf dem unterem Stelenrand einzeilige Inschrift: По $\lambda \varepsilon \mu$ - - $\alpha \tau-$ - - Der Stelentypus mit Krieger in Ausfallstellung von vorn mit Rundschild kehrt in qualitätsvollerer und etwas älterer Ausführung an einer Grabstele aus Stratonikeia in Bodrum wieder, die Antiochener Stele ist jedoch gröber und summarischer gearbeitet. Das Motiv und die räumliche Wirkung von Arm und Schild, auch der die Figur durchziehende Schwung der ausholenden Bewegungen weisen in hochhellenistische Zeit. Die Ausführung dürfte in ihrer flächigen Plastizität und wenig feinen Ausmodellierung kaiserzeitlich sein.

Vgl.: Özgan 1999, 154 GR 9 Taf. 51 d.

\section{Naiskosstele}

Inv. 9013. - H $63 \mathrm{~cm}$; B $33 \mathrm{~cm}$ - - Abb. 3.

Flacher Giebel mit verkümmerter Rosette und angedeutete Seitenakrotere im Block. Die Anten tragen korinthische Kapitelle. Ein bossierter Streifen des Hintergrundes über dem Kopf der Figur ist nicht geglättet. Füße und unterer Stelenabschluss fehlen. Das Gesicht scheint einem Ikonoklasmus zum Opfer gefallen zu sein; die linke Hand, ein Teil des rechten Unterschenkels und große Teile der Pilaster sind abgeschlagen.

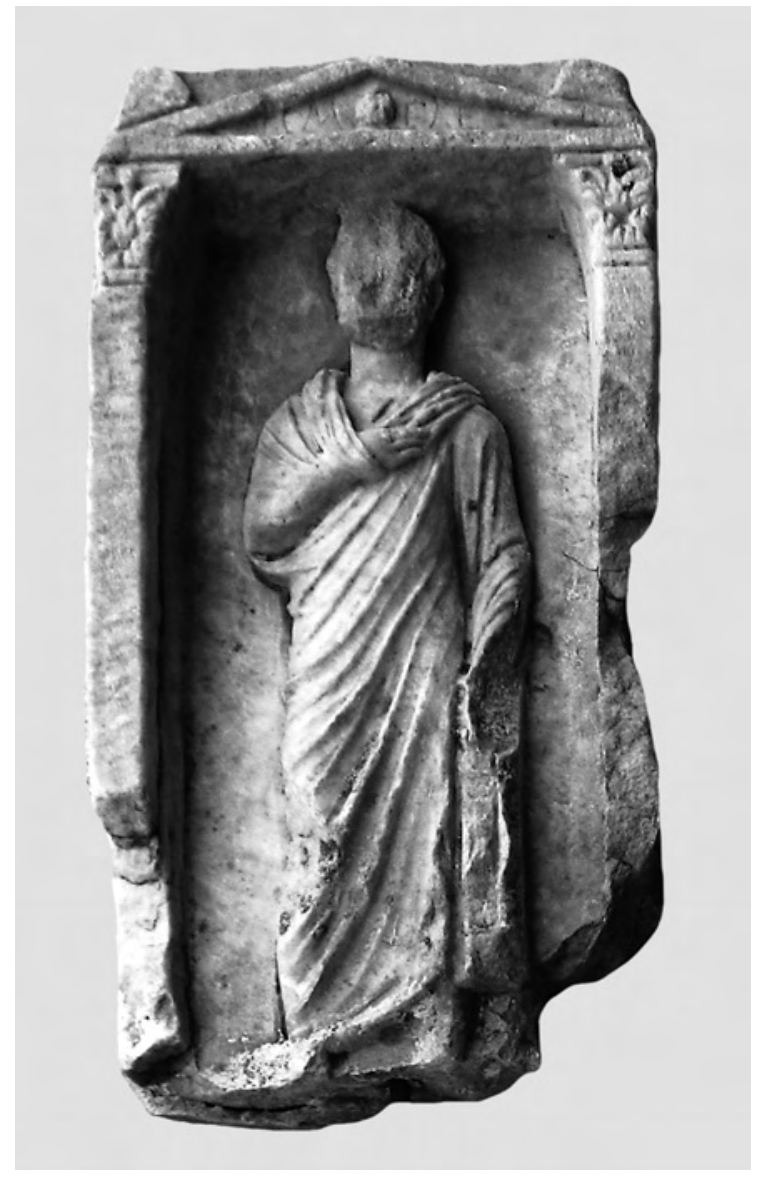

3 Kat. 3: Naiskosstele Inv. 9013

Der schmale Raum des Naiskos ist von einer fron-

tal stehenden männlichen Mantelstatue in ganzer Höhe ausgefüllt. Kaum angedeutet ist das Knie des rechten Spielbeins. Der rechte Arm liegt angewinkelt in der Mantelschlinge; der linke, herabhängende ist vom Mantel umwickelt. Am Hals wird der Chiton sichtbar. Dieser Manteltypus mit eingewickelten Armen wird im Hellenismus ponderiert und mit rechtem Standbein ausgeführt (PM 156-171). Seit dem Späthellenismus nimmt die Körperproportion schlanke, hohe Gestalt an, eine Ponderation entfällt weitgehend, und das linke Bein wird zum Standbein (PM 184-234). Der Dioskurides von Delos ${ }^{5}$ zeigt bereits 138/137 v. Chr. diese fassadenhafte Statuarik in frontaler Einansichtigkeit. Die älteste Stele des jüngeren Typs ist PM 203 mit Schwalbenschwanzfalten und dünnen Beinchen. Zum jüngeren Typus gehört auch das Antiochener Beispiel. Wie die Beine von PM 203 ist auch die Hand des Antiochener Palliatus disproportioniert, seine starre Frontalität ist aber entschieden jünger als die Pose des »anmutigen«, verschollenen Reliefs PM 203. Giebel und korinthische Pilaster ergeben jedoch eine gewissermaßen anspruchsvolle Atmosphäre.

Insgesamt handelt es sich um eine steife Arbeit des 1. Jahrhunderts v. Chr.

Vgl. zum Manteltypus: Kat. 6. 18; W. Papaephthimiou, Grabreliefs späthellenistischer und römischer Zeit aus Sparta und Lakonien (Würzburg 1992) 25 Abb. 3-10 Gruppe 2 mit eng gestellten Beinen und schmalem Körper ohne Ponderation; zu den Proportionen von Naiskos und Figur, dem Verhältnis von Figur und Reliefgrund vgl. PM 422.

R. Lullies, Griechische Plastik ${ }^{4}$ (München 1979) 279; K. Polaschek, Untersuchungen zu griechischen Mantelstatuen (Berlin 1969) 18 f.; zum `Normaltypus` der Mantelstatue auf Grabreliefs s. PM S. 61 f. 


\section{Naiskosstele mit Einlasszapfen}

Inv. 8448. - H $52 \mathrm{~cm}$; B $30 \mathrm{~cm} .-$ Abb. 4.

Der flache Giebel mit drei Akroteren ist nicht freigeschlagen. Profiliertes Gesims; Pilaster mit profilierten Kapitellen.

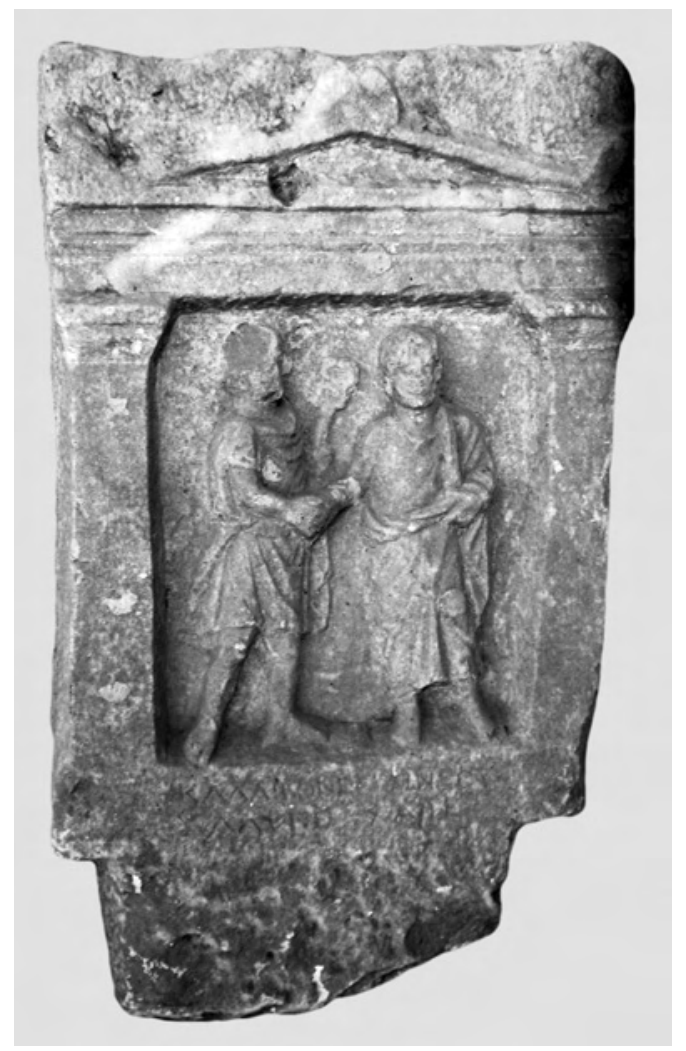

4 Kat. 4: Naiskosstele mit Einlasszapfen Inv. 8448

Hermes als Psychopompos steht im Halbprofil und hält in der Linken das Kerykeion, seine Rechte reicht er dem frontal stehenden Mann. Hermes ist bloßfüßig, trägt einen knielangen Ärmelchiton und einen ebenfalls knielangen Mantel, der nur den Rücken bedeckt. Vorn wird der Mantel wohl wie auf der großen Stele in İznik (PM 1831) oben mit einer Kordel zusammengehalten. Hermes' Gesicht ist abgeschlagen, das kantige Halbrund hinter seinem Kopf gehörte zu einem Petasos, wie ihn auch die Parallele in İznik zeigt. Der Verstorbene steht und blickt frontal. Er trägt Schuhe sowie langen Chiton und Mantel, in dessen Wulst er mit der linken Hand greift. Unterhalb des Bildfeldes eine zweizeili-

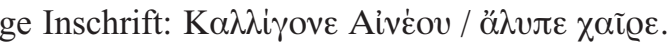

Dieselbe Position des frontal stehenden Verstorbenen in langem Ärmelchiton und Mantel, dessen linke Hand den Mantelwulst umfasst, findet sich auf der qualitätsvoll gearbeiteten, von E. Pfuhl in die zweite Hälfte des 2. Jahrhunderts v. Chr. datierten Stockwerkstele PM 1831 in İznik. Hermes trägt dort den Petasos, den kurzen Ärmelchiton, aber einen langen Mantel sowie ebenfalls das Kerykeion in der Linken. Wie bei Kat. 4 reicht er dem Toten die rechte Hand. Beider Gesichter wenden sich einander zu. Das untere Bildfeld der Stockwerkstele, von dem der Teil mit den Füßen abgeschlagen ist, ist reich mit Beiwerk ausgestattet: einem Tischchen mit Schlange, Früchten und Kuchen; einem Baum, einer Säule, auf der eine Sonnenuhr angebracht ist. Eine etwa lebensgroße Dienerfigur in Trauerhaltung ist in İznik an der rechten Leiste angelehnt.

Nur diese beiden Stelen mit Hermes Psychopompos sind in dieser Form überliefert. Motivische Varianten sind auf dem Zweifigurenrelief in Antiochia der kniekurze Mantel des Hermes und der frontal blickende Kopf des Toten. Das Zweifigurenrelief ist ungleich nachlässiger als die Stockwerkstele in İznik gearbeitet, doch spiegeln die ins Halbprofil gedrehte Figur des Hermes und die räumliche Wirkung seiner Arme mit Kerykeion noch späthellenistischen Bildaufbau des ausgehenden 2. Jahrhunderts v. Chr. wider. Der stoffreiche, rahmende Mantel des Hermes und die gespannte Tütenfalte zwischen den Beinen des Verstorbenen stehen in hellenistischer Formtradition und datieren das Relief in die erste Hälfte des 1. Jahrhunderts v. Chr.

Vgl.: Parlasca 1982, 8 mit Anm. 46 (dort muss es heißen AA 1970) Taf. 5, 3. Vgl. auch PM 45 Nr. 1831. 2104 Taf. 303 (im Register S. 587 übersehen).

\section{Fragment einer Bildfeldstele}

Inv. ? - H $40 \mathrm{~cm}$; B 47 cm. - Abb. 5.

Die Figuren füllen die gesamte Breite des Bildfeldes aus. Unten Bruch entlang der Gewandränder.

Zwei frontal stehende Männerfiguren in Chiton und Mantel. Links steht eine Frau im Profil mit zurückgesetztem rechten Bein. Neben ihrer Umrisslinie von Gesäß, Oberschenkel und Wade verläuft der Reliefgrund. Die rechten Arme der Männer sind angewinkelt, die linken, in den Mantel gewickelt, hängen herab. Die Frau trägt einen faltenreichen Chiton und einen wadenlangen Mantel. Ihr linker Arm, von dem 


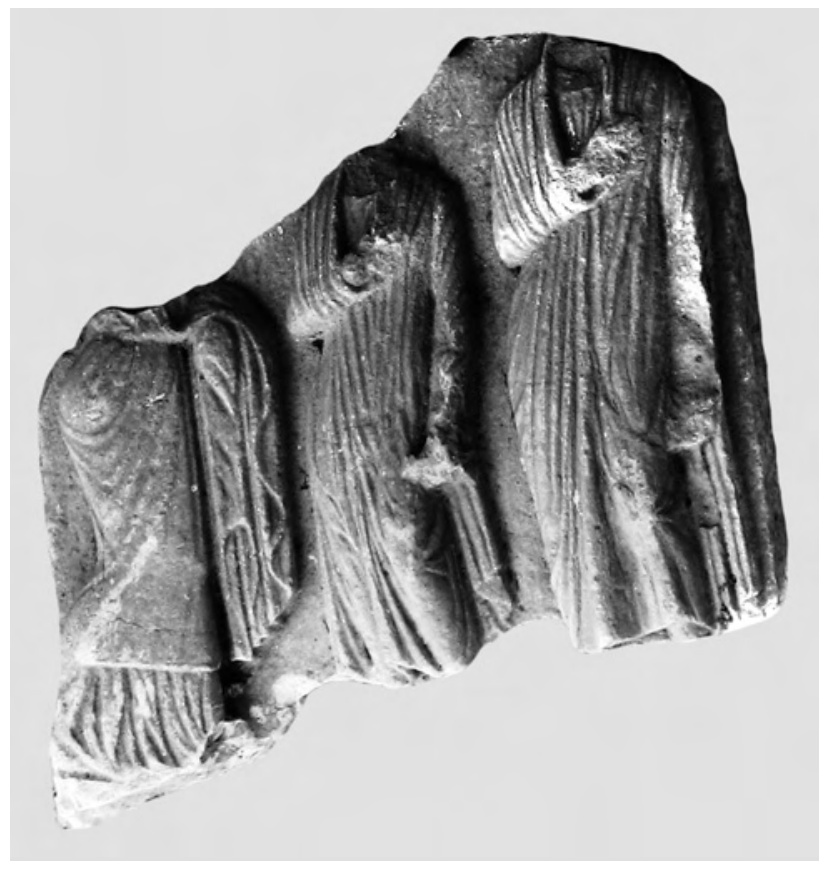

5 Kat. 5: Fragment einer Bildfeldstele Inv. ?

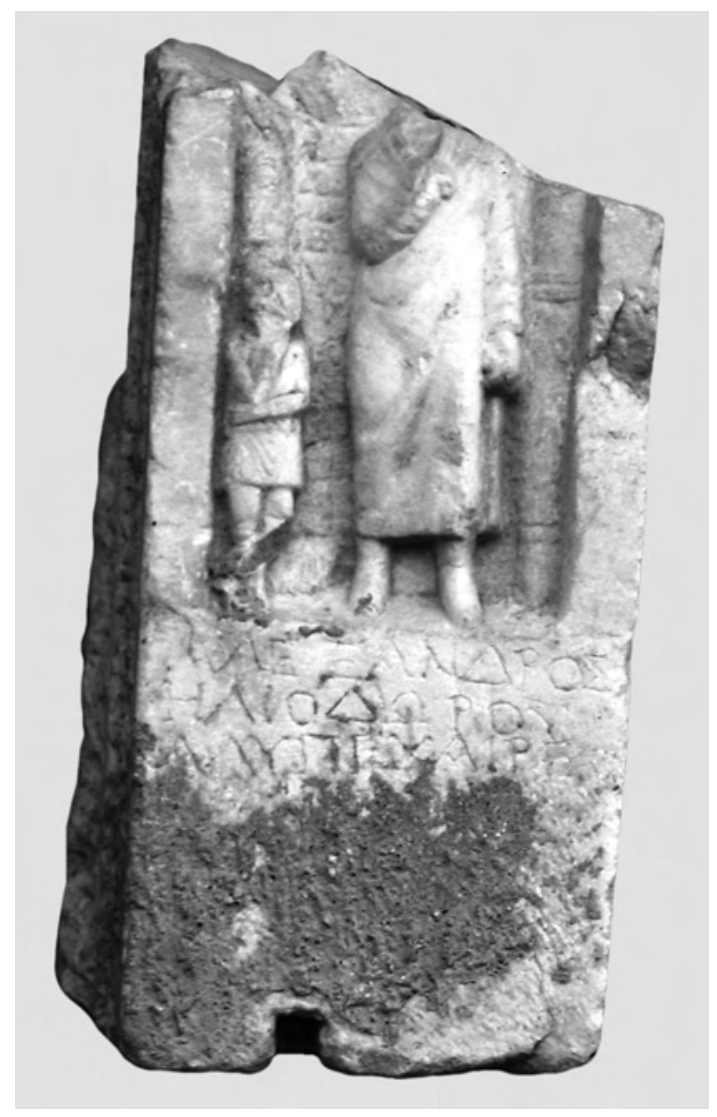

6 Kat. 6: Trapezoide (Giebel?-)Stele Inv. 15747

ein langes, breites Mantelende herabhängt, war aufgestützt. Das unübliche Motiv der im Profil gezeigten Frau kontrastiert mit den mageren Männerfiguren. Reihung von Männern und Frauen, geringfügig in ihrer Haltung variiert, sind nichts Außergewöhnliches, hier jedoch stehen zwei >spindeldürreく Männer in Chiton und Mantel frontal ausgerichtet und eine Frau im Profil nach rechts. Ihr Positionswechsel um $45^{\circ}$ ist ungewöhnlich, zumal die Qualität der Arbeit bescheiden ist und man der betreffenden Werkstatt keine eigene Kompositionsvariante zutrauen möchte; sie mag vom Auftraggeber gewünscht worden sein.

Weibliche Mantelfiguren im Profil kommen vor, im Handschlag mit einem Gegenüber verbunden oder in der Umarmung zweier Frauen (PM 702. 706. 724. 725). Mit der Haltung der Frau lässt sich besonders PM 721 vergleichen, eine Stele des 2. Jahrhunderts v. Chr., auf der ein Paar im Profil einander eng gegenübersteht; hinter der vorgestreckten rechten Hand der Frau hängt ein breites Mantelende wie auf Kat. 5 faltig herab.

>Dürreく Reliefarbeit des 1. Jahrhunderts v. Chr.

Vgl. zu Stil und Motiv der gereihten Figuren: PM 663. 666. 674.

\section{Trapezoide (Giebel?-)Stele}

Inv. 15747. - H $54 \mathrm{~cm}$; B $31 \mathrm{~cm}$. - Abb. 6.

Der obere Teil mit dem Kopf des Mannes ist weggebrochen, die Stele verjüngt sich nach unten.

Der Mann in Mantel und Schuhen steht frontal mit rechtem Stand- und linkem Spielbein. Beide Arme sind in den Mantel gewickelt, der rechte, hochgehoben, greift in den Mantelsaum, der linke hängt an der Hüfte herab. Der Manteltypus entspricht dem auf der Naiskosstele Kat. 3. Der frontal Stehende der Giebel- 


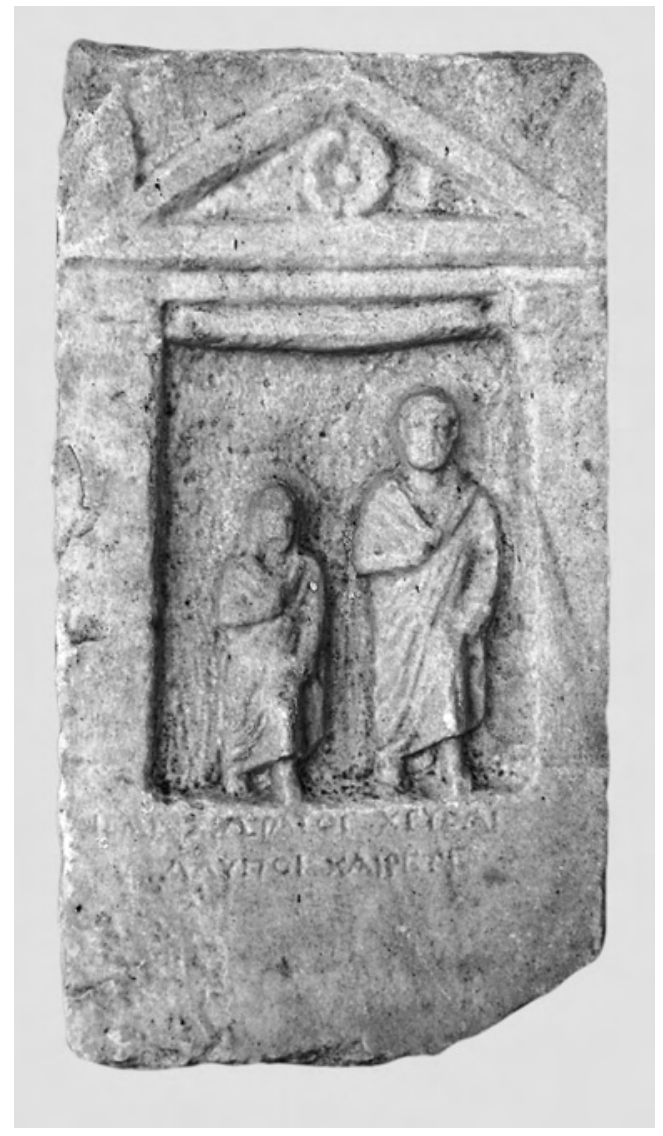

7 Kat. 7: Giebelstele Inv. 9045

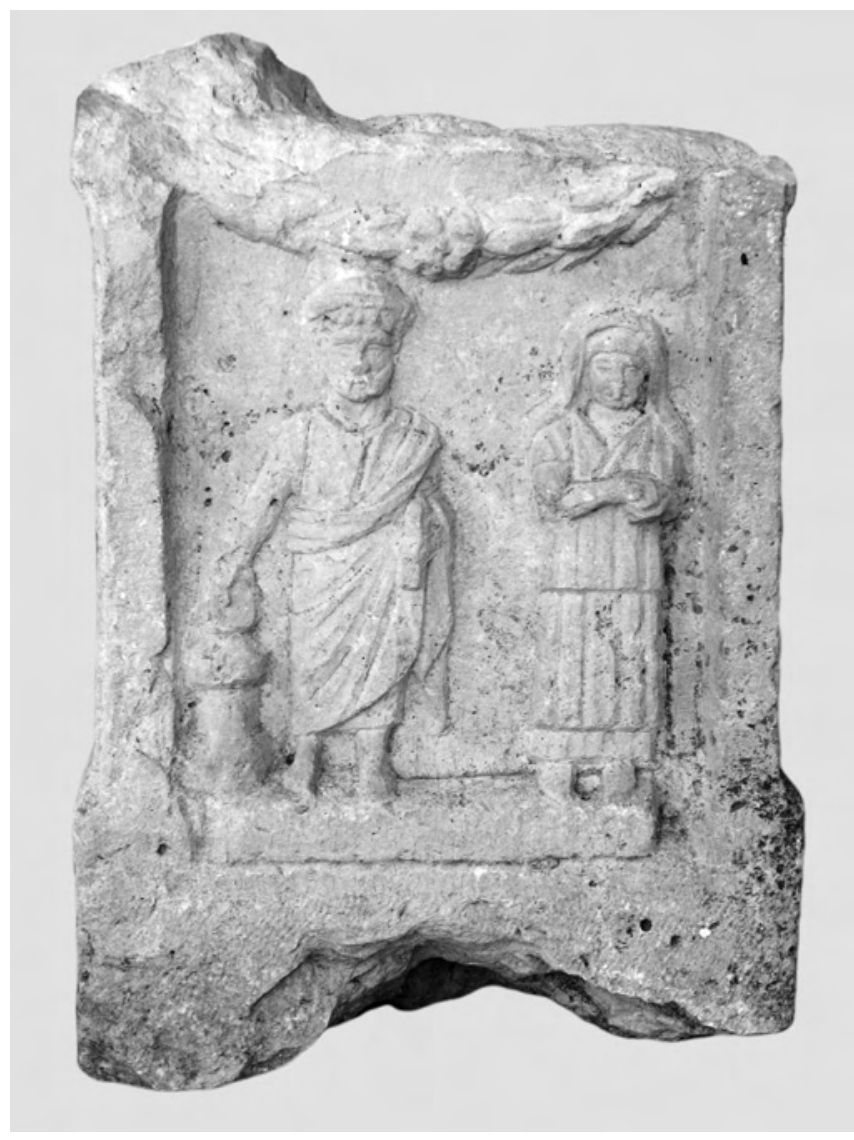

8 Kat. 8: Leistenstele Inv. 13380

stele weist aber noch deutliche Merkmale der älteren, ponderierten Ausführung mit linkem Spielbein auf; so ist sein Körperwuchs nicht überschlank wie auf Kat. 3 und 18, und die Stele ist dementsprechend älter. Am linken Rand steht frontal ein Pais in kurzem Chiton mit überkreuzten Beinen, der trauernde Diener. Sein rechter Arm ist auf die linke Hand gestützt und greift ans Kinn. Im Hintergrund ist zwischen zwei bildfeldgroßen Fackeln ein Vorhang mit horizontalen Falten gespannt (vgl. Kat. 18. 19). Unter der Bildfeldnische

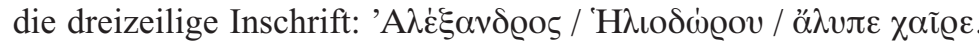

Gute, räumlich empfundene Arbeit des 2. Jahrhunderts v. Chr.

\section{Giebelstele}

Inv. 9045. - H $50 \mathrm{~cm}$; B $26 \mathrm{~cm} .-\mathrm{Abb} .7$.

Zweitverwendung. Die angedeuteten Eckakrotere sind nicht freigeschlagen; Rosette. Im rechteckigen Bildfeld oben durchhängender Wulst, eine unausgearbeitete Girlande.

Ein Mann und eine kleine Frau im Mantel mit bedeckten Armen stehen frontal in korrespondierender Haltung der Arme und Beine. Die Füße sind nicht angegeben. Unter dem Bildfeld zweizeilige Inschrift:

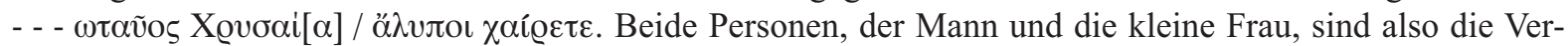
storbenen.

>Trockeneく Arbeit des späten 1. Jahrhunderts v. Chr. 


\section{Leistenstele}

Inv. 13380. - H $60 \mathrm{~cm}$; B $40 \mathrm{~cm} .-\mathrm{Abb} .8$.

Der obere Stelenrand ist abgeschlagen. Am oberen Bildrand über den Köpfen eine leicht durchhängende Blattgirlande mit Mittelrosette.

Auf einem linksbündigen Podest stehen frontal ein Mann und eine Frau in Chiton und Mantel. Der Mann, bekränzt, opfert aus einer Schale über einem Altar. Die Frau in Chiton und Schleiermantel mit Überschlag hält in der Linken eine Dose, in die sie mit der Rechten greift.

Bescheidene Arbeit des ausgehenden 1. Jahrhunderts v. Chr.

\section{Giebelstele mit Einlasszapfen}

Inv. ? - H $57 \mathrm{~cm}$; B $33 \mathrm{~cm} .-\mathrm{Abb} .9$.

Der Giebel und drei angedeutete Akrotere sind nicht freigeschlagen.

In der Mitte des Rechteckfeldes, das von schmalen Randleisten gerahmt wird, steht frontal ein Mann im Mantel, den rechten Arm angewinkelt. Der Mantelrand umwickelt beide Arme und hängt in Falten links bis zum Boden herab. Das rechte Stand- und das linke Spielbein sind unterschieden. Links sitzt im Halbprofil ein Mann, den linken Ellenbogen auf die rechte Hand gestützt. Rechts sitzt ebenfalls im Halbprofil eine verschleierte Frau, den rechten Ellenbogen auf die linke Hand gestützt. Der Stehende ist der Tote ${ }^{6}$. Die verschränkte Haltung des links Sitzenden wirkt lebendig und suggeriert Relieftiefe.

Mittelmäßige Arbeit des späten 2. Jahrhunderts v. Chr.

\section{Giebelstele mit Einlasszapfen}

Inv. 2453. - H $72 \mathrm{~cm}$; B $31 \mathrm{~cm}$. - Abb. 10 .

Drei bossierte Akrotere. Schwach angedeutetes Giebeldreieck.

Eine Frau in Chiton und schräg zur linken Hüfte hochgezogenem Mantel steht im Halbprofil mit erhobener linker Hand, die den Griff eines Spiegels umfasst. Der ehemals perspektivisch gezeichnete Spiegel zeichnet sich noch erkennbar über der geschlossenen linken Hand als Oval ab. Der rechte, gesenkte Arm liegt unter dem Mantel. Die Chitonfalten variieren leicht; der feine

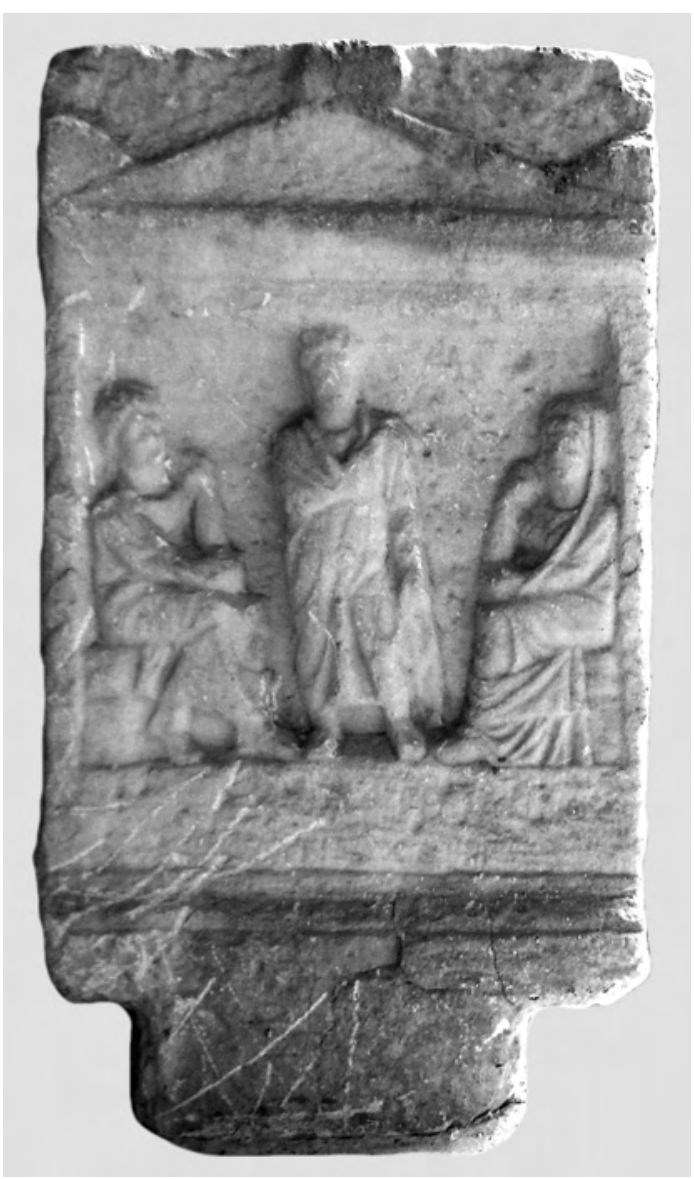

9 Kat. 9: Giebelstele mit Einlasszapfen Inv. ? Mantel folgt den Körperformen. Unmittelbar unterhalb

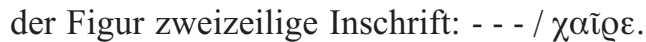

Die überzeugende Körperwiedergabe und die gelungene Perspektive datieren die Einfigurenstele in die zweite Hälfte des 2. Jahrhunderts v. Chr.

\footnotetext{
${ }^{6}$ Parallelen zum Bildtypus s. u.: Verstorbene und Hinterbliebene.
} 


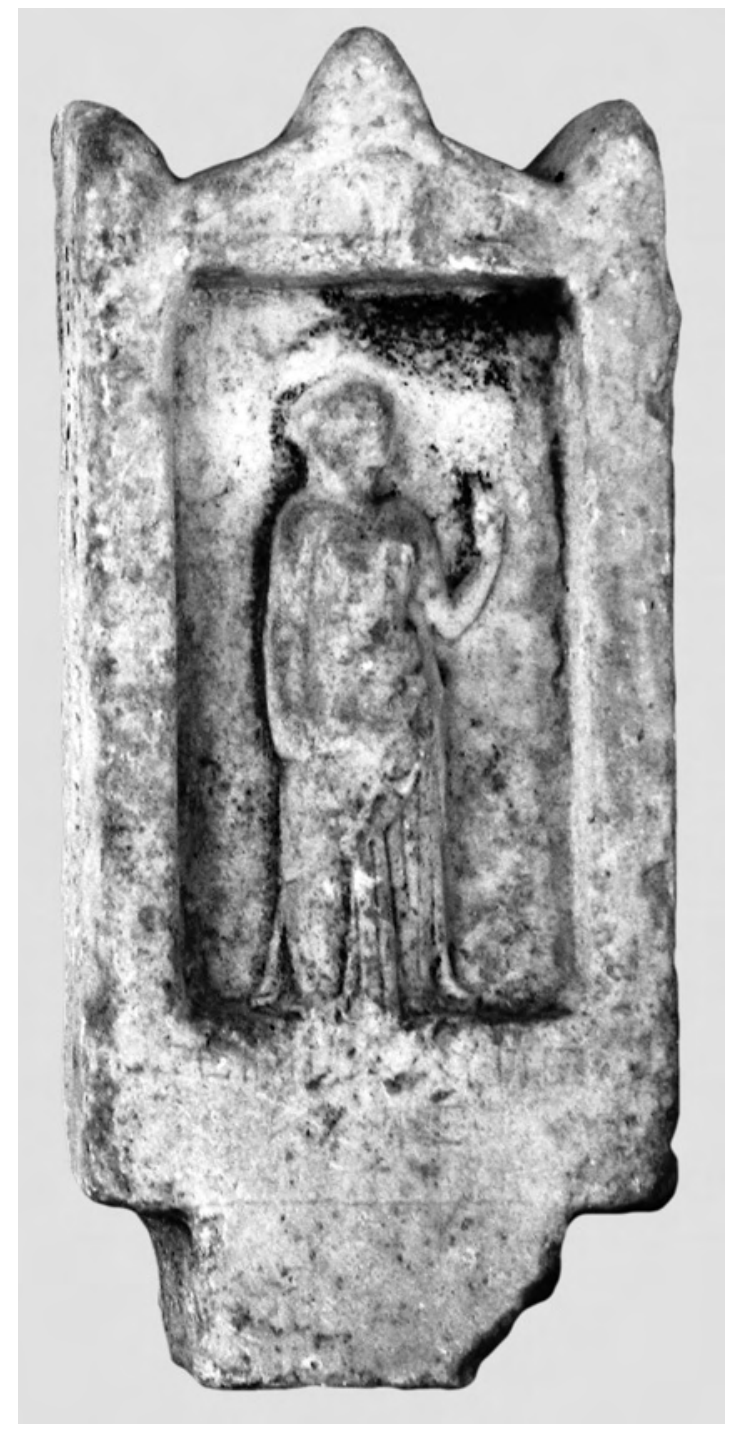

10 Kat. 10: Giebelstele mit Einlasszapfen Inv. 2453

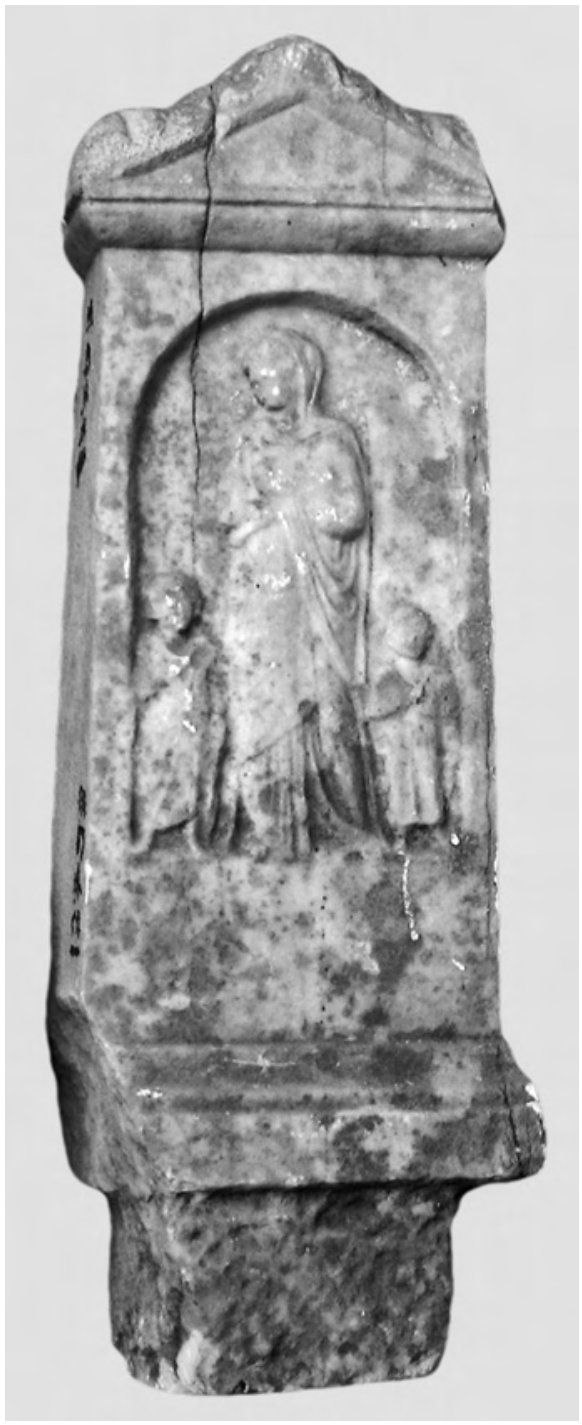

11 Kat. 11: Giebelstele mit Bogennische und Einlasszapfen Inv. 13793

11. Giebelstele mit Bogennische und Einlasszapfen

Inv. 13793. - H $70 \mathrm{~cm}$; B $22 \mathrm{~cm} .-$ Abb. 11.

Der Giebel schließt unten mit einem vorspringenden, zweigliedrigen Gesims ab. Unten, über dem Einlasszapfen, ein hohes, flaches Sockelprofil.

Im Bogenfeld steht eine Frau, frontal, nach rechts blickend. Sie trägt Chiton und Schleiermantel, dessen vorderer Rand am Hals zusammengedreht ist. Der linke Arm ist quer vor den Leib gelegt und zieht einen langen Mantelzipfel zur linken Hüfte hoch. Auf den Handrücken stützt sich der rechte Ellenbogen. Zu Seiten der Frau stehen zwei unterschiedlich große Kinder frontal in langem Mantel mit Armschlaufe: Die Verstorbene muss die Mutter zweier nicht mehr ganz kleiner Kinder sein. Unter dem Bildfeld wäre Platz für eine Inschrift. Sie könnte farbig aufgemalt gewesen sein und muss die Mutter benannt haben.

Die reichen, fließenden Faltenmotive hochhellenistischer Prägung datieren die Stele sehr guter Arbeit in die Mitte des 2. Jahrhunderts v. Chr. 
12. Giebelstele mit Bogennische und Einlasszapfen

Inv. 17736. - H $60 \mathrm{~cm}$; B $21 \mathrm{~cm} .-$ Abb. 12.

Die unausgearbeiteten Mittel- und Seitenakrotere sind nicht freigeschlagen.

In der flüchtig ausgehauenen Bogennische steht ein Palliatus frontal mit umwickelten Armen. Am Hals wird ein doppelter Chitonrand sichtbar. Er trägt Schuhe, rechtes Stand- und linkes Spielbein sind unterschieden. Links hält ein Diener in kurzem Chiton mit gekreuzten Beinen, aber mit deutlich langem Haar eine hohe Fackel. Die Art frontale Haarrolle des Dieners ähnelt der Frisur der Diener auf PM 208 aus dem 2. Jahrhundert n. Chr. Unterhalb der Bogennische

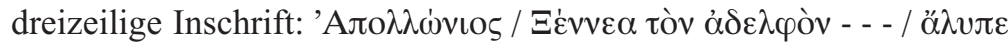

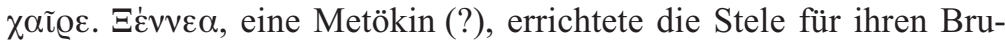
der.

Schlechte Routinearbeit des 1. Jahrhunderts v. Chr.

\section{3. (Giebel?-)Stele mit Einlasszapfen}

Inv. ? - H $58 \mathrm{~cm}$; B $37 \mathrm{~cm}$. - Abb. 13 .

Zweitverwendung aus einem Pilasterkapitell. Rechts und links am Zapfen Dübellöcher. Die Köpfe sind wohl bewusst abgeschlagen.

Links sitzt eine Frau in stoffreichem Chiton und Schleiermantel auf einem Hocker mit gedrechselten Beinen und Kissen. Den linken Arm hält sie im >Pudicitia〈-Motiv auf die rechte Hand gestützt. Ein Mantelzipfel hängt vor dem Hockerbein. Vor ihr steht frontal mit unterschiedenem Stand- und Spielbein ein Mann in Chiton und über der rechten Hüfte zusammengedrehtem Mantel. Er trägt Schuhe. Seine Linke greift in den gedrehten Mantelrand, die Rechte hängt herab und scheint das linke Knie der Frau zu berühren; die plumpe rechte Hand ist nicht ausgearbeitet. Das Zusammentreffen von Hand und Knie ist natürlich nicht beabsichtigt, die Komposition der Gruppe insgesamt misslungen ${ }^{7}$. Die Ausführung der Figuren aber ist von guter handwerklicher Qualität. Die Sitzhaltung der im Halbprofil

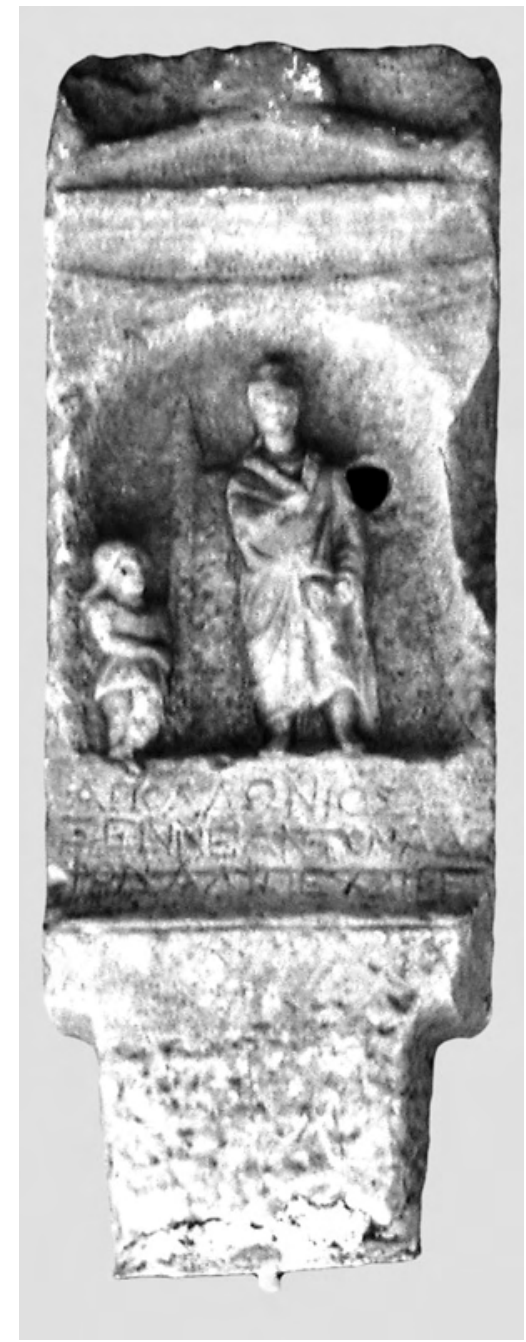

12 Kat. 12: Giebelstele mit Bogennische und Einlasszapfen Inv. 177736 gezeigten Frau, der ponderierte und nicht gänzlich frontal wiedergegebene Stand des Mannes mit zurückgestelltem Standbein sind von befriedigender Tiefenwirkung. Auf dem unteren Stelenrand, unmittelbar unter der Standfläche, steht eine zweizeilige Inschrift: - - $\varphi \iota \lambda \omega v / \alpha ̋ \lambda v \pi \varepsilon \chi \alpha \tilde{\varrho} \varepsilon$. Die Namensendung ist männlich, somit ist in dem Stehenden der Verstorbene zu sehen.

Die leichte Schrägstellung der Oberkörper und deren erzielte Tiefenwirkung, die Tiefenstaffelung der Beine und Arme sowie die plastische Differenzierung der Faltenzüge weisen die Stele als gute Arbeit des mittleren 2. Jahrhunderts v. Chr. aus.

\section{Bildfeldstele}

Inv. ? - H $17 \mathrm{~cm}$; B $16 \mathrm{~cm}$. - Abb. 14.

Stark verwittert. Die obere Hälfte fehlt.

Eine Frau mit zurückgestelltem linkem Bein sitzt auf einem Diphros mit Kissen. Ihr Mantel ist faltenreich und bedeckt auch die Füße, ein Zipfel hängt unter ihrem rechten Oberschenkel vor dem Hocker herab. Sie

${ }^{7}$ Vgl. die etwas glücklicheren Lösungen Délos 167. 169. 173. 174. 187; PM 1032. 


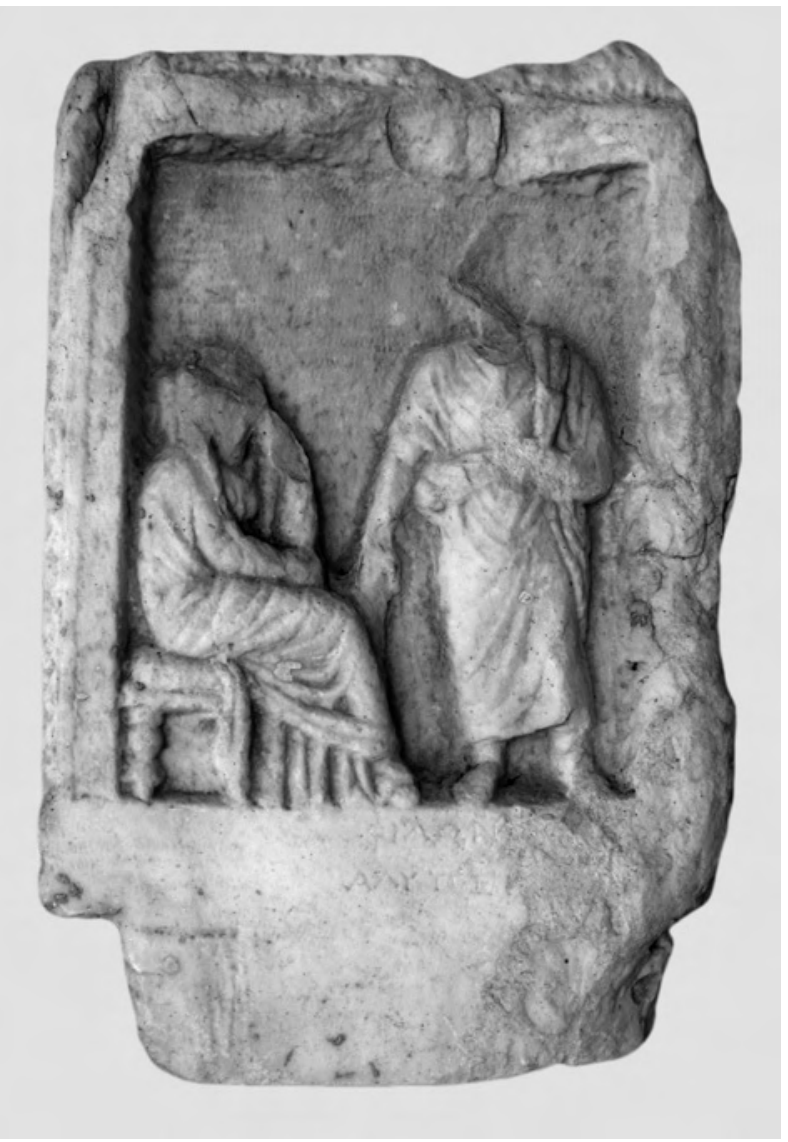

13 Kat. 13: (Giebel?-)Stele mit Einlasszapfen Inv. ?

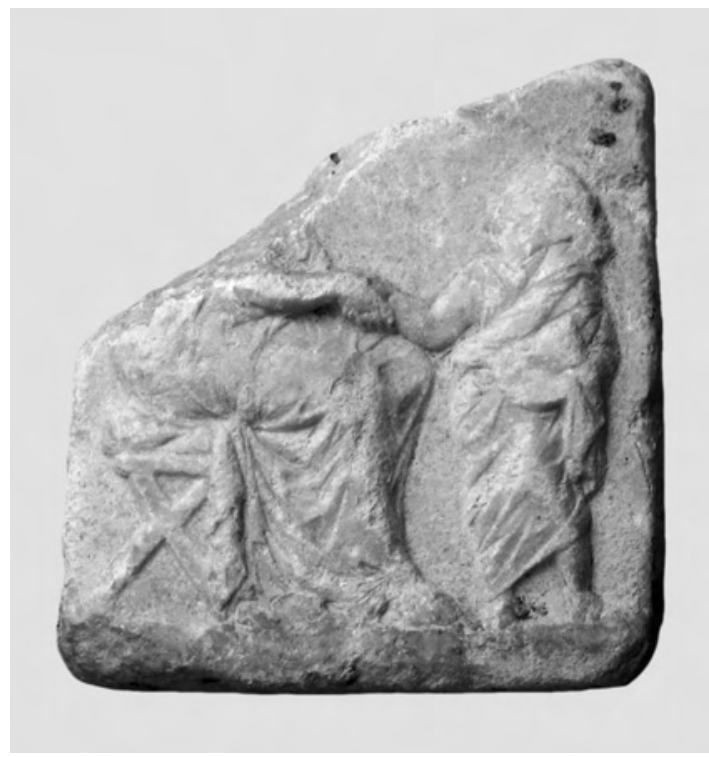

14 Kat. 14: Bildfeldstele Inv. ?

reicht die Rechte einer kleinen Person, die sie anblickt, deren Körper aber frontal ausgerichtet ist, und die eine Stufe herabzusteigen scheint. Die kleine Figur trägt einen Ärmelchiton und einen diagonal über der Brust zusammengedrehten Mantel. Der Chiton lässt ihre Füße mit einem Teil der Unterschenkel frei - die Person ist als männlich zu verstehen. Ihr rechter Arm liegt verkrampft am Oberkörper an. In der linken Armbeuge hält die eigenartige Figur einen großen, rechteckigen Gegenstand, aus dem rechts zwei spitze
Ecken hervorragen: Es könnte ein Diptychon, eine Schreibtafel, sein. Der Kopf der kleinen Figur sitzt ohne Hals auf den Schultern und ist schwer zu erkennen. Es muss sich um eine komische Groteske handeln. Die sitzende Frau entspricht Sitzenden auf Grabstelen. Die vorliegende Figurenkombination - die Figuren sind durch dextrarum iunctio miteinander verbunden - auf einer Grabstele wirkt befremdlich. Nach E. Pfuhl bedeutet Dexiosis nicht Abschied, sondern »liebevolles Beieinandersein ${ }^{8}$. Ist der verwachsene Mann mit Diptychon ein Lehrer?

Ehemals gute Arbeit des 2. Jahrhunderts v. Chr.

\section{Naiskosstele mit Giebel}

Inv. 8937. - H $55 \mathrm{~cm}$; B $30 \mathrm{~cm}$. - Abb. 15.

Der Naiskos wird durch zwei Säulen mit dreiteiliger Basis begrenzt. Über den Köpfen der Figuren bleibt ein breiter Freiraum, der unter dem Giebel mit einem vorspringenden Gesims abschließt. Im Giebelfeld zeichnet sich eine rau belassene Scheibe ab, die wohl bemalt war: eine Rosette oder vielleicht ein Rundschild? Die Gesichter sind gezielt abgeschlagen.

Eine Frau, eng in Chiton und Mantel gehüllt, sitzt auf einem Hocker mit gedrechselten Beinen und einem hohen Sitzkissen, das nicht die gesamte Tiefe des Schemels bedeckt. Ihre Füße ruhen auf einer

\footnotetext{
${ }^{8}$ PM S. 45.
} 


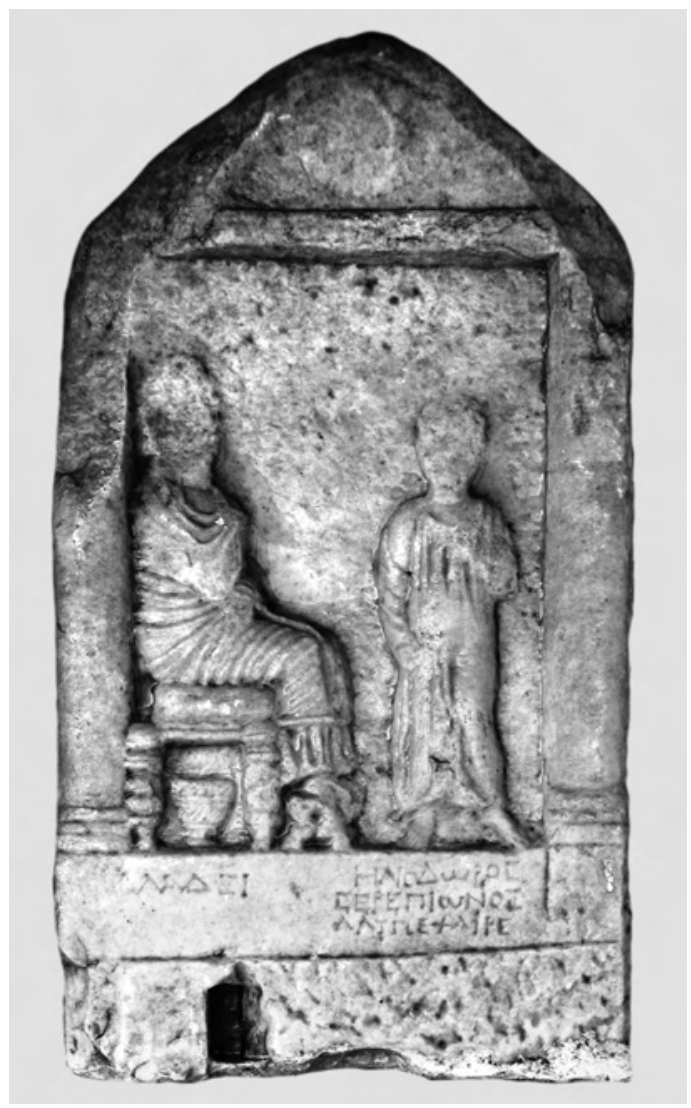

15 Kat. 15: Naiskosstele mit Giebel Inv. 8937

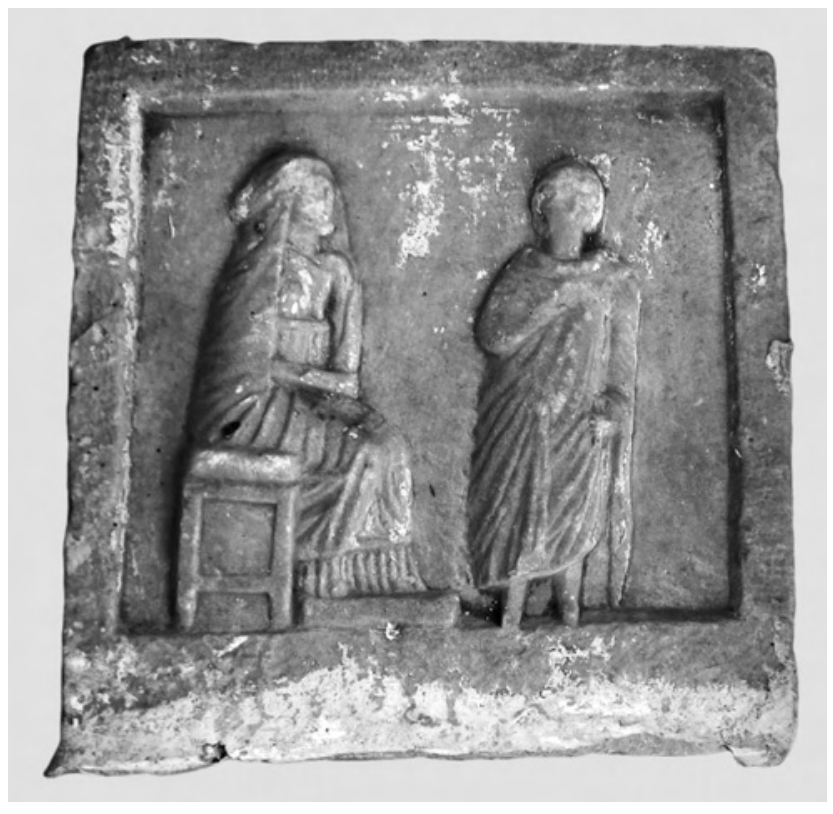

16 Kat. 16: Leistenstele Inv. 8950

Fußbank mit gewinkelten Beinen, unter dem Schemel steht ein Wollkorb. Vor der Frau steht bloßfüßig, mit rechtem Stand- und linkem Spielbein, frontal der junge Verstorbene. Er trägt einen langen Chiton und stolaartig umgelegt den Mantel, der den rechten Arm umwickelt. Das Größenverhältnis zwischen der sitzenden Frau und dem stehenden Jugendlichen ist realistisch. Am unteren

Stelenrand ist dezentral unter der stehenden Mantelfigur eine dreizeilige Inschrift angegeben: . . . ] $\lambda \dot{\alpha} \delta \varepsilon \iota /$

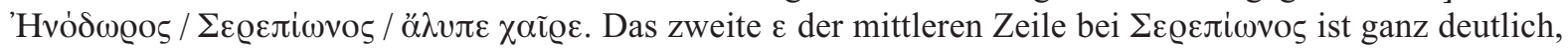
jedoch kommen Verschreibungen vor. Mit den mehrfach gegliederten Beinen von Schemel und Fußbank, dem steifen Kissen und dem Wollkorb ist die Darstellung, zu Lasten ihrer Feingliedrigkeit, mit einer gewissen behäbigen Sorgfalt ausgestattet. Die einfallslos parallel gerieften Faltenzüge entsprechen stilistisch einer gegen 100 v. Chr. datierten Stele in Delos ${ }^{9}$. Die an den Stelenrand gelehnte Sitzende auf hohem Kissen und der Stand des Mannes mit frontal gezeigtem rechtem Fuß und abgespreiztem linkem sind verwandt.

Das Sigma hat die Form des rechts offenen Rechtecks, »die sonst nicht in vorchristlicher Zeit vorzukommen pflegt $\ll^{10}$. Das Omega hat die Minuskelform $\omega^{11}$.

Biedere Arbeit des frühen 1. Jahrhunderts v. Chr.

\section{Leistenstele}

Inv. 8950. - H $42 \mathrm{~cm}$; B $42 \mathrm{~cm}$. - Abb. 16.

Die quadratische Stele, ohne Giebel und Einlasszapfen, ist oben und an den Seiten von einer $3 \mathrm{~cm}$ breiten Leiste eingefasst. Die untere Leiste, ohne Inschrift, ist doppelt so breit.

\footnotetext{
${ }^{9}$ Délos 1; vgl. auch Délos 301. 357; PM 139. 342. 343. 364. 420. 532. 664. 855. 956. 998. 1421. 1432.

${ }^{10}$ G. Klaffenbach, Die Grabstelen der einstigen Sammlung Roma in Zakynthos (Berlin 1964) 15 Nr. 25 Abb. 27.

${ }^{11}$ L. Jalabert - R. Mouterde, Inscriptions grecques et latines de la Syrie III 2 (Paris 1953) 626 Nr. 1152.
} 
Von den schmalen Randleisten abgerückt, erscheinen links eine sitzende Frau und ein frontal stehender, scharf nach rechts zur Frau hin blickender Mann. Die Frau, in Chiton und Mantelschleier, sitzt mit zurückgestelltem rechtem Bein auf einem Hocker mit Querleiste und Kissen. Die vom Chiton verdeckten Füße ruhen auf einer blockförmigen Fußbank. Die Modellierung der Schienbeine setzt sich zu den Füßen hin unter dem Chiton nicht fort. Der linke, dünne Arm der Frau ist auf die rechte Hand gestützt, der rechte Unterarm ist äußerst vereinfacht, ohne jede natürliche Modellierung wiedergegeben. Parallel zieht sich wie ein dicker Reif die Gürtung des Chitons vor die Brust. Der Mantelrand verläuft vom Gesicht zum Oberschenkel als vertikale Kante. Die Arme der männlichen Figur sind in den Mantel gewickelt, der rechte gewinkelt, der linke herab-

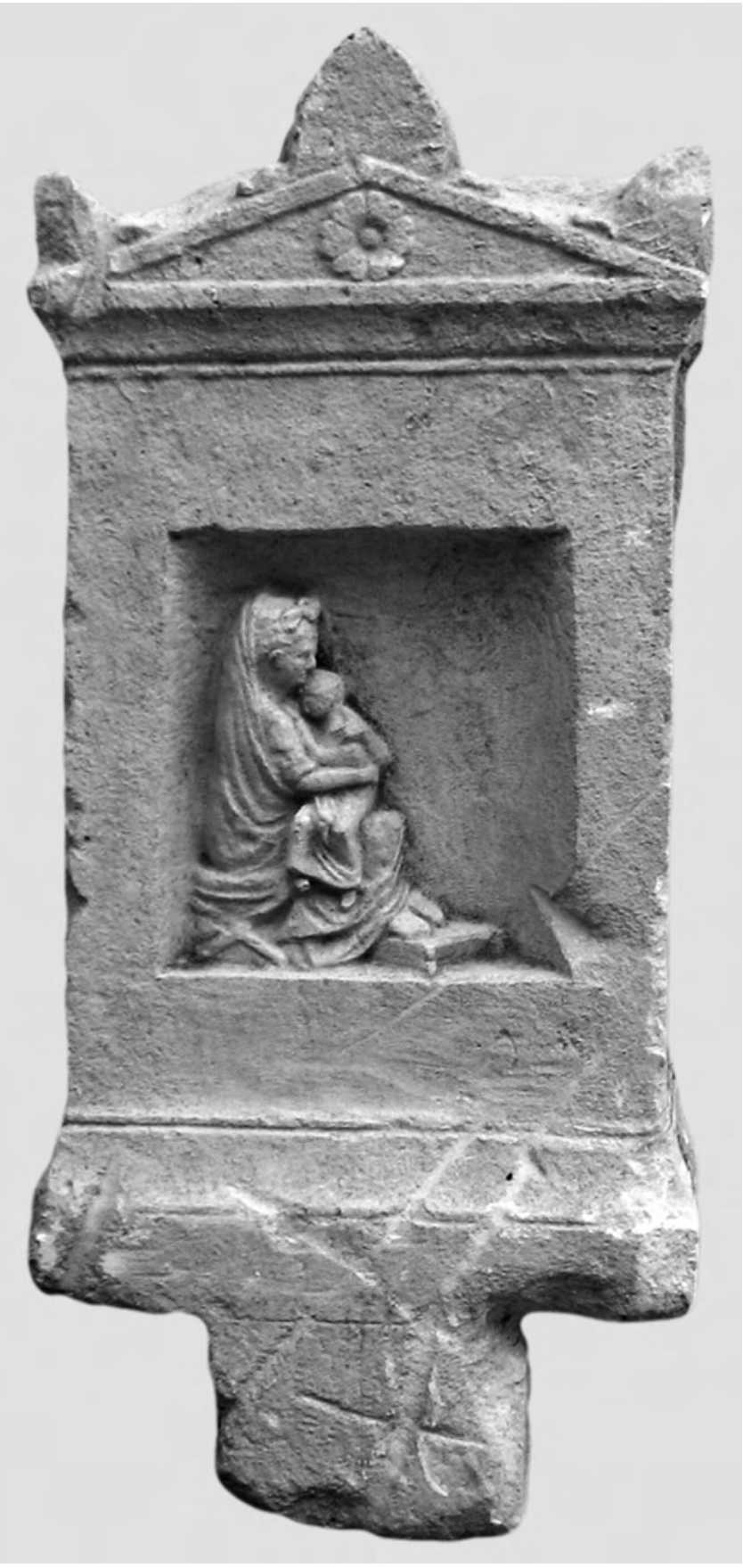

17 Kat. 17: Giebelstele mit Einlasszapfen Inv. ? hängend mit Buchrolle; ein Mantelzipfel hängt bis zum Boden. Beide Figuren zeigen keine Füße. Die dichte Faltenangabe ist schematisch, die Körperhaltungen laienhaft unbewegt. Der rechts stehende Mann ist, wie vielfach, etwa gleich groß wie die sitzende Frau.

In Istanbul befindet sich ein ähnlich unbeholfen gearbeitetes Grabrelief desselben Schemas (PM 1013). Auf beiden Reliefs sind die Figuren höchst ungeschickt kopiert. Gefällige Faltenwürfe wiederzugeben und organische Gliedmaßen nachzuzeichnen, überforderte den Steinmetzen. E. Pfuhl datiert die Istanbuler Platte in die mittlere Kaiserzeit. Kunstlos primitive Reliefs können, als Ausklang des Späthellenismus, auch älter sein und der frühen Kaiserzeit des 1. Jahrhunderts n. Chr. angehören.

\section{Giebelstele mit Einlasszapfen}

Inv. ? - H $77 \mathrm{~cm}$; B $32 \mathrm{~cm}$. - Abb. 17.

Drei Akrotere; Rosette. Profilierter Gesimsstreifen. Kleine Rechtecknische.

Eine Frau sitzt auf einem Klapphocker mit Kissen, die Füße auf einer schräg stehenden Fußbank. Sie hat ein großes Kind auf dem Schoß, das sie sowohl mit dem rechten Arm in der Taille als auch mit dem linken an Rücken und Schulter umfasst. Das Kind trägt einen langen Chiton, unter dem sich die hängenden Beine abzeichnen. Es schmiegt sich an und legt den linken Arm an die Brust der Frau. Sie ist in einen weiten Mantel gehüllt, der über die Füße fällt und ihren Hinterkopf bedeckt. Im Haar trägt sie einen Blütenkranz. Die Inschrift unter der Bildnische ist unleserlich, sie muss sich aber auf die verstorbene Mutter eines Kindes bezogen haben. Die Komposition des kleinen Reliefs ist von bemerkenswerter Originalität, als es nur die Hälfte der Bildfläche ausfüllt und diese diagonal begrenzt. 
Die innige Stimmung und die überzeugende Räumlichkeit der Gruppe weisen spätestens in die Mitte des 2. Jahrhunderts v. Chr.

\section{Naiskosstele}

Inv. 8986. - H $74 \mathrm{~cm}$; B $43 \mathrm{~cm}$. - Abb. 18.

Der Giebel und die angedeuteten Seitenakrotere sind nicht freigeschlagen; im Giebel befindet sich eine große Rosette. Eine flache Rechtecknische wird durch Pilaster mit profilierten Kapitellen begrenzt.

Im Bildfeld rechts steht frontal eine Dienerfigur in kurzem Chiton. Die Hände ihrer gesenkten Arme greifen ineinander. Dicht neben der Dienerfigur, ebenfalls frontal, steht ein Mann im Mantel mit eingewickelten Armen, den rechten angewinkelt. Er ist im jüngeren, überschlanken Manteltypus, entsprechend Kat. 3, wiedergegeben, aber mit linkem Spielbein, wie es sonst am älteren, ponderierten Typus, hier Kat. 6, erscheint. Hinter beiden Figuren ist zwischen zwei dünnen Fackeln ein Parapetasma gespannt. Die linke Fackel steht nicht wie die rechte am Bildfeldrand, sondern hinter dem Kind auf dem Schoß der Mutter. Zwischen ihr und dem Mann bleibt freier Hintergrund mit Parapetasma. Dieses hängt in flachen, horizontal gespannten Bögen mit breiten, schematisch gekennzeichneten Falten. Links sitzt auf einem Klappstuhl mit Kissen

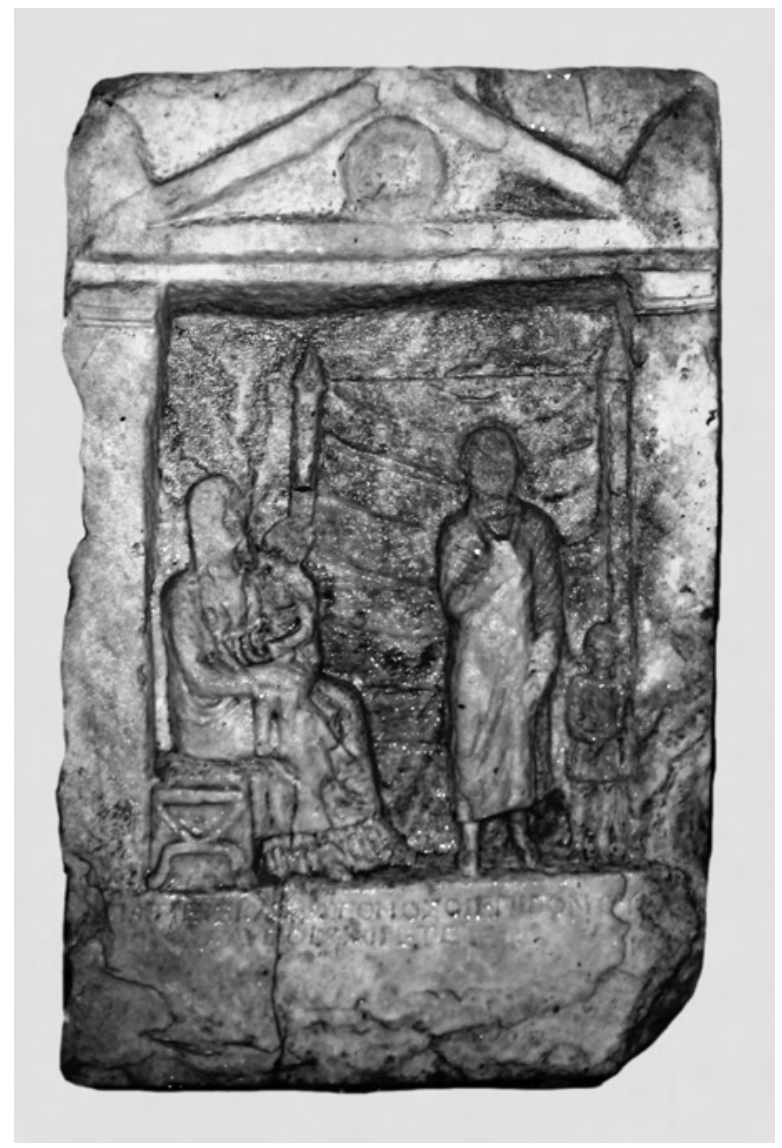

18 Kat. 18: Naiskosstele Inv. 8986 eine Frau in hoch gegürtetem Chiton und offenem Mantel. Sie hält ein steif und frontal sitzendes Kind auf dem Schoß. Die Füße der Frau sind zu sehen. Unter

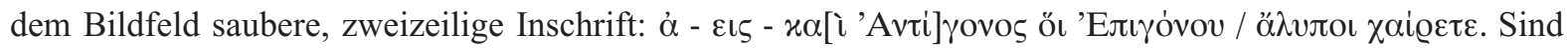
beide Erwachsene verstorben?

>Trockeneく Arbeit des 1. Jahrhunderts n. Chr.

\section{Giebelstele mit Einlasszapfen}

Inv. 16831. - H $52 \mathrm{~cm}$; B $32 \mathrm{~cm} .-$ Abb. 19

Im flachen Giebel mit Profilleiste und Rosette sind die groben Seitenakrotere nicht freigeschlagen.

An den Seitenrändern stehen zwei nach unten verjüngte Fackeln. Zwischen ihnen spannt sich im Hintergrund der tiefen Rechtecknische ein Parapetasma mit horizontal durchhängenden Falten. Diese sind, wie auf Kat. 18, in breiten, regelmäßigen Abständen nur grob linear eingezeichnet. Vor dem Vorhang sitzt auf einem Hocker mit gedrechselten Seitenwangen (ohne Beine) eine Frau im Halbprofil in Chiton und Mantelschleier. Ihre Füße sind zur Gänze sichtbar. Auf ihrem Schoß mit spitzen Knien hält sie ein großes Kind. Es sitzt in guter Perspektive schräg auf dem linken Bein der Mutter; seine Beine streckt es über ihren rechten Oberschenkel. Langhaarig, in kurzem Chiton hält es einen großen Vogel in den Armen. Unterhalb der Standfläche unleserliche Inschrift mit Namen und Vaternamen der Frau; unter der Trennlinie zum Zapfen:

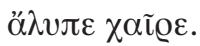

Trotz gekonnter Perspektive ungelenke Arbeit wohl noch des mittleren 1. Jahrhunderts v. Chr. 


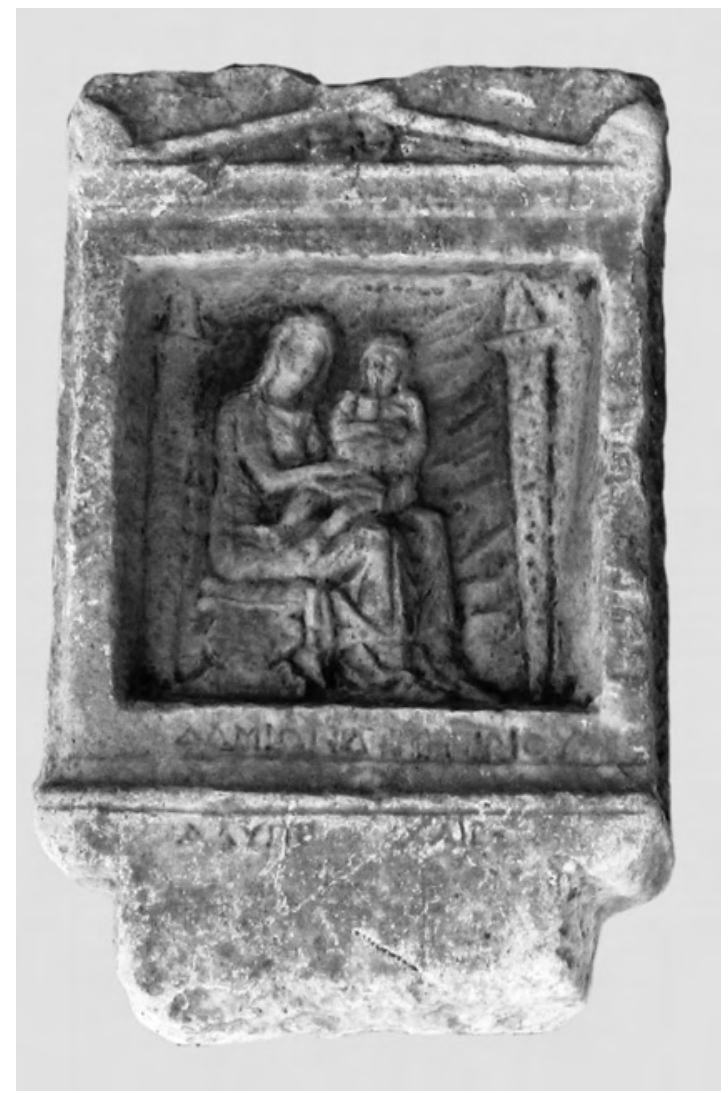

19 Kat. 19: Giebelstele mit Einlasszapfen Inv. 16831

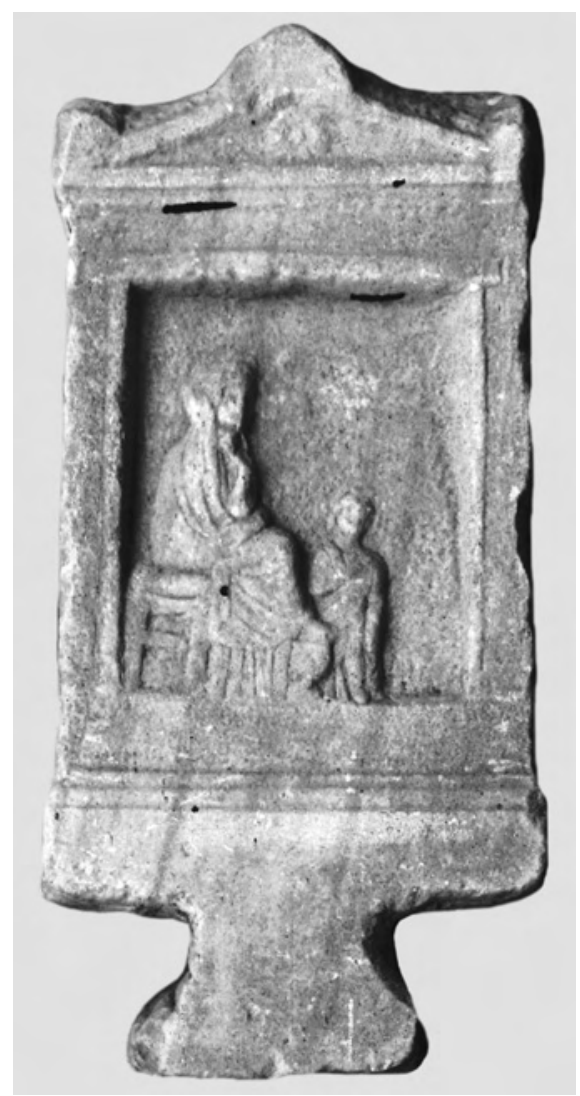

20 Kat. 20: Giebelstele mit Einlasszapfen Inv. 9547

\section{Giebelstele mit Einlasszapfen}

Inv. 9547. - H $66 \mathrm{~cm}$; B $28 \mathrm{~cm} .-$ Abb. 20.

Drei angedeutete Akrotere, im Giebelfeld eine Rosette. Um die Rechtecknische zieht sich ein vorkragendes Profil; es folgen ein freier Streifen und ein doppeltes Sockelprofil.

Eine Frau in Chiton und Mantelschleier sitzt auf einem Hocker mit Querleiste und Kissen. Ihr rechter Arm ist aufgestützt. Die Füße stehen auf einer hohen Fußbank, hinter der ihr Chiton bis zum Boden herabhängt. Nahe vor ihr, von der Fußbank überschnitten, steht frontal die kleine Tochter mit langen Haaren. Sie trägt einen langen Chiton und stoffreichen Mantel, in den beide Arme gewickelt sind. Der rechte Bildrand bleibt frei. Die Position des Mädchens, nicht separat, sondern dicht an die Beine der Frau geschmiegt, gibt seine Rolle als Tochter, nicht etwa als Dienerin, zu verstehen.

>Trockene< Routinearbeit des späten 1. Jahrhunderts v. Chr.

\section{Trapezoide Stele mit Bogennische}

Inv. 17914. - H $67 \mathrm{~cm}$; B 36 cm. - Abb. 21.

Der Umriss der Stele verjüngt sich etwas nach unten.

Von der linken Seite abgerückt sitzt eine Frau im Mantelschleier mit aufgestütztem linkem Arm auf einem Klapphocker mit Kissen. Eine Fußbank ist mit einem Tuch verhangen. Vor ihr, direkt am rechten Bildrand steht frontal eine Dienerin in langem Chiton mit freien Füßen. Ihr linker Arm ist im >Pudicitia<-Motiv auf 


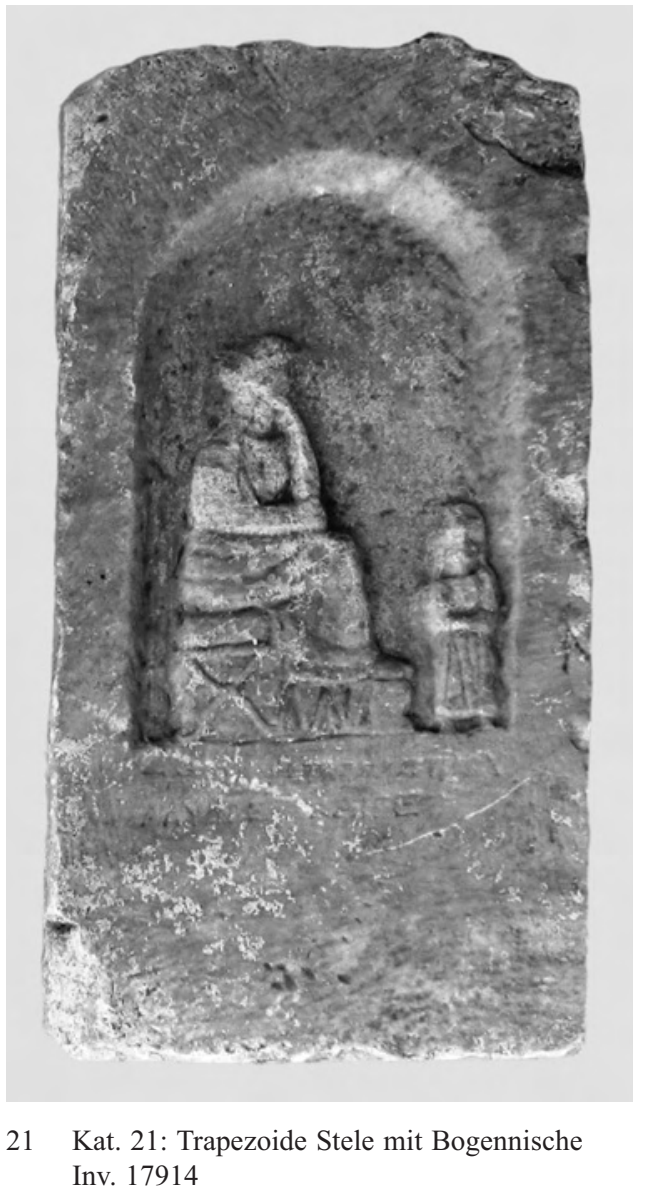

die rechte Hand gestützt, ihr Haar reicht ihr bis auf die Schulter. Der Hintergrund des Bogensegments bleibt frei. Die Oberflächenplastizität ist dürftig; der Mantel der Sitzenden ist zwischen Rücken und Knien in drei

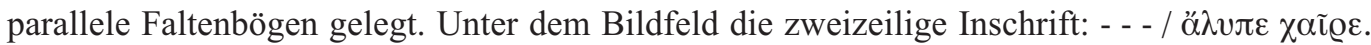

>Hölzerneく Arbeit des fortgeschrittenen 1. Jahrhunderts v. Chr.

\section{Trapezoide Naiskosstele}

Inv. 8939. - H 75 cm; B 32 cm. - Abb. 22.

Die Stele verjüngt sich nach unten. Das untere, unbearbeitete Ende war in den Boden eingelassen. Die Oberfläche des Reliefs ist stark verwittert, das Relief im Bildfeld sehr verwaschen. Der Stein ist hinter dem Giebel nicht weggeschlagen. Breite Giebelrahmung; große Rosette.

Das Bildfeld wird von Pilastern mit profilierten Kapitellen eingefasst; darüber befindet sich ein schmales Inschriftband: - - $\omega \iota \varsigma \mu \eta ่ \tau \eta \varrho ~ ' A \varrho \tau \dot{\varepsilon} \mu \varepsilon ı \varsigma$. Artemis ist also die verstorbene Mutter des Kindes auf ihrem Schoß. Auf der Kline mit gedrechselten Beinen und Kissen liegt aber ein Mann, der eine Schale in der linken Hand hält; davor steht ein Tisch. Vor dem Fußende der Kline sitzt auf einem Hocker mit gedrechselten Beinen Artemis, verschleiert (mit Haarschleife?) und mit abgestreckten Unterschenkeln. Artemis hält ein Kind auf dem Schoß, das sie mit ihrem horizontal abgewinkelten Unterarm umfasst. Unter dem Bildfeld zweizeilige

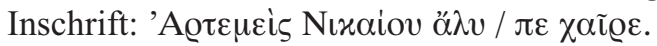

Mittelmäßige Arbeit des mittleren 1. Jahrhunderts v. Chr. 


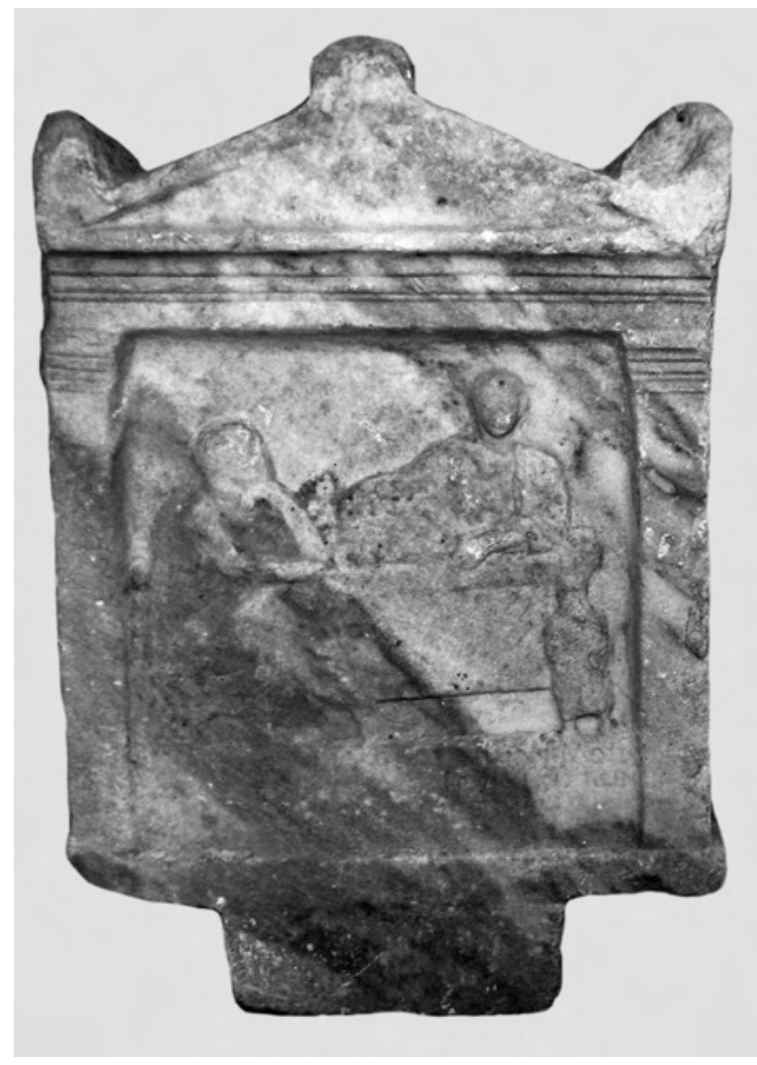

23 Kat. 23: Naiskosstele mit Einlasszapfen Inv. 9026

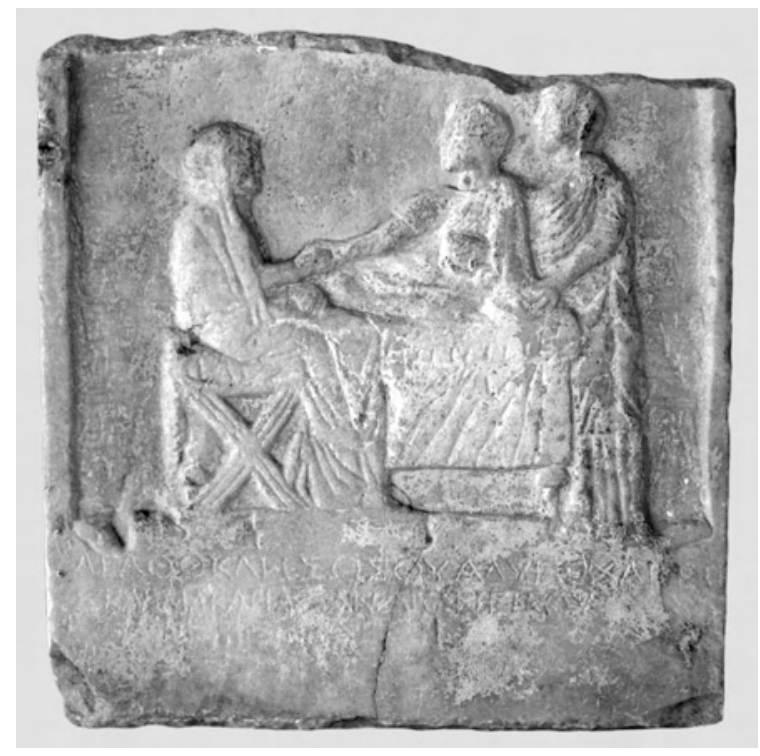

24 Kat. 24: Leistenstele Inv. ?
23. Naiskosstele mit Einlasszapfen

Inv. 9026. - H $70 \mathrm{~cm}$; B $45 \mathrm{~cm}$. - Abb. 23.

Drei unausgearbeitete Akrotere; das Gesims unter dem Giebelprofil dagegen ist fein profiliert. Das rechteckige Bildfeld ist von Pilastern mit gegliederten Kapitellen gerahmt.

Auf verhangener Kline liegt hoch aufgerichtet eine verschleierte Frau; ein Mann sitzt mit angezogenen Knien und weggestreckten Unterschenkeln links vor der Kline auf niedrigem Schemel. Er stützt das Kinn auf den linken Handrücken: Es ist das >Pudicitia<-Motiv, das auch bei Männern vorkommt ${ }^{12}$, bei einem Sitzenden aber nur eine Parallele in Delos (Délos 316) hat. Rechts steht eine kleine Dienerin, frontal in langem Chiton. Im Bildfeld unten befindet sich die dreizeilige Inschrift, zu großen Teilen unleserlich: - - $\varphi \iota \lambda \circ \pi / \sigma \iota \omega v$.

Auf der delischen Stele 316 des 1. Jahrhunderts n. Chr. sitzt ein Mann in derselben Haltung an gleicher Stelle. Dort ist die ebenfalls auf verhangener Kline mit Matratze ausgestreckt liegende Frau im Formular genannt. Die gelagerte Frau muss also beide Male die Tote sein. Die Position des Mannes mit abgestreckten Beinen und dem nach hinten gebogenen linken Handrücken stimmt genau mit der Antiochener Stele überein er muss eine geläufige >Musterbuch-Figur gewesen sein. Auch die Pilaster kehren wieder; der obere Abschluss ist in Delos aber bogenförmig.

Die Antiochener Stele ist die ältere. Die räumliche Wiedergabe des im Halbprofil Sitzenden, die Haltung von Knien und Armen, aber auch der steil abgeknickte Oberkörper der gelagerten Frau weisen noch in das 1. Jahrhundert v. Chr.

\section{Leistenstele}

Inv. ? - H $45 \mathrm{~cm}$; B $45 \mathrm{~cm}$. - Abb. 24 .

Der obere Rand ist über dem Bildfeld abgeschlagen. Das Dreifigurenrelief ist an den Seiten etwa $5 \mathrm{~cm}$ von der schmalen Randleiste abgerückt. Es ist einschichtig flach; die Überschneidungen erzeugen keine räumliche Tiefenillusion. Hinter dem Rücken der links sitzenden Frau und der rechts Stehenden bleibt ein breiter Streifen des Reliefgrundes frei.

Auf verhangener Kline liegt mit hoch aufgerichtetem Körper ein Mann im Profil. Er reicht der neben dem Fußende seiner Kline auf einem Klapphocker mit Kissen sitzenden, verschleierten Frau die rechte Hand. Die Füße der Sitzenden stehen auf einer kastenförmigen Fußbank. Eine dritte Person steht hinter dem Rücken des Liegenden an der rechten Schmalseite der

\footnotetext{
12 PM S. 63.
} 
Kline. Die im Halbprofil stehende, halbverdeckte Frau in Chiton und Mantelschleier schmiegt sich unüblich eng an die Rückseite der Kline. Ihre Position gehört nicht zu den standardisierten Typen, denn eine am rechten Bildrand stehende Figur ist in der Regel frontal dargestellt. Die hier gewählte Stellung ist gewollt und soll wohl persönliche Verbundenheit zum Ausdruck bringen. Dexiosis zwischen gelagerter und sitzender Figur ist nicht häufig, kommt aber vor ${ }^{13}$ und scheint auf besonderem Wunsch des Bestellers zu beruhen. Ein Totenmahl-Tisch fehlt.

Unter dem Bildfeld nimmt eine zweizeilige Inschrift auf mindestens zwei Personen Bezug: - - - ov xai - боv ö̉ Dexiosis mit der Sitzenden als auch durch seine besondere Nähe zu der Stehenden mit dieser verbunden. Dass zwei Verstorbene einander die Hand reichen, ist vielfach belegt. Denkbar ist, dass die auf ihre Weise emotional hervorgehobene, rechts stehende Frau dann die weihende Hinterbliebene ist. Ihre unübliche, eng an den Verstorbenen gelehnte Position wäre indes auch als zweite Verstorbene, die nicht wie der Mann auf der Kline gelagert erscheint, erklärbar. Das offenbar auf Sonderwunsch des Bestellers unbeholfen umgesetzte Motiv der neben der Kline stehenden Frau verleiht dem Relief eine lebendigere Stimmung, als sonst von standardisierten Typen ausgeht. Seine reflektierte Komposition könnte noch dem frühen 1. Jahrhundert v. Chr. angehören.

\section{Giebelstele mit Einlasszapfen}

Inv. 17737. - H $72 \mathrm{~cm}$; B $31 \mathrm{~cm}$. - Abb. 25.

Die Stele verjüngt sich nach oben. Drei Akrotere; Rosette. Zwei Faszien unterhalb des Giebels. Vorspringende Bodenleiste unter dem Inschriftfeld. In der Fläche unter dem Giebel - diese ist in der Regel Kränzen und Rosetten vorbehalten - eine zweibogige Wulstgirlande mit drei Bukrania.

In der Bildnische sitzt links eine verschleierte Frau mit Kopfputz, Mantel und Chiton auf einem Puff mit Kissen. Sie hält in der Linken eine Schale hoch. Tiefe Falten durchziehen den Mantel, dessen hängender Teil hinter dem Schienbein in Dreiecke mit gebogenen Linien gegliedert ist. Der unterhalb sichtbare Chiton bedeckt den halben Fuß. Ihre steife, turbanartige Frisur entspricht der von Kat. 29. Im Hintergrund eine gepolsterte Kline, die mit einer faltenlosen, im Bogen durchhängenden Decke bezogen ist. Neben der Decke wird ein gedrechseltes Klinenbein sichtbar. Auf der Kline mit Polster und Armstützen liegen mit frontalem Oberkörper zwei bekränzte Männer in Chiton und Mantel. Sie halten in der auf ein Kissen gestützten Linken jeweils einen Skyphos. In der Mitte vor der Kline steht ein Pais in knielangem Chiton, im Profil nach rechts. Unterhalb des

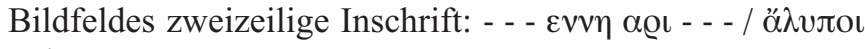

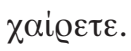

Handwerklich gute Arbeit des späteren 2. Jahrhunderts v. Chr.

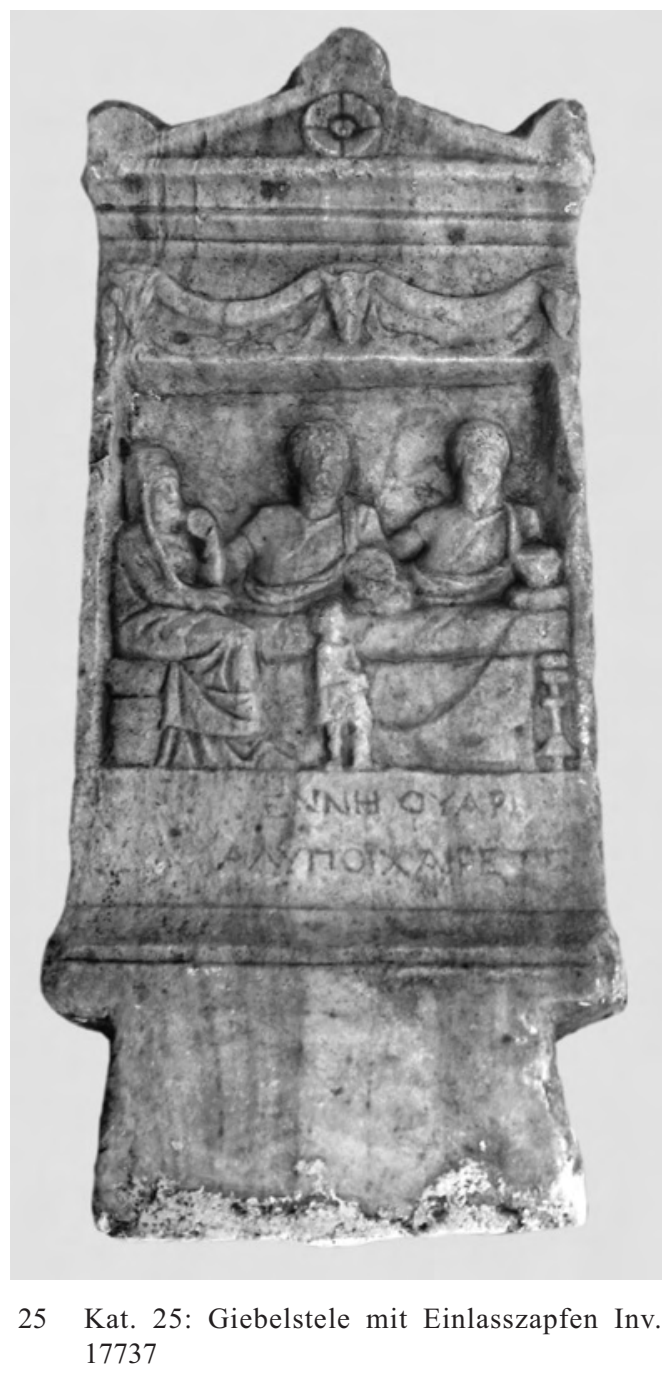

${ }^{13}$ PM 1539. 1540. 1756-1758. 1761. 2025; Délos 319. 


\section{Querrechteckige Giebelstele}

Inv. 8444. - H $72 \mathrm{~cm}$; B $73 \mathrm{~cm}$. Abb. 26.

Zweitverwendung eines Pilasterkapitells. Sehr flacher Giebel; unausgearbeitete Akrotere, nicht freigeschlagen; Rosette. Zierleisten über dem Bildfeld.

In dem Bildfeld befindet sich eine siebenfigurige Totenmahl-Szene. Auf mit einem Tuch verhangener Kline mit Matratzenauflage liegen rechts zwei Frauen in gegürtetem Chiton und Schleiermantel, links ein Mann in Ärmelchiton und Mantel. Der linke Unterarm der Figuren ruht auf einem Kissen, die rechte Hand auf dem angezogenen rechten Knie. Vor ihnen steht ein Tischchen mit drei nach außen gebogenen Beinen; auf dem Tischchen liegen drei kugelige $\mathrm{Ku}-$ chen. Vor den Klinenenden sitzt im Halbprofil je eine verschleierte Frau auf einem kompakten (Lehn?)-Stuhl.

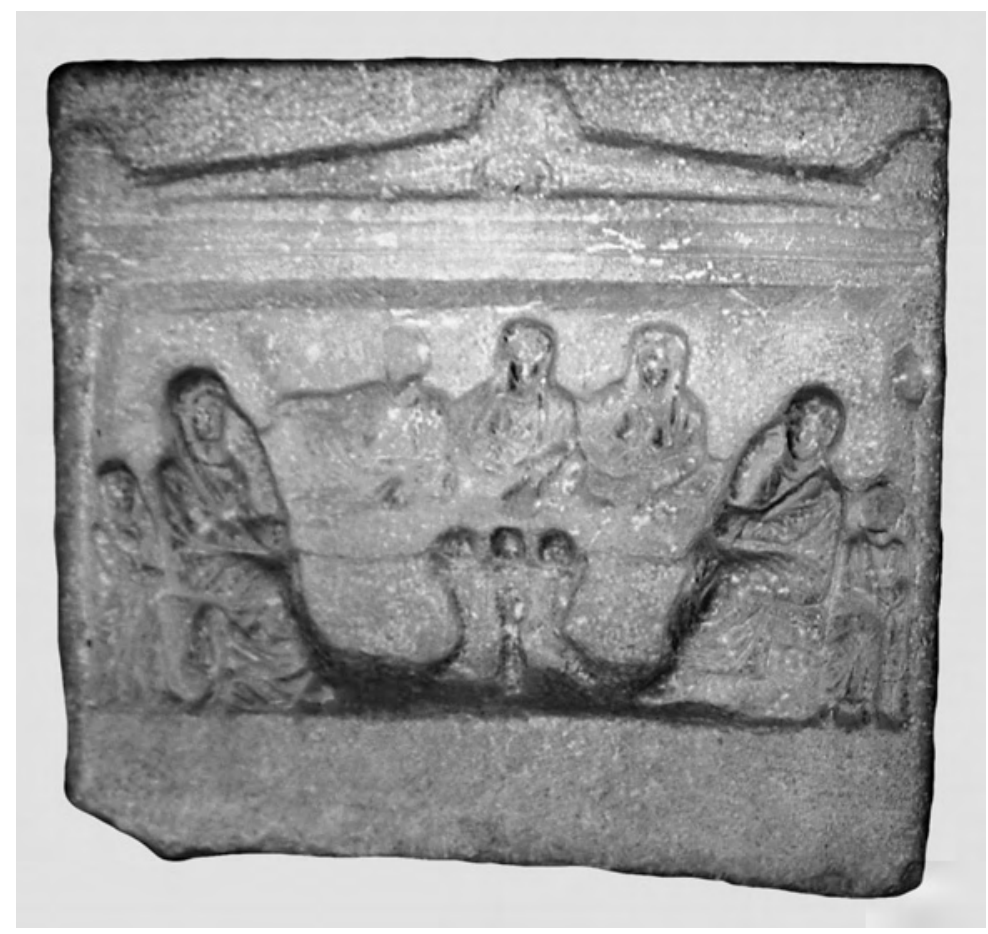

26 Kat. 26: Querrechteckige Giebelstele Inv. 8444

Am Rand der Darstellung befindet sich jeweils eine frontal stehende Dienerfigur, die linke ist ein Mädchen. Der Mantel der rechten Dienerfigur endet in Knöchelhöhe - sie ist männlich. Die links sitzende Frau schlägt ihre Beine übereinander. Die Armhaltungen der Sitzenden entsprechen einander zwar spiegelbildlich, indem sie mit dem hinteren Arm in den Schleier greifen, jedoch ist die links Sitzende stärker aus der Profil- in die Frontansicht gerückt. Auch ihr übergeschlagenes rechtes Bein fördert die Lebendigkeit der Gesamtkomposition, die bereits durch beide auf der Kline liegenden Geschlechter gegeben ist. Der Rückgriff auf einen verworfenen Architekturblock zeugt von nur bescheidenen Möglichkeiten des Auftraggebers, und auch die Herrichtung des Stelenrahmens entspricht diesem Eindruck. Das Bildfeld selbst indessen beeindruckt durch die variierte Figurenkomposition, bei der vier Frauen und ein Mann wiedergegeben sind. Unten dreizeilige

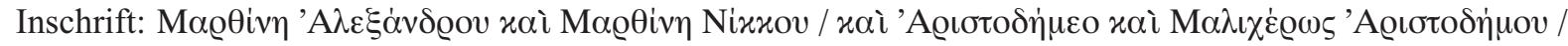

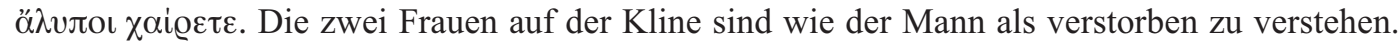

Die kleinen Varianten innerhalb des sonst symmetrischen Aufbaus, auch die angepasste Lebensgröße der Dienerfiguren weisen das Relief noch in das 2. Jahrhundert v. Chr.

\section{Giebelstele}

Inv. 16174. - H $72 \mathrm{~cm}$; B 44 cm. - Abb. 27.

Flüchtig gearbeitete Seitenakrotere; der Mittelakroter ist abgeschlagen. Feine Gesims- und Fußprofile. Das Bildfeld mit den sechs Figuren ist in Zweitverwendung ohne Glättung des Reliefgrundes eingetieft. Die Figuren sind stark verwittert. Das Bildfeld rahmen ungleich schmale Randleisten.

Links sitzt hölzern und steif eine Frau auf einem kastenförmigen Hocker im Profil; das Gesicht bleibt frontal. Ihr Rücken ist parallel zur Randleiste als senkrechte Linie gezeichnet. Der Unterarm ist eng angewinkelt; Ober- und Unterschenkel sind rechteckig umrissen. Rechts liegen auf einer Kline uniform und dicht gedrängt vier Figuren. Am Fußende sitzt ein Kind mit hängenden Beinen. Unterhalb des Bildfeldes

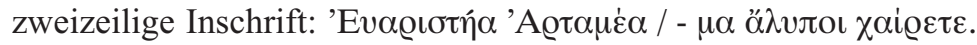


Besonders im Nordwesten Kleinasiens gab es vielfigurige Totenmahl-Darstellungen, die ab dem 1. Jahrhundert v. Chr. in der Weise wie auf dem Antiochener Relief frontal gereiht erscheinen ${ }^{14}$. Wie hier das Kind, begegnen in Mytilene und Samos auch links auf der Kline sitzende Frauen (PM 1908. 1909. 1911. 1912. 1990. 1991). So roh das Relief ist, die links auf der Kline sitzende kleine Person mit hängenden Beinen ist ein Kind, ein Knabe im Mantel mit umwickeltem linkem Arm und angewinkeltem rechtem. Parallelen zu diesem auf der Kline sitzenden Kind gibt es nicht. Inhaltlich, als Familienbild, überrascht diese Version des Motivs indessen nicht. Der Platz für sechs Personen ist ausreichend berechnet, aber dürftig ausgearbeitet.

Ein Werk vielleicht des 1. Jahrhunderts n. Chr.

\section{Leistenstele}

Inv. 15744. - H $57 \mathrm{~cm}$; B $70 \mathrm{~cm} .-\mathrm{Abb} .28$

Zweitverwendung eines Architekturteils, der obere Rand ist abgeschlagen.

Auf einer langen Kline, von zweifacher Länge als gewöhnlich, mit sechs gedrechselten Beinen sind auf einer Matratze vier Männer und zwei Frauen gelagert. Ihre Köpfe sind stark beschädigt. Die linken Arme und Hände, die keine Trinkgefäße halten, liegen auf dem Rand der Matratze. Die

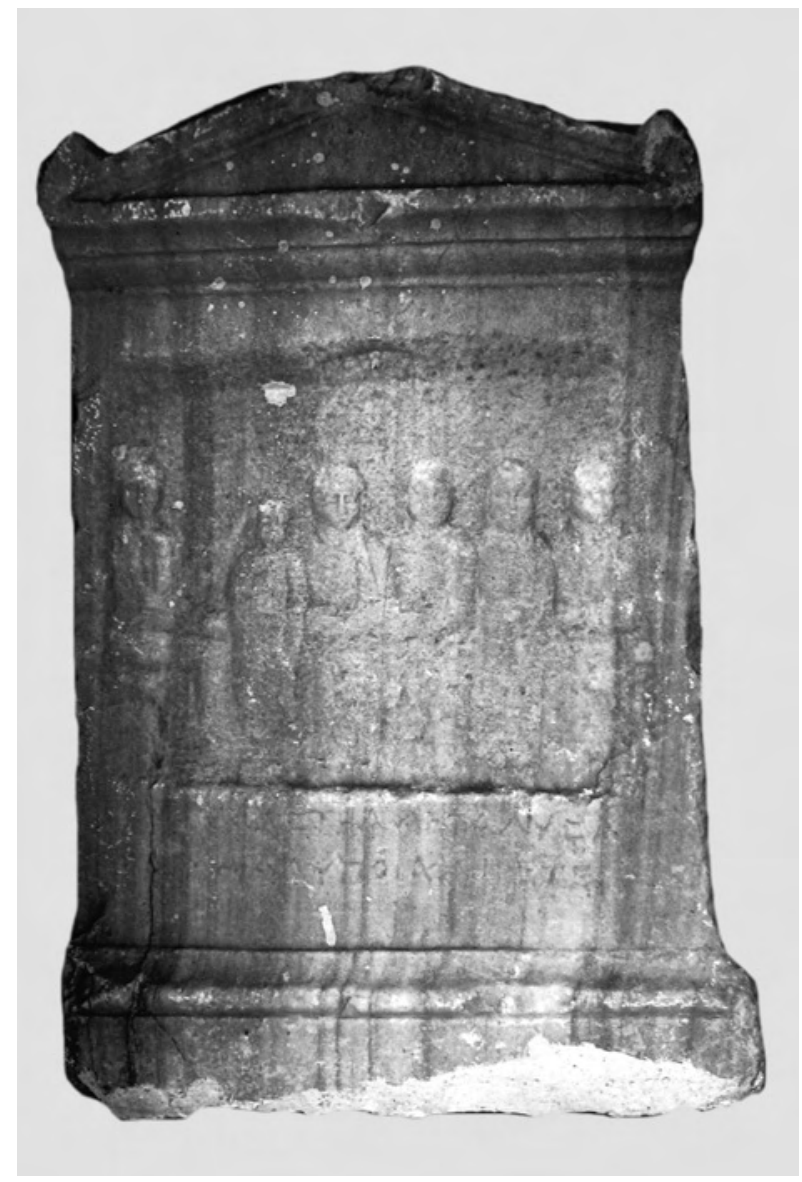

27 Kat. 27: Giebelstele Inv. 16174 jeweils zweite Figur von rechts und links ist eine Frau in hochgegürtetem Chiton. Weder sind Dienerfiguren, sitzende Frauen noch ein Tisch dargestellt. Unterhalb der Kline, deren Beine teilweise verdeckend, stehen vier maßstäblich zu kleine Figuren: links zwei Frauen in Chiton und Mantel frontal, in der Mitte im Profil nach rechts ein Mann in knielangem Chiton mit überkreuzten Beinen und rechts von diesem, vom äußeren Klinenbein abgerückt, eine weitere männliche Mantelfigur in Frontalansicht. Im Gegensatz zu den Häuptern der männlichen Figuren überschneiden die Köpfe der Frauen die Matratze. Auf dem breiten Streifen unterhalb der Figuren und über dem Abschlussprofil findet sich eine zweizeilige, unleserliche Inschrift.

Von persönlicher Raffinesse zeugt das Motiv der Figuren im Vordergrund der Kline. Es muss in dieser witzigen Komposition ein Käuferwunsch oder ein originelles Angebot einer Werkstatt gesehen werden, die sich über die übliche Typenkonvention hinwegsetzte. Warum sind die beiden links stehenden Frauen größer als die rechts stehenden Männer? Der gänzlich unkonventionelle Typus ist ohne Parallele. Eine sechsbeinige Kline ist sonst unbekannt, und singulär ist auch die Kombination mit den vor ihr stehenden Mantelfiguren. Diese erstaunen durch ihre statuenhafte Präsentation, doch ist ihre Anordnung zwischen den gedrechselten Klinenbeinen, von denen das rechte zur Gänze sichtbar ist, nicht ohne Reiz.

Im rechten Zwischenraum steht die äußere der vier Figuren, männlich, im Mantel, ohne ausgearbeitete Füße. Die Arme, der rechte angewinkelt, sind in den Mantel gewickelt. Die zweite Figur von rechts ist die raffinierteste: Sie steht mit zurückgesetztem rechtem Bein und in Achselhöhe auf einen Stock gestützt im Profil nach rechts und lässt das mittlere Klinenbein gerade noch sichtbar. Die beiden linken Mantel-

\footnotetext{
14 Fabricius 1999, 284.
} 


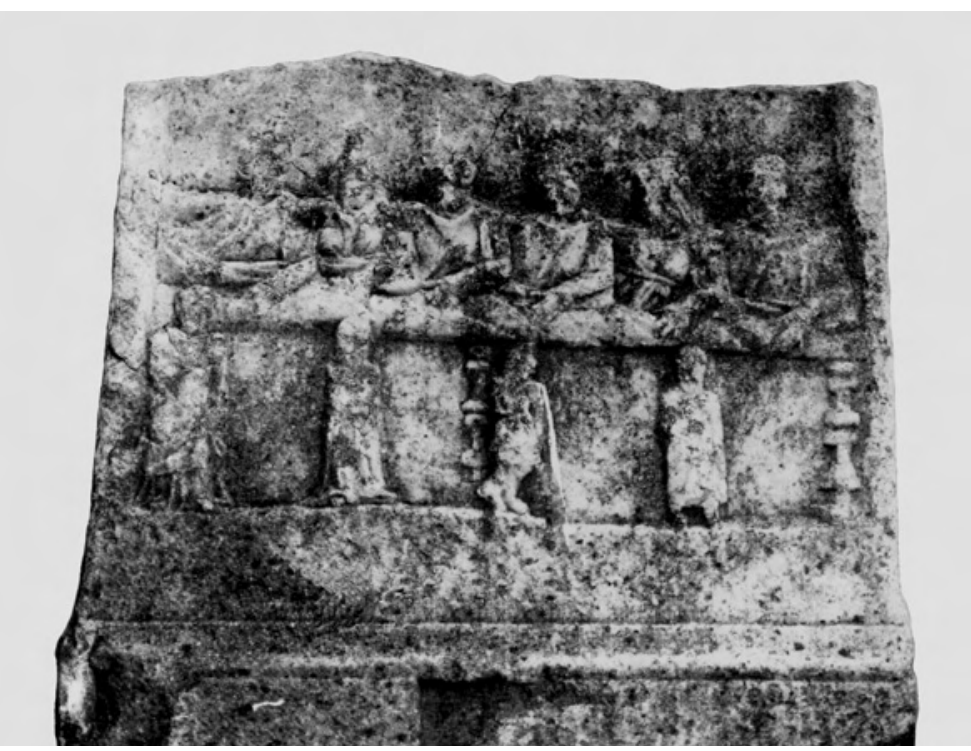

28 Kat. 28: Leistenstele Inv. 15744

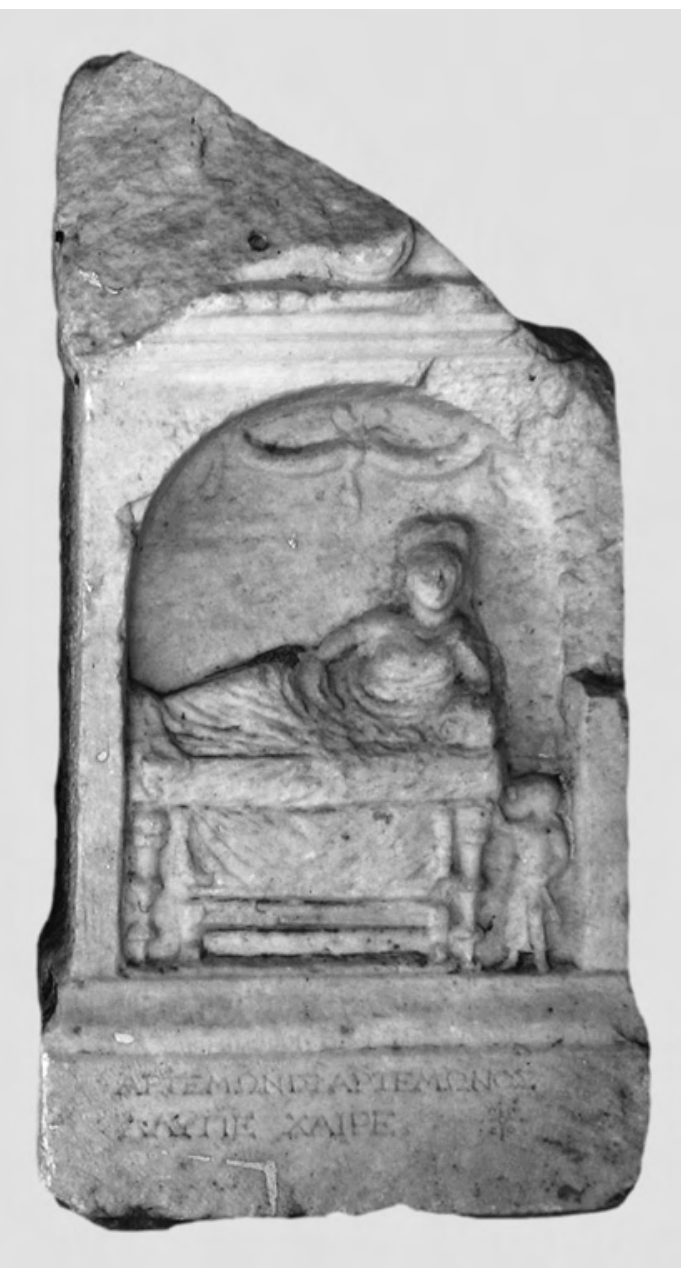

29 Kat. 29: Giebelstele mit Bogennische Inv. 8936 statuen sind weiblich. Wie bei den männlichen Figuren sind auch ihre Arme in den Mantel gewickelt. Die äußere Frau verdeckt das linke Klinenbein vollkommen, und ihr Kopf überschneidet die Matratze. Eine besondere Bedeutung wird an ihrer unterschiedlichen Größe nicht abzulesen sein - der Steinmetz nutzte die räumlichen Möglichkeiten für die Anordnung der Figürchen auf seine Weise. Die vier Männer und zwei Frauen auf der Kline hingegen sind symmetrisch geordnet. Das Bildfeld ist aufs Äußerste ausgenutzt.

Die plastische Ausführung aller Figuren hat, bis auf die plumpen Hände der Gelagerten, einiges Niveau. Die Chitone beider weiblichen Mantelfiguren fallen stoff- und faltenreich. Die vier verschiedenen Mantelfigürchen von geschlossenem Umriss, das eine bewegt, und auch die plastisch empfundenen Oberkörper der auf Schulterschluss Gelagerten wirken frühhellenistisch, gehören aber wohl dem 1. Jahrhundert v. Chr. an.

\section{Giebelstele mit Bogennische}

FO: Nekropole von Antiochia. - Inv. 8936. - H 58 cm; B 28 cm. - Abb. 29.

Der obere Teil des Giebels ist abgeschlagen. Im Giebel Schild; mehrgliedriges Gesims. Bildfeld in Bogennische. Im Bogen hängt eine zweiteilige Girlande an Bändern.

Eine Frau in Chiton und Mantel, mit langem Haar und steifem Kopftuch liegt auf einer Kline, den linken Arm auf ein Kissen gestützt. Ihr Unterkörper wirkt viel zu kurz. Die mit einem faltigen Tuch verhangene Kline hat gedrechselte Beine. Unter der Kline steht ein niedriger, langer Tisch ohne Teller oder Früchte, rechts neben ihr im Halbprofil eine kleine Dienerin in langem Chiton mit erhobenem rechtem Arm. Ihr Kopf ist zu groß, die Beinchen sind zu dünn. Unter dem Bildfeld befindet sich eine abgesetzte profilierte Basis, unter dieser wiederum die

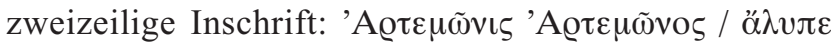
$\chi \alpha \tilde{\varrho} \varrho \varepsilon$.

Die Gelagerte trägt das zylindrisch steif gewickelte Kopftuch unter dem Mantelschleier, wie es vielfach an nordsyrischen Reliefs begegnet, z. B. bei Kat. 25 in Antiochia. Verwandt ist eine Stele in Marseille mit verhangener Kline und ebenfalls gerieftem Polster. Wieder ist der Unterkörper zum Dreieck verkürzt. Das zylindrisch 
hochstehende Kopftuch der Frau und die Position der Dienerin, die nach oben blickt, entsprechen, desgleichen die sauberen Buchstaben der Inschrift. Der zum Dreieck verkümmerte Unterkörper und auch die sorgfältige Beschriftung sind Kennzeichen derselben Werkstatt, wobei aber die Stele in Marseille jünger ist - die sauberen Buchstaben mit Apices an Kat. 29 gehören dem 2. Jahrhundert v. Chr. an. Der Typus der Kline, zu der ein voluminöses Kissen und eine dicke Matratze gehören, mit gemustertem Behang und dem niedrigen, untergeschobenen Tischchen ähnelt auch PM 2020; dieses Motiv wirkt auf Kat. 29 abgegriffener als dort. E. Pfuhl datiert die »ungeschickte Arbeit« sicher zu spät in die »späte Kaiserzeit«.

Kat. 29 dürfte, auch im Vergleich mit Kat. 30, noch dem 2. Jahrhundert v. Chr. angehören.

Vgl.: Parlasca 1982, 8 Taf. 19, 4; zum steifen Kopftuch, Parlasaca 1982, Taf. 6, 1; 7, 4; 11, 1; 12, 1; 13, 1; Wagner 1976, Nr. 122-124 Taf. 49; Nr. 150 Taf. 56; zur Inschrift Jalabert - Mouterde 1950, 498 Nr. 905; CIL VI 26433.

\section{Giebelstele mit Bogennische und Einlasszapfen}

FO: Antakya, Nähe Peterskirche. - Inv. 8992. - H $71 \mathrm{~cm}$; B 35 cm. - Abb. 30.

Giebel nicht freigeschlagen; drei Akrotere sind nur flüchtig aus der Vorderschicht des Steins herausgeschlagen. Der Giebel ist extrem flach, die kleine Rosette aber ausgearbeitet. Profiliertes Gesims und Fußprofil.

Im Bogenfeld auf einer Kline mit gedrechselten, extrem dünnen Beinen, mit Matratze und Armkissen liegt ein Mann in Ärmelchiton und Mantel. Sein Gesicht ist beschädigt, das Haar gelockt. Die linke Hand mit abgespreiztem Daumen hängt vor dem Kissen; die rechte liegt auf dem angezogenen Knie. Die Ausarbeitung der Füße ist unklar bzw. misslungen. Links vor der Kline steht ein Pais in knielangem Chiton nach rechts. Unter dem Bildfeld ist die zweizeilige Inschrift angebracht: $\Theta \varepsilon$ coóoøı

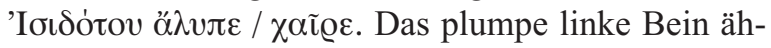
nelt stark dem rechten der Frau auf PM 2020, und auch die wenig überzeugende Draperie der Mantelfalten könnte auf dieselbe Werkstatt zurückzuführen sein. Beide Male ist die Darstellung des Unterkörpers auf gleiche Weise misslungen.

Aufgrund der manierierten Klinenbeine, der misslungenen Füße und des Miniformats des Pais ist die Stele später als Kat. 29, also etwa in die zweite Hälfte des 1. Jahrhunderts v. Chr. zu datieren.

Vgl.: Jalabert - Mouterde 1950, 511 Nr. 939.

\section{Leistenstele}

Inv. ? - H $25 \mathrm{~cm}$; B $24 \mathrm{~cm}$. - Abb. 31.

Die niedrige, etwa quadratische Stele mit Seitenleisten ist oben in Form eines flachen Giebeldreiecks begrenzt. Die Seitenleisten enden in zwei angedeuteten Seitenakroteren.

Eine Kline mit ausladend gedrechselten Beinen und steil geschwungenen Fulcra nimmt die gesamte Breite des Bildfeldes ein. Eine dicke Matratze geht

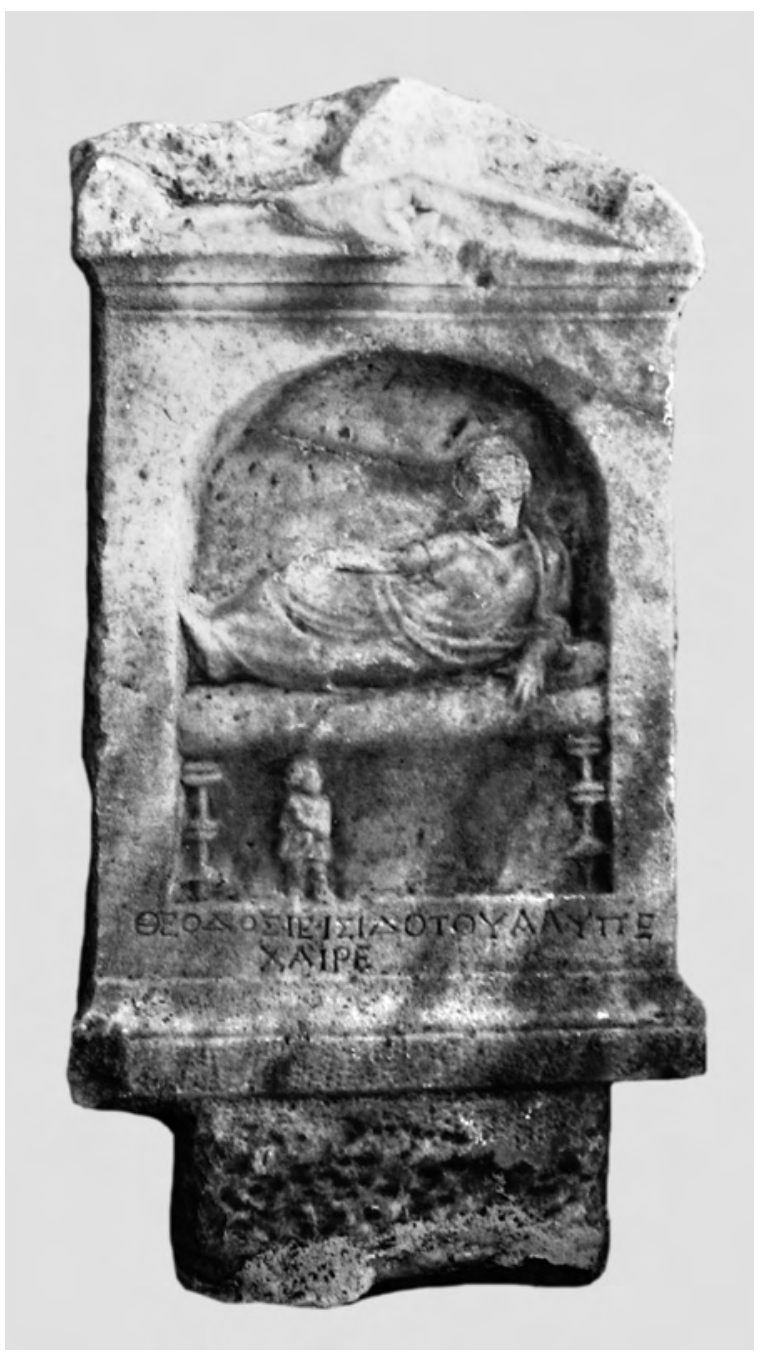

30 Kat. 30: Giebelstele mit Bogennische und Einlasszapfen Inv. 8992 


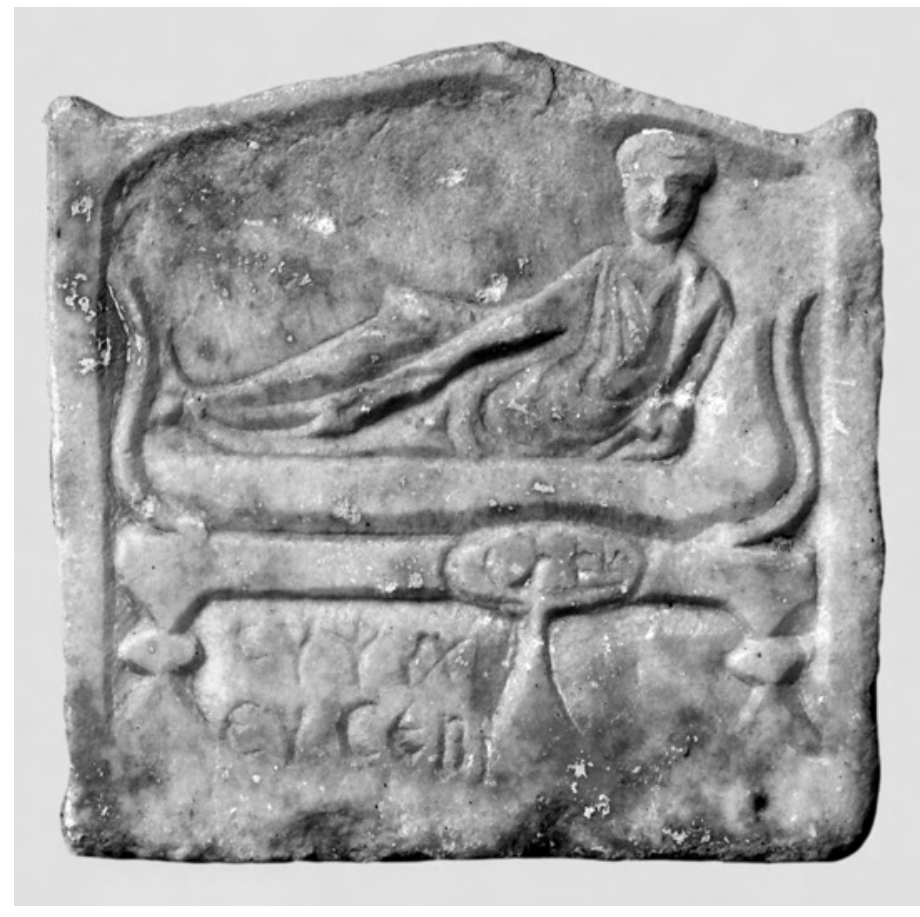

31 Kat. 31: Leistenstele Inv. ?

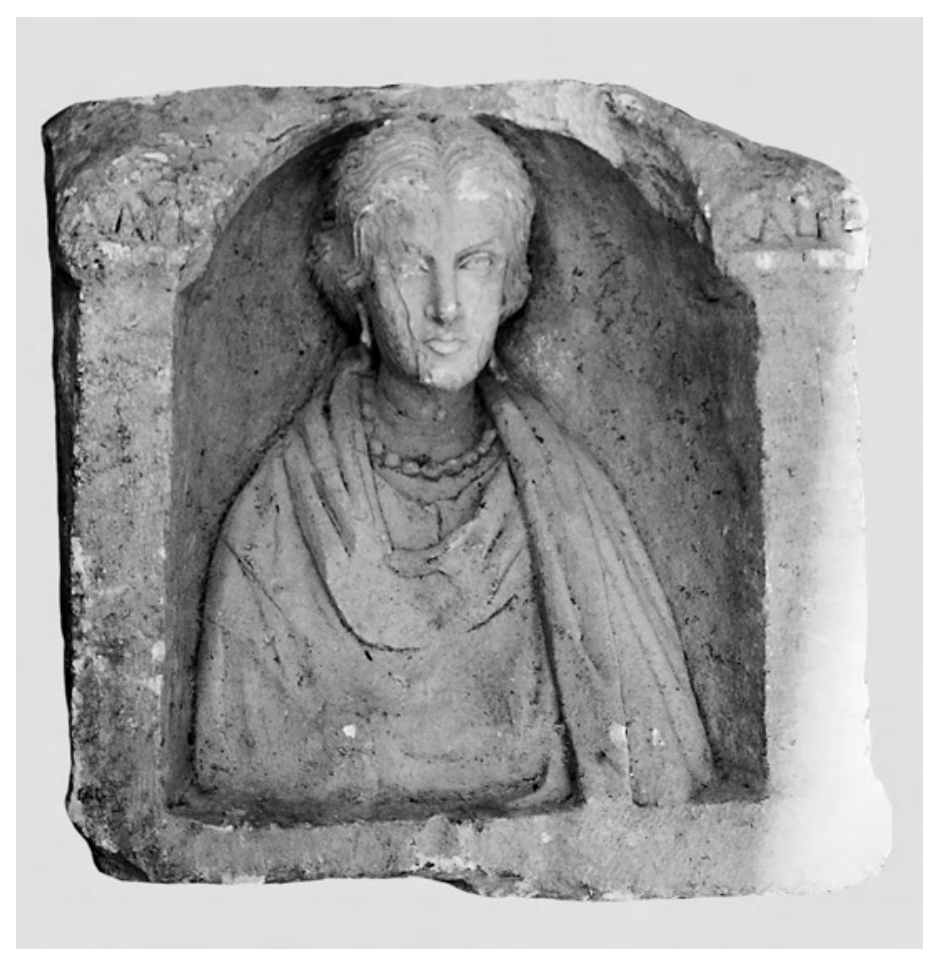

32 Kat. 32: Loculus-Verschlussplatte mit Bogennische und Naiskos Inv. 8739 rechts in ein voluminöses Armkissen über, das sich in die Rundungen der geschwungenen Lehne schmiegt. Der Gelagerte in Chiton und Mantel hält in der Rechten des ausgestreckten Armes eine Handgirlande; die Linke hielt nach Aussage zweier Parallelen (s. u.) eine Trinkschale. Vor der Kline steht ein rundes, einbeiniges Tischchen in schlechter Perspektive, auf ihm liegen runde, kleine Kuchen. Zwischen den Klinenbeinen grobe Inschrift in großen Buchstaben: عvvı / - - -, die in dieser Form wohl nicht ernst gemeint sein kann. Die sehr hoch geschwungenen Lehnen treten im späten 1. Jahrhundert n. Chr. auf und leben auf Sarkophagen bis in das 3. Jahrhundert n. Chr. fort.

Zwei weitere Exemplare dieses Stelentyps schließen sich mit Kat. $31 \mathrm{zu}$ einer Werkstattgruppe zusammen. Gemeinsam ist ihnen die ungeschickte Perspektive des Tischchens, die späte Klinenform mit hochgestellten Seitenwangen und ausladend gedrechselten Beinen, die einfache Fünfeckform der niedrigen Stele und der Typus der gelagerten Figur mit dreieckig konturiertem Unterkörper. Ein Exemplar wurde in Üsküdar gefunden und befindet sich heute in Istanbul ${ }^{15}$, das andere im Musée Rodin, Paris ${ }^{16}$. Die Istanbuler Stele ist die in dieser Gruppe am sorgfältigsten gearbeitete, an ihr sind auch die Füße der gelagerten Frau ausgeführt. Deren Porträt könnte nach Aussage des breiten Geflechts über scharf markierter Strähnengliederung des Scheitelhaars dem mittleren 2. Jahrhundert n. Chr. angehören. Die Exemplare in Antakya und Paris sind nachlässiger reliefiert, an ihnen sind die Füße nicht wiedergegeben. Die Inschrift auf den Stelen in Paris und Istanbul ist unter dem Bildfeld deutlich zu sehen, während die Antiochener Stele unter dem Bildfeld kaum Platz für eine Inschrift aufweist. Unleserlich steht diese mit großen Buchstaben neben dem Tischchen, direkt unter der Kline. Einzig die Antiochener Stele ist mit >Seitenak-

\footnotetext{
${ }^{15}$ M. Cremer, Hellenistische und römische Grabstelen im nordwestlichen Kleinasien II. Bithynien (Bonn 1992) 97. 173, Stele der Epicharis Taf. 29 o. r. (aus Üsküdar).

16 Parlasca 1982, 17 mit Anm. 170 Taf. 18, 6.
} 
roteren ausgestattet: Dieserart nur durch einfachsten Umriss angedeutete Giebel mit >Akroteren $<$ wiederholen sich insbesondere an Bildfeldern mit rechteckig begrenztem Reliefgrund (PM 2019 u. a.). Die voluminöse Lockenfrisur von Kat. 31 entspricht der des Pariser Reliefs - beide werden spätantoninisch zu datieren sein.

Vgl. zur Klinenform: G. Richter, The Furniture of the Greeks, Etruscans and Romans (Oxford 1966) 109 Abb. 550-558; PM 360 f. Nr. 1267 Taf. 188; 1494 Taf. 217; 1503 u. a.; R. Amedick, Die Sarkophage mit Darstellungen aus dem Menschenleben. Vita privata, ASR I 4 (Berlin 1991) Taf. 53, 1; 57, 1. 2; M. Fantar, La mosaïque en Tunisie (Paris 1994) 2 f.; H. Wrede, Stadtrömische Monumente, Urnen und Sarkophage des Klinentypus in den beiden ersten Jahrhunderten n. Chr., AA 1977, 429 Abb. 115; Parlasca 1982, 18 Taf. 19, 2.

\section{Loculus-Verschlussplatte mit Bogennische und Naiskos}

Inv. 8739. - H $43 \mathrm{~cm}$; B $31 \mathrm{~cm}$. - Abb. 32.

Oberkörperbüste im Bogenfeld, seitlich gerahmt von >korinthischen`Kapitellen. Rechte obere Ecke abgeschlagen. Unten schmale Leiste.

Die gesamte Bogennische füllt eine weibliche Mantelbüste mit stark abfallenden Schultern aus. Unter dem faltig gebauschten Mantelabschluss wird der breite Rand eines Chitons sichtbar. Die Frau trägt eine Kette großer Perlen und Ohrgehänge. Ihr Gesicht ist gestreckt, die edlen Züge sind deutlich eingetragen, die großen Pupillen sind flach ausgearbeitet. Ihre Frisur mit Mittelscheitel ist zu der frühseverischen Knotenfri-

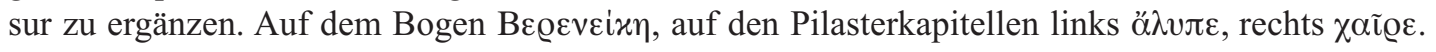

Vgl.: Jalabert - Mouterde 1950, 500 Nr. 908.

\section{Typologie der Stelen}

21 der 32 Stelen aus Antiochia sind als Giebelstelen konzipiert. Die sorgfältig mit Profil und Rosette ausgearbeiteten Giebel gehören zu den früheren, im 3. (Kat. 1) und 2. Jahrhundert v. Chr. (Kat. 17. 25) entstandenen Stelen. In der Güteskala folgen Giebel mit ausgehauenen, aber nicht ausgearbeiteten Akroteren (Kat. 10. 11. 20. 30); die Rosette kann fehlen. Vielfach ist der Stein hinter den reliefartig markierten Giebeln belassen worden: Diese Nachlässigkeit datiert die Stelen in das 1. Jahrhundert v. Chr. (Kat. 2. 4. 7. 9. 12. 18. 19. 26. 30). Drei Stelen (Kat. 6. 9. 22) verjüngen sich nach unten, zwei (Kat. 15. 25) nach oben. Vierzehn Stelen sind mit breiten oder auch schmalen Einlasszapfen in den Boden gearbeitet, wobei der Form der Einlasszapfen eine chronologische Entwicklung nicht zu entnehmen ist. Zehn Stelen sind ohne Einlasszapfen gearbeitet - sie sind verhältnismäßig nachlässig ausgeführt und waren in gesamter Breite ein Stück in den Boden eingesenkt. Das Mahl einer Frau mit Tisch und Dienerin in der Bogennische mit Giebel (Kat. 29) hat unterhalb der Inschrift nicht genug Platz, um in den Boden eingesenkt zu werden: Hier ist eine Verdübelung an der Rückseite, so wie auch an den Leistenstelen, anzunehmen. An fünf Stelen (Kat. 11. 12. 21. 29. 30) ist das Bildfeld als Bogennische umgrenzt, sechs fassen das Bildfeld als Naiskos mit architektonischer, d. h. mit Säulen- oder Pilasterrahmung ein (Kat. 1. 3. 4. 18. 22. 32). Eine Rechtecknische oder ein flacheres Relieffeld über der Fläche mit Inschrift sind die geläufigsten Formen für das Bildfeld. Leistenstelen haben weder Giebel, Zapfen, Nische noch Pilasterrahmung. Sie sind plattenartig in eine Wand oder Mauer eingelassen worden. Die Grabformulare stehen meistens unter dem Bildfeld, finden sich aber auch unter dem Fußprofil (Kat. 19. 29), auf dem >Architrav ` (Kat. 22), an kaiserzeitlichen Exemplaren auf dem Bildfeld (Kat. 31) und an Kat. 32 auf den Naiskos-Kapitellen. 


\section{Typologie der Reliefs}

Eine stehende Person: Kat. 1-3. 6. 10. 12

Zwei oder drei stehende Personen: Kat. 5. 7.8

Ein stehender Mann mit Hermes: Kat. 4

Sitzende Frau und stehender Mann: Kat. 13-16

Sitzende Frau, stehender Mann, sitzender Mann: Kat. 9

Sitzende Frau, stehender Mann, ein Kind, ein Diener: Kat. 18

Sitzende Frau, eine Dienerin: Kat. 21

Sitzende Frau mit Kind: Kat. 17-19. 20. 22

Stehende Frau, zwei Kinder: Kat. 11

Eine liegende Person auf der Kline: Kat. 19-21. 31

Eine liegende Person auf der Kline, eine sitzende: Kat. 22. 23

Eine liegende Person auf der Kline, eine sitzende, eine stehende: Kat. 24

Zwei liegende Personen auf der Kline, eine sitzende: Kat. 25

Drei liegende Personen auf der Kline, zwei sitzende: Kat. 26

Vier liegende und eine sitzende Person auf der Kline, eine sitzende: Kat. 27

Sechs liegende Personen auf der Kline: Kat. 28

Büste: Kat. 32

Dienerfiguren: Kat. 6. 12. 18. 21. 23. 25. 26. 29. 30

Angehörige Kinder: Kat. 11. 17-20. 22. 27

\section{Typologie der Figuren}

Frontal stehender Mann in Mantel und Chiton

Rechter Arm angewinkelt in Mantelschlaufe: 2. Jh. v. Chr. - 1. Jh. n. Chr. (Kat. 3. 5-7. 9. 12. 16. 18)

Rechter Arm in Mantel gewickelt: 1. Jh. v. Chr. (Kat. 15)

Rechter Arm bewegt: 2.-1. Jh. v. Chr. (Kat. 4. 8. 13)

Stehende Frau in Mantel und Chiton

Im Profil: 1. Jh. v. Chr. (Kat. 5)

Frontal: 1. Jh. v. Chr. (Kat. 7)

Opfernd: 1. Jh. v. Chr. (Kat. 8)

Im Halbprofil mit Handspiegel: 2. Jh. v. Chr. (Kat. 10)

Zwischen zwei Kindern: 2. Jh. v. Chr. (Kat. 11)

Im Halbprofil mit liegendem Mann und sitzender Frau: 1. Jh. v. Chr. (Kat. 24)

Sitzende Frau in Mantel und Chiton

Mit stehendem und sitzendem Mann: 2. Jh. v. Chr. (Kat. 9)

Mit stehendem Mann: 2. Jh. v. Chr. - 1. Jh. n. Chr. (Kat. 13. 15. 16)

Mit Groteske: 2. Jh. v. Chr. (Kat. 14)

Mit Tochter: 1. Jh. v. Chr. (Kat. 20)

Mit Dienerin: 1. Jh. v. Chr. (Kat. 21)

Neben Kline: 2.-1. Jh. v. Chr. (22. 24-27)

Mit Kind auf dem Schoß: 2.-1. Jh. v. Chr. (Kat. 17-19. 22)

Mit Mann und Diener vor Parapetasma: 1. Jh. v. Chr. (Kat. 18)

Sitzender Mann

Mit übergeschlagenen Beinen, mit stehendem Mann und sitzender Frau: 2. Jh. v. Chr. (Kat. 9)

Neben Kline: 1. Jh. v. Chr. (Kat. 23) 
Mann auf Kline

2. Jh. n. Chr. (Kat. 30. 31)

Mit sitzender Frau mit Kind auf dem Schoß: 1. Jh. v. Chr. (Kat. 22)

Mit sitzender und stehender Frau: 1. Jh. v. Chr. (Kat. 24)

Zwei Männer mit sitzender Frau: 2. Jh. v. Chr. (Kat. 25)

Neben zwei Frauen auf Kline und zwei sitzenden Frauen sowie zwei Dienern: 2. Jh. v. Chr. (Kat. 26)

Vier Figuren und ein Kind mit sitzender Frau: 1. Jh. v. Chr. (Kat. 27)

Drei Männer und zwei Frauen: 1. Jh. v. Chr. (Kat. 28)

\section{Frau auf Kline}

Mit Dienerin: 1. Jh. v. Chr. (Kat. 29)

Zwei Frauen, ein Mann mit zwei sitzenden Frauen und zwei Dienern: 2. Jh. v. Chr. (Kat. 26)

Zwei Frauen und drei Männer auf Kline: 1. Jh. v. Chr. (Kat. 28)

Kind

Zwei Kinder und stehende Mutter: 2. Jh. v. Chr. (Kat. 11)

Auf dem Schoß der Mutter: 2.-1. Jh. v. Chr. (Kat. 17-19. 22)

Mit sitzender Mutter: 1. Jh. v. Chr. (Kat. 20)

Sitzend auf Kline mit vier liegenden Figuren und sitzender Frau: 1. Jh. v. Chr. (Kat. 27)

Diener/in

Lebensgroß: 2-1. Jh. v. Chr. (Kat. 6. 12. 18. 21)

Mit zwei sitzenden und zwei liegenden Frauen sowie einem liegenden Mann: 2. Jh. v. Chr. (Kat. 26)

Miniaturgröße: 2.-1. Jh. v. Chr. (Kat. 23. 25. 29. 30)

Krieger

Frontal: 3. Jh. v. Chr. (Kat. 1)

In Ausfallstellung: 1. Jh. v. Chr. (Kat. 2)

Hermes

Im Halbprofil im Handschlag mit frontal stehendem Mann: 2. Jh. v. Chr. (Kat. 4)

Groteske

Im Handschlag mit sitzender Frau: 2. Jh. v. Chr. (Kat. 14)

Statuenfiguren vor Kline

Vier Figuren: 1. Jh. v. Chr. (Kat. 28)

Die 32 erhaltenen Grabreliefs aus dem Raum Antiochia-Dafne verteilen sich über annähernd 500 Jahre. Die schöne Kriegerstele Kat. 1 ist der älteste überlieferte Vertreter. Ihr Standmotiv ist klassisch - sie muss früh im 3. Jahrhundert v. Chr. entstanden sein. Die ihrerseits schöne Büste der Lokulusplatte Kat. 32 ist gegen 200 n. Chr. entstanden. Anspruch und Qualität von Grabskulpturen noch der mittleren Kaiserzeit haben weiterhin hohes Niveau. In dem hier durch die wenigen Reliefs abgedeckten langen Zeitraum von fünf Jahrhunderten entstanden erwartungsgemäß neben kleinen Kunstwerken (Kat. 1. 11. 17) überwiegend durchschnittliche und sehr bescheidene Arbeiten. Das Gros der überlieferten Stücke gibt geläufige Typenkombinationen wieder, deren Ausführung keine besonders zu beachtenden Merkmale aufweist (Kat. 3. 5. 6. 9. 12. 13. 15. 25. 29. 31. 32). Nicht wenige Stücke schließlich gehören einer unterdurchschnittlichen Massenware an, deren Komposition bar jeder Phantasie und deren Ausführung am untersten Rand handwerklichen Könnens bleibt (Kat. 7. 8. 16. 18. 19. 21. 31).

Insgesamt begegnet ein breites Spektrum an Personenkombinationen: Unter ihnen finden sich einfachste Frontalansichten, allein oder neben einer Sitzfigur. Obwohl eine Reihe der Antiochener Grabreliefs nur von sehr durchschnittlicher Bildhauerarbeit und ihre Thematik nicht außergewöhnlich ist, entbehren Kombination und Wiedergabe nicht einer gewissen Originalität. Eindrucksvoll ist beispielsweise der mächtig ausho- 
lende Krieger Kat. 2: grob gearbeitet, aber tief empfunden. Auf Kat. 22 sitzt die verstorbene Frau, während der auf der Totenmahl-Kline liegende Mann der Hinterbliebene ist. Selten sitzt der hinterbliebene Mann wie auf Kat. 23 neben der Kline, wie es üblicherweise der Frau vorbehalten ist. Schlicht motiviert, aber ohne Parallele ist das Nebeneinander von Mutter und stehendem Kind auf Kat. 20, wohlkomponiert die siebenköpfige Familienszene auf Kat. 26.

Ein Charakteristikum der Antiochener Grabreliefs ist aber ihre lebhafte Variationsbereitschaft. Auffallend sind ganz ungewöhnliche Motive, für die es in der Überlieferung griechischer Grabstelen keine Parallelen gibt. Singuläre Erfindungen sind so die Reliefs Kat. 2, 4, 10, 14, 24 und 28, wobei die inhaltliche Intention besonders der Stücke Kat. 14, 24 und 28 schwer verständlich bleibt. Derartige höchst originelle Szenen müssen indessen nicht von herausragender künstlerischer Qualität sein - es sind nicht die handwerklich hochstehenden Arbeiten, die einmalige Motive oder Typenkombinationen kreieren. Künstlerische Spitzenstücke wie Kat. 1, 11 und 17 wiederum sind ohne inhaltliche Problematik. Auch mittelmäßige Ausführungen wie der ausschreitende Krieger auf Kat. 2, der Totengeleiter auf Kat. 4 und die Frau mit Handspiegel auf Kat. 10 kehren so kein zweites Mal in der antiken Überlieferung wieder. Ihre Thematik indessen ist unmittelbar einsichtig.

Es ergibt sich ein weit gefächertes Bild der Grabkunst im Raum von Antiochia. Dieses erschöpft sich weder in einem lokal umgrenzten Stil noch durch Abhängigkeit von Importen. Die syrische Metropole blieb über fünf Jahrhunderte bis in die Spätantike am Schnittpunkt der Kulturen mannigfachen kulturellen, geistesgeschichtlichen und wirtschaftlichen Einflüssen ausgesetzt. Entsprechend sind Anregungen für die eigene Industrie durch Handel und Zuwanderer zu erwarten. Diese Anregungen können natürlich nicht im Kopistenwesen bestanden, sondern müssen Handwerk und Unternehmertum zum Erblühen gebracht haben. Eine speziell syrische Komponente ist schwer auszumachen, es sei denn, diese ist der Mannigfaltigkeit der Thematik abzulesen.

\section{Ikonographie der Darstellungen}

\section{Ausstattung der Bildszenen}

Der weich fließende Vorhang, der den Hintergrund der >klassischen< Kriegerstele Kat. 1 vollständig verdeckt, wiederholt sich in dieser Form weder in Antiochia noch außerhalb Syriens. Immer sind Vorhänge am Hintergrund horizontal an einzelnen Punkten befestigt, sodass sie in einem oder mehreren Bögen horizontal durchhängen. In der Regel sind sie unplastisch flach angegeben und nur durch eingekerbte Bogenlinien als Vorhang gekennzeichnet. Zwischen Fackeln gespannte Parapetasmata gibt es in Antiochia an Kat. 6, 18 und 19, des Weiteren an PM 1647 und 1656. Auf Kat. 1 ist eine horizontale Befestigung an der Decke zu vermuten, fest oder verschiebbar, wenn überhaupt eine reale Konstruktion wiedergegeben sein sollte. Doch wird die elegante Bezugnahme des klassisch posierenden Kriegers auf den schlichten, aber wirkungsvollen Hintergrund nicht auf künstlerische Phantasie zurückgehen. Eher sind vergleichbare Theatervorhänge im modernen Sinn anzunehmen, deren Konstruktion den antiken Dekorateur nicht überfordert haben sollte. Allein die künstlerische Komposition ist hervorzuheben: Das klassische Standbild, ohne Aktion und ohne Beiwerk der Ausstattung des Naiskos, diesen nur zur Hälfte füllend, wird durch den zurückhaltenden, aber nicht toten Hintergrund zu einer dramatischen Szene ausgestaltet. Eine derartige Dekoration ist wiederum singulär. Der Vorhang auf Kat. 18 und 19, jeweils hinter der Frau mit Kind auf dem Schoß, ist denkbar grob und kantig ausgeführt.

Ausstattungsmobiliar ist nur auf das Äußerste reduziert anzutreffen. Eine einzelne Fackel hält der Diener auf Kat. 12. Ein rundes Tischchen vor der Totenmahl-Kline gibt es in der üblichen dreibeinigen Form auf Kat. 26. Auf einem Mittelbein steht der primitiv wiedergegebene Tisch auf Kat. 31. Der lange Rechtecktisch auf der Stele mit gelagerter Frau Kat. 29 scheint unter die verhangene Kline geschoben zu sein. Kylikeia, Schankgefäße oder Wandborde finden sich nicht. Abgesehen von der Kline gibt es an Mobiliar lediglich die Hocker mit Kissen der üblicherweise links sitzenden Frau. Diese sind Diphroi mit Kreuzverstrebung, feste Hocker mit Querstreben und glatten Beinen oder ohne Querstreben mit gedrechselten Beinen. Die Frau mit Kind auf Kat. 19 scheint auf einem Hocker mit durchgehenden Seitenwänden zu sitzen. Kat. 25 zeigt einen runden Puff. Hohe oder niedrige Fußbänke gibt es an Kat. 15-17, 20 und 21; an Kat. 21 ist sie verhan- 
gen. Als weiteres Requisit erscheint auf Kat. 15 ein Wollkorb unter dem Hocker. Dieser ist, abgesehen von Schwert, Lanze und Schild der Kriegerstelen Kat. 1 und 2, das einzige Objekt, das auf die Beschäftigung oder den Beruf der dargestellten Personen Bezug nimmt. Weder symbolhafte noch realitätsbezogene Gegenstände wie etwa Buchrollen, Kränze oder Bäume spielen eine Rolle.

\section{Verstorbene und Hinterbliebene}

Ist nur eine erwachsene Figur dargestellt, erübrigt sich die Frage nach dem oder der Verstorbenen, mag sie sitzen oder stehen ${ }^{17}$. Erscheinen zwei Personen und ist das Formular im Plural gegeben, so sind beide Gezeigten verstorben (Kat. 7). Allgemein verbindliche Schemata, Hinterbliebene und Verstorbene zu unterscheiden, gibt es jedoch nicht. E. Pfuhls Urteil über Familienszenen, diese stellten »Tote und Lebende vereint dar«, hat weiterhin Bestand. Dennoch lassen sich der Komposition, der Position des Formulars und der Nennung von Namen Merkmale entnehmen, welche die Kennzeichnung der Verstorbenen wahrscheinlich machen.

Die weit verbreitete Interpretation der Dexiosis auf Grabstelen als Abschiedsgeste lehnt E. Pfuhl mit Hinweis auf das Relief PM 1096 ab: Auf diesem erscheinen drei durch Handschlag verbundene Personen. Die namentlich genannte Sitzende ist verstorben; die hinter ihr stehende Frau aber reicht dem Mann die Hand. Die Geste der dextrarum iunctio sei lediglich Ausdruck »liebevollen Beieinanderseins $\aleph^{18}$, bedeute aber niemals Abschied. Durch Dexiosis miteinander verbundene Personen begegnen in Antiochia auf Kat. 4, 14 und 24, das Dexiosis-Motiv ist hier also verhältnismäßig selten ${ }^{19}$. Diese drei Grabreliefs mit dextrarum iunctio spiegeln zudem nicht die gängigen Kombinationsschemata wider. Kat. 4 ist, genau genommen, keine Dexiosis zwischen Menschen, sondern die Geste meint hier das Geleit des Gottes Hermes ins Totenreich. Auf Kat. 14 scheint die kleine Person mit Diptychon im Arm eine Treppe hinabzusteigen. Sie wirkt, über ihre ungewöhnliche Haltung hinaus, verkrüppelt. Die Verbundenheit der beiden ungleichen Personen bezöge sich auf ein inniges Lehrer-Schüler-Verhältnis. Der Handschlag des Mannes auf der Kline zur sitzenden Frau auf Kat. 24 hat eine Parallele in Délos 319. Dexiosis zwischen liegender und sitzender Figur ist selten, und die Position der hinter der Kline im Rücken des Mannes stehenden Frau ist - wie die des >Lehrers $<$ auf Kat. 14 - ohne Parallele. Die Inschrift auf Kat. 24 nennt zwei Personen, es sind also mindestens zwei Personen verstorben; dargestellt sind jedoch drei: Zwei reichen einander im Dexiosis-Motiv die Hände. Dicht an das untere Ende der Kline und den Liegenden geschmiegt steht aber eine weitere Frau. Sicher ist der Mann einer der zwei inschriftlich genannten Toten. In der rechts, unglücklich hinter die Kline `geklemmten〈 Frau möchte man die Hinterbliebene erkennen, womöglich durch ihre Stellung als emotional Beteiligte charakterisiert; als zweite Tote wirkte sie wenig repräsentativ. In ihrer Funktion als weihende Hinterbliebene käme sie zwischen den durch Handschlag Verbundenen - in der links sitzenden Frau wird die zweite Tote zu erkennen sein - nicht zur Geltung.

Sind die sitzende und die stehende Person verstorben, werden sie beide namentlich genannt. Ist nur eine Person genannt, sind aber zwei Personen durch Dexiosis verbunden dargestellt, geht aus dem Geschlecht der im Formular genannten hervor, ob die sitzende oder die stehende Person die verstorbene ist. Ist das Formular nicht mehr leserlich oder fehlt es, ist der Verstorbene nur anhand seiner Haltung, ob sitzend oder stehend, nicht zu identifizieren (Kat. 16): Etwas häufiger wird der oder die Verstorbene sitzend wiedergegeben, oft aber auch stehend. Es erscheinen auch zwei als verstorben Genannte, die stehend aufeinander bezogen sind - naturgemäß können diese zwei weiblich oder männlich sein. Eine delische Naiskosstele zeigt drei Personen und nennt drei Namen ${ }^{20}$. Auf PM 1575 wird sogar der Name einer nicht dargestellten Person genannt. Eindeutig ergibt sich die verstorbene Figur auf Kat. 15: Hier ist die jugendliche, stehende Mantelfigur, 'Hvóठwoos, der Tote, gekennzeichnet durch die dezentral unter ihr eingemeißelte Inschrift. Ein siebenfiguriges Totenmahl aus Byzanz (PM 2012) nennt nur eine Frau in der unter ihr angebrachten Inschrift.

\footnotetext{
17 PM S. 45.

${ }_{18}^{18}$ PM S. 45.

${ }_{19}$ Vgl. B. Schmalz, Griechische Grabreliefs (Darmstadt 1983) 242.

${ }^{20}$ Délos Nr. 34. 107.
} 
Aufgrund seiner exponierten zentralen Stellung ist der in der Mitte Stehende auf Kat. 9 der Verstorbene, nicht aber die zu seinen Seiten Sitzenden, ein Mann und - diesem symmetrisch gegenüber - eine Frau. Ein Formular fehlt. Das Schema wiederholt sich vielfach, so auf PM 1110, wo unter dem zwischen den sitzenden Eltern stehenden jungen Mann sein Grabformular angegeben ist. Auf einer Parallele in Bursa steht der verstorbene Sohn des zu seinen Seiten sitzenden Elternpaars in gleicher zentraler Pose ${ }^{21}$. Ein Gegenbeleg wäre aber die hellenistische Stele Délos 185: Hier steht der Sohn zwischen seinen sitzenden Eltern, unter denen das Formular angegeben ist. Sie sind tot; der Sohn weiht die Grabstele. Einfacher, zwischen seinen stehenden Eltern, wird der tote Knabe auf PM 624, 627, 629, 630, 633, 635 auf einem Podest gezeigt. Auf PM 1193 sind laut Formular zwei Verstorbene wiedergegeben. Eine Frau sitzt, ein Schauspieler steht; zwischen ihnen, aber etwas in den Hintergrund gerückt, steht ein junger Knabe. Eine weitere Variante ist die Darstellung des jugendlichen Toten zwischen seinen Eltern in sitzender Haltung, auch auf einem Podest (PM 1790). Und schließlich muss nicht der Liegende der Verstorbene sein, sondern es ist der zentral stehende, den Liegenden etwas verdeckende, große Knabe, so auf PM 1691, 1804 (entgegen Pfuhl), 1811, 1812 (mit kurzem Chiton und Lagobolon, also in Jagdkleidung), 1815, 1816, 182122, 1878 und 1879. Auf PM 1690 und 1818 steht hier ein Mädchen. Dieselbe Position vor der Kline, und mit der sitzenden Frau wie auf PM 1804 persönlich verbunden, nimmt der nackte Knabe auf dem samischen Totenmahl-Relief PM $1883^{23}$ ein. Seine Nacktheit, seine hervorgehobene Bedeutung im Zentrum der Komposition, sein vertraulicher Umgang mit der links sitzenden Frau weisen dem nackten, halbwüchsigen Knaben eine zentrale Bedeutung zu, die über die einer Staffage-Person hinausreicht. Die motivische Entwicklung des vor der Kline stehenden Jünglings weist diesen auch auf dem etwas früheren samischen Relief als den heroisierten Verstorbenen aus. Die gleiche Deutung ist auch bei mehreren gemeinsam auf einer Kline lagernden Personen angesagt, vor denen neben dem Tisch und zwischen zwei sitzenden Frauen ein junger Mann im Mantel steht (PM 2010). Auf dem Relief in Zweitverwendung Kat. 27 sitzt ein Kind frontal auf der Kline; das Totenmahl-Relief von insgesamt sechs Personen ist die einzige Szene dieser Art in Antiochia. Die spätantike Analogie PM 1787, die durch ihr Formular klar zu erkennen gibt, dass das vorn auf der Kline sitzende Kind verstorben ist, macht es wahrscheinlich, dass eine auf der Kline am Fußende frontal sitzende Person als verstorben zu gelten hat, nicht aber als hinterbliebenes Familienmitglied.

Das opfernde Paar auf gemeinsamem Sockel Kat. 8 ist wohl gemeinsam als verstorben zu verstehen. Auf Kat. 18 sind die zwei inschriftlich genannten Personen die Eltern des Kindes auf dem Schoß der Mutter, die kleine Randfigur im kurzen Chiton ist ein Pais. Die sich nach unten verjüngende Stele Kat. 22 verdient insofern einige Aufmerksamkeit, als im Formular ober- und unterhalb des Bildfeldes nur die verstorbene, mit dem Kind auf dem Schoß sitzende Frau Artemis genannt wird - hier liegt der Tote also nicht auf der Kline. Als geläufiges Schema ist der liegende Mann nur Versatzfigur, nicht aber verstorben. Es ist somit keineswegs davon auszugehen, dass der Mann auf der Kline immer der Tote sein muss. Auf PM 2012 aus der Troas wird nur eine verstorbene Frau genannt, ihr Formular steht unter der zweiten der vier sitzenden Frauen. Wieder liegen auf der Kline ein Mann und zwei Halbwüchsige, denen das Grabrelief, wie auf Kat. 22, aber nicht gewidmet ist. Anders wird auf Kat. 23 die Wahrheit nicht verdreht: Die Liegende ist hier eine verschleierte Frau mit Dienerin. Links vor der Kline sitzt jedoch ein Mann, gleichsam im >Pudicitia<-Motiv, das Kinn auf den linken Handrücken gestützt. Obwohl die Inschrift unleserlich ist, ist die Szene eindeutig: Die Frau ist tot, der Mann trauert. Auf niedrigem Hocker sitzend, mit abgestreckten Beinen, die Arme auf die Knie gestützt, ähnelt seine Haltung den auf See Umgekommenen der delischen Grabreliefs. Auf Kat. 23 aber besteht in Kombination mit der Frau auf der Kline kein Anlass, im leger sitzenden Mann mit krummem Rücken den Verstorbenen zu erkennen. Seine Haltung vor der Kline mit Frau wiederholt sich auf Délos 316, einer schmalen Bogennischenstele, deren Inschrift sich eindeutig auf die Frau bezieht. Die Inschrift von Kat. 27 nennt drei Namen - eine der vier auf der Kline Liegenden, ebenso wie die Sitzende und das Kind, gehört also nicht zu den Verstorbenen. Tote und Hinterbliebene klar zu unterscheiden, wird weder durch Beischrift noch Position angestrebt. Auf einer siebenfigurigen Stele in Paris sitzen je zwei Frauen seitlich der Kline mit Mann und zwei Kindern, das Formular nennt aber nur eine Frau ${ }^{24}$.

\footnotetext{
${ }^{21}$ Cremer 1991, 59 KH 9 Taf. 6.

22 Fabricius 1999, Taf. 11 a.

23 Fabricius 1999, Taf. 4 a.

${ }^{24}$ Cremer 1991, KST 29 Taf. 12.
} 
Totenmahle

Unter den 32 Grabstelen in Antiochia gibt es zehn Totenmahl-Reliefs. Von ihnen bleiben drei, Kat. 24, 25 und 27, ohne Tisch. Ein konventionelles Schema in vergleichsweise sorgfältiger Ausführung zeigt Kat. 25. Die Stele ist einschließlich der Akrotere und des Einlasszapfens vollständig erhalten. Giebel und Standleiste sind facettiert. Die Fläche zwischen Gesims und Bildfeld ist mit einer schlauchartigen Girlande geschmückt, die von drei Bukranien gestützt wird. Das Formular nennt zwei Verstorbene: Die zwei liegenden Männer sind also die Toten. Das Sitzschema der Frau, der Pais im Kleinformat und die minutiös gedrechselten Klinenbeine passen in den Späthellenismus des frühen 1. Jahrhunderts v. Chr. und bieten keine untypischen Besonderheiten. Die Frau trägt die syrische steife Turbanfrisur, wie auch die Frau auf Kat. 29, die hier auf der Kline liegt; Totenmahl-Tisch und Dienerin sind auf Kat. 29 ebenfalls dargestellt, in der Bogennische hängt eine Wulstgirlande an drei Bändern.

Die Zweitverwendung des Pilasterkapitells Kat. 26 verweist zwar auf ökonomische Rücksichten des Bestellers, doch die Komposition der personenreichen Szene ist mit Geschmack und einer gewissen Variationsfreude ausgeführt. Über einem Mehrfaszien-Architrav erstreckt sich ein sehr niedriger Giebel mit Rosette und angedeuteten Akroteren. Ein derartig flacher Giebel findet sich ein weiteres Mal im kaiserzeilichen Odessos (PM 1416). Je eine Frau mit Dienerin sitzt zu Seiten der Totenmahl-Kline, auf der keine Symmetrie herrscht: Links liegt ein Mann, in der Mitte und rechts eine Frau. Die Asymmetrie setzt sich in der Haltung der beiden sitzenden Frauen fort: Ihre Pose mit an den Schleier greifendem innerem Arm ist nicht genau spiegelbildlich angelegt. Die linke Sitzende ist aus der Profil- stark in die Frontansicht gedreht. Sie schlägt ihr rechtes Bein über das linke, wie der zu Boden hängende Mantelzipfel deutlich macht. Die rechte Frau sitzt bis zur Taille im Profil, sodass der Hocker zu sehen ist. Ihr Oberkörper ist ebenfalls etwas nach vorn gedreht. Das späthellenistische Relief ist >flott< und detailreich gearbeitet.

Auf eradiertem Grund der Giebelstele Kat. 27 erscheinen vier gelagerte Figuren mit steif aufgerichteten Oberkörpern. Links auf der Kline sitzt ein Junge im Mantel mit durchscheinenden Beinen, den rechten Arm angewinkelt. Die Inschrift nimmt auf mehrere Tote Bezug, unter denen das dieserart dargestellte Kind, in Analogie zu PM 1787, zu zählen sein mag. Die hinterbliebene Frau, kantig an den linken Bildrand gezwängt, dreht den Kopf aus dem Profil nach außen. Das Relief ist ohne jede künstlerische Bedeutung, bleibt ohne Tischchen und Dienerfigur, hebt aber das sitzende Kind hervor.

Ein verworfenes Architekturfragment ist auch für das weitestgehend untypische Totenmahl-Relief Kat. 28 wiederverwendet worden. Auf einer langen, sechsbeinigen Kline liegen zwei Frauen und vier Männer in symmetrischer Anordnung. Vor der Kline, zwischen den drei vorderen Beinen, stehen keine Dienerfiguren, sondern vier verschiedene Mantelstatuen, deren Größe den sonst üblichen Dienerfiguren entspricht. Diese Mantelfiguren, die detailliert durchmodelliert sind, wirken eher früh- als späthellenistisch. Was bedeuten aber diese vier Gestalten unterschiedlicher Pose und Größe vor der sechsbeinigen Kline? Sie scheinen bewusst nicht symmetrisch zwischen die Klinenbeine platziert, sondern entweder bedacht oder unbedacht in gleichen Abständen von links nach rechts so angeordnet worden zu sein, dass das rechte Klinenbein frei bleibt, das mittlere etwas, das linke aber zur Gänze verdeckt wird. Der traditionelle Ort für kleine Dienerfiguren wird bewusst und demonstrativ umfunktioniert. War die Identität der beiden weiblichen und der zwei männlichen Mantelstatuen vor der Kline für den Betrachter gegenwärtig und verständlich?

\section{Mutter mit Kind}

Im gesamten zweibändigen Corpus der ostgriechischen Grabreliefs von 2323 Nummern begegnen bei nur 14 Einträgen (PM 701. 883. 949. 953. 1028. 1165. 1297. 1692. 1693. 1747-1750. 1972) sitzende Mütter mit Kind auf dem Schoß; E. Pfuhl kommentiert sie als »durchweg primitiv « ${ }^{25}$. Es sind überwiegend grobe Routinearbeiten der Kaiserzeit aus dem Schwarzmeergebiet. In Antiochia finden sich unter 32 Grabstelen immerhin vier dieser Thematik (Kat. 17-19. 22), wovon drei (Kat. 18. 19. 22) die von E. Pfuhl oben zitierte

\footnotetext{
${ }^{25}$ PM S. 229.
} 
Bewertung verdienen. Zwei, Kat. 18 und 19, gehören derselben Werkstatt und Entstehungszeit, der zweiten Hälfte des 1. Jahrhunderts v. Chr., an. Die Gliedmaßen sind kantig, die Haltung ist hölzern und steif. Kat. 22 ist stark verwittert und dürfte ursprünglich von durchschnittlicher Qualität gewesen sein.

Von besonderer Qualität dagegen ist Kat. 17. Die Giebelstele mit Akroteren hat bescheidene Ausmaße; das Bildfeld füllt eine tiefe Rechtecknische, deren rechte Hälfte völlig frei bleibt, da die Grenze der plastischen Gruppe diagonal verläuft. Die Gruppe von Mutter und Kind ist keine Routinearbeit, sondern lässt persönliche Hingabe des Bildhauers spüren. Details wie der Blütenkranz der Mutter über dem Schleier und die Faltenzüge des Mantels, auch beim Kind, werden mit liebevoller Sorgfalt wiedergegeben; die nicht parallel hängenden Beinchen des Kindes mit ausgearbeiteten Knien sind eingehend beobachtet. Die Innigkeit der Verbundenheit von Mutter und Kind ist ohne Parallele. Das Engagement des Auftraggebers und auch des ausführenden Bildhauers steht erlebbar hinter der Komposition. Das kleine Kunstwerk voller Leben und Sentiment gibt eine intime Atmosphäre wieder, die dem Hellenismus des späteren 2. Jahrhunderts v. Chr. eigen ist. Neben seinem echten Stimmungsgehalt versagen so dürftige Szenen wie die auf Kat. 18, 19 und 22.

Kat. 17 und 19 zeigen nur die Mutter-Kind-Gruppe, Kat. 18 und 22 erweitern sie unterschiedlich. Auf Kat. 19 ist die Gruppe von Mutter mit großem Kind auf dem Schoß nur durch ein Parapetasma zwischen zwei Fackeln erweitert. Die gleiche Hintergrundgestaltung hat Kat. 18, wo neben der Mutter-Kind-Sitzgruppe, etwas durch leeren Raum getrennt, auch der Vater mit einem Pais, beide frontal stehend, erscheint. Zwei Geschwister, Kinder des Epigonos, sind die Toten. Sind beide Erwachsene die verstorbenen Geschwister? Kat. 22 ist mit der Kline eines Mannes kombiniert. Tot ist Artemis, die Mutter des auf ihrem Schoß sitzenden Kindes. Der liegende Mann ist, wie oben gezeigt, nur Versatzfigur, nicht aber verstorben. Verstorbene Kinder werden, wie bei Kat. 9 zu sehen war, anders hervorgehoben

Eine außerordentlich lebendige Mutter-Kind-Gruppe ist PM 1028 in Londoner Privatbesitz, möglicherweise aus Rhodos. Die hochhellenistische Stele ist gegen 200 v. Chr. entstanden. Dargestellt ist eine Familie mit zwei kleinen Mädchen, von denen das eine auf dem Schoß der Mutter kniet und das andere sich neben dem Stuhl der Mutter zu einer Gans bückt; die Mutter fasst es an der Schulter. Das singuläre Gruppenmotiv und die Faltenwiedergabe sind von großer Natürlichkeit. Drei originelle Reliefs einer Mutter mit Kind von etwa 100 v. Chr. ${ }^{26}$ begegnen in Delos. Das Formular gilt den verstorbenen Knaben. Diese drei Darstellungen sind von einer ebenso überzeugenden Herzlichkeit der Mutter-Kind-Verbindung wie Kat. 17 in Antiocha. Die Kompositionsschemata aller drei delischen Reliefs mit Mutter und Kind sind verschieden. Einmal beugt die Mutter ihren Kopf zu dem auf ihrem Schoß sitzenden Kind hinab und hält seine linke Hand. Ein anderes Mal steht das Kind vor der Mutter; beider ausgestreckte Arme verbinden sie. Die Weihenden sind die

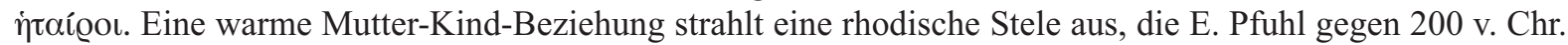
datiert ${ }^{27}$. Das Motiv entspricht der letztgenannten delischen Stele: Das Kind steht vor der sitzenden Mutter, die sich zu ihm beugt und nach ihm greift, der Kleine streckt ihr beide Arme entgegen. Die Komposition der delischen Stelen wie auch die der rhodischen wirkt locker und entspannter als die etwas >süßliche< Szene von Antiochia Kat. 17. J. Fabricius ${ }^{28}$ möchte in der Darstellung der rhodischen Stele einen klassizistischen Rückgriff auf klassische Typen sehen, was angesichts der delischen Parallele mit stehendem Kind nicht zwingend begründet ist. Singulär und originell ist die lebendige Szene mit Kleinkind auf einer Stockwerkstele in Bursa, die E. Pfuhl m. E. zu spät, in das 2. Jahrhundert n. Chr. datiert. Das Kind sitzt auf dem Schoß des auf der Kline liegenden Mannes, wird aber von der Mutter von diesem weg zu sich herüber gezogen ${ }^{29}$.

Die Stele der Mutter mit zwei Kindern im Mantel, Kat. 11, gibt ein schlichtes, natürliches, nicht sonderlich originelles Motiv wieder. Die Mutter zweier Kinder wendet sich zum größeren. Kinder als Begleitfiguren, nicht etwa als verstorben, erscheinen vielfach zusammen mit ihren Eltern oder mit einem Elternteil. Die Proportionen der drei Personen, die Haltung, Umrisse und das Standmotiv der Mutter, auch die Fußstellung der Kinder sind lebensnah durchkomponiert. Die feinen, fließenden Mantelfalten und ihre mehrschichtige Drapierung zeugen von einer meisterhaften Arbeit hochhellenistischer Entstehungszeit des 2. Jahrhunderts v. Chr.

\footnotetext{
${ }^{26}$ Délos Nr. 441-443.

${ }^{27}$ PM 954.

${ }^{28}$ Fabricius 1999, 185-190. 193 f.

${ }^{29}$ PM 1297 Taf. 257.
} 
Fast immer sind Kinder von Dienern gut zu unterscheiden. Knaben tragen den langen Mantel und langen Chiton (PM 152. 350-352. 835 b, wo das Kind an der Hand des Vaters auf hohem Sockel steht), Diener den kurzen Chiton (Kat. 6. 12. 18. 21. 23. 25. 26. 29. 30; PM 1797. 1799). Dieser Regel widerspricht aber auch mal eine provinzielle Arbeit des 3. Jahrhunderts n. Chr., wo der Vater seine Hand auf die Schulter seines Sohnes in kurzem Chiton legt (PM 355); hingegen ist der rechte Knabe in langem Mantel auf PM 417 natürlich kein Diener ${ }^{30}$. Zur Unterscheidung von Kindern und Dienerfiguren verhilft auch die Position der Kinder inmitten der Szene, nicht als steife Randfiguren oder -figürchen (PM 1799). Kindliche Knabenfiguren im Mantel, zwischen ihren verstorbenen Eltern auf einem Podest stehend, sind keine Diener, sondern deren Kinder (Délos 8. 126; PM 1030). Dieselbe Position zwischen dem Paar nehmen zwar auch Dienerfiguren auf Délos 87, 88 und 90 ein, sie sind aber durch ihr Format und die kurze Exomis als solche zu erkennen. Viele als Dienerfiguren eindeutig gekennzeichnete Kinder stehen mitunter auch zwischen den Hauptpersonen und nicht an den Rand gedrückt. Ebenso kommen Dienerfiguren, die mit Erwachsenen gestikulierend in Kontakt stehen, vor (Délos 287. 294; PM 119. 120. 130); durch Kleidung, Format und Haltung sind sie nicht mit Kindern zu verwechseln (PM 1031). Durch ihre Position, nicht aber durch ihre Größe ist die kleine Dienerin PM 1109 in der Ecke hinter der Frau von den beiden Knaben im Mittelfeld abgehoben. Mitunter erscheinen spielende Kinder und Dienerfiguren überdeutlich unterschieden (Délos 179; PM 671. 730. 766).

Meistens nehmen Kinder auf Mutter oder Vater Bezug, in der Regel kommt eine herzliche, warme Atmosphäre zum Ausdruck (s. o. und PM 152. 956. 1805. 1806). Wenn der Mann auf PM 700 den Knaben im Mantel an der Hand hält, so ist dieser natürlich sein Sohn; unter beiden steht ein Grabformular - hier sind Vater und Sohn verstorben. Auf Antiochia Kat. 20 ist es die enge Anlehnung des Mädchens an die Mutter. Auf Kat. 11 spricht die Szene für sich, so einfach ihr Motiv ist, so außergewöhnlich ist die Arbeit. Die Stele ohne Inschrift ist, neben Kat. 1 und 17, eines der herausragenden Werke von Antiochia. Eine gegenteilige Wertung gilt für Kat. 18. Der kleine Diener in kurzem Chiton nimmt seine übliche, dicht an den Rand gedrängte Position ein und gehört, obwohl nahe neben dem Vater stehend, nicht zur Familie.

\section{Krieger}

Grabreliefs einer gepanzerten Kriegerfigur, die nicht in einer Kampfhandlung mit einem oder mehreren Gegnern gezeigt wird, sind selten ${ }^{31}$. Für den oströmischen Bereich nachklassischer Zeit kann lediglich auf vier Exemplare verwiesen werden, wovon allein zwei aus Antiochia (Kat. 1. 2) kommen. Ein qualitativ vergleichbares Relieffragment in Bodrum stammt aus Stratonikeia ${ }^{32}$, die Herkunft des vierten Belegs in Treviso ist unbekannt ${ }^{33}$.

Die älteste dieser vier Kriegerstelen, Kat. 1 in Antakya, präsentiert den gewappneten Krieger mit Lanze und kleinem Rundschild in statuarischer Pose, welche dem spätklassischen Kontrapost verpflichtet ist: Die rechte Standbeinseite wird durch die lange, vom Boden bis an den Architrav reichende Lanze geschlossen. Die Blickrichtung geht zur Spielbeinseite. Diese, die >offene< Seite, komplettiert der kleine, runde Schild. Die Kopfwendung in dieselbe Richtung erzeugt beruhigte Konzentration auch für die Spielbeinseite. Die >geschlossene Standbeinseite und die >offeneく Spielbeinseite werden gleichermaßen gewichtet. Die Ponderation wird mit zwei gegenläufigen Schwerpunkten versehen und so zerrissen. Die nachklassische Gewichtung wird gleichsam bühnenreif inszeniert, durch einen Hintergrund, der in Höhe und Breite vollständig mit einem schweren Vorhang bedeckt ist. Der Vorhang fällt in dichten, weichen Falten. Diese Bühnenpräsentation atmet nachklassisches Bewusstsein und passt zur Stimmung des frühen Hellenismus des 3. Jahrhunderts v. Chr., der - etwa bei Demosthenes oder der »Medea $\aleph^{34}$ - gern dramatische Akzente setzt.

Die genannten drei weiteren Kriegerstelen zeigen den Akteur in direkter Kampfhaltung. Er ist jeweils in Ausfallstellung und frontal wiedergegeben. Eine Kat. 1 vergleichbar gute Arbeit ist die Stele aus Strato-

\footnotetext{
${ }^{30}$ Vgl. PM S. 68.

${ }^{31}$ Vgl. PM 306.

32 Özgan 1999, 154 GR 9 Taf. 51 d.

${ }_{33}$ PM 1274.

${ }^{34}$ W.-H. Schuchhardt, Die Kunst der Griechen (Berlin 1940) Abb. 350. 351 Taf. 4.
} 
nikeia. Die körperliche Räumlichkeit und Plastizität des Reliefs überzeugen, und die Dynamik der zentrifugalen Komposition ist noch hochhellenistisch, dem 2. Jahrhundert v. Chr. angehörend. Eher misslungen erscheint der Laufschritt auf der Stele in Treviso, die eine Ansicht im Viertelprofil wiederzugeben versucht. Die anspruchsvolle Komposition ist gegen 100 v. Chr. entstanden.

Wenig ansprechend gibt sich der mit ausgreifenden Bewegungen kämpfende Krieger auf Kat. 2. Körper, Gliedmaßen, Schild und Schwert sind in die Fläche geklappt, die Bewegungen sind eckig und steif. Das Motiv ist anspruchsvoll und lebendig, die Ausführung - kaiserzeitlich - hingegen wenig überzeugend.

\section{Groteske}

Es gibt auch unter mittelmäßigen Ausführungen mitunter originelle, einmalige und nicht wiederholte Figurentypen. Ohne Parallele ist das auf PM 1621 vor den Füßen der rechten Figur am Boden sitzende Kind, das seinen Rücken dem Tisch zukehrt. Auf PM 1429 ist die kniende Dienerin ein derartiges Einzelmotiv. Beide untypische Haltungen mögen auf individuelle Absprachen oder besondere Einfälle des Bildhauers zurückgehen, komisch sind sie nicht. Wie ist das Motiv eines Mannes zu erklären, der auf dem Stelenfragment in Chios PM 720 seinen linken Fuß hoch auf ein korinthisches Säulenkapitell stellt? Seine Pose ist so exzeptionell wie die des Antiochener Fragments Kat. 14.

Trotz des schlechten Erhaltungszustandes lässt das Bild eine komische Szene erkennen. Während die sitzende Frau dem geläufigen Typus etwa der zweiten Hälfte des 2. Jahrhunderts v. Chr. entspricht, wirkt die rechts in Schrittstellung gezeigte Figur krüppelhaft und untersetzt. Ihre vertikal versetzten Füße erzeugen den Eindruck, als stiege sie aus dem Hintergrund abwärts. Ihr Oberkörper beugt sich schräg nach hinten, die Aktion ihrer Arme ist deutlich: Ihren rechten, mit einem Ärmelchiton bekleideten Arm reicht sie mit der üblichen Geste der dextrarum iunctio der Sitzenden. Spielt die Figur, die eventuell ein Diptychon und Griffel hält, auf einen Hauslehrer oder Philosophen an? Gemäß E. Pfuhl handelt es sich bei der hier wiedergegebenen dextrarum iunctio nicht um Abschied, sondern um ein »liebevolles Miteinander « ${ }^{35}$, also die Darstellung eines herzlichen Verhältnisses zwischen Lehrer und philosophierender Frau. Welche der beiden Figuren ist die verstorbene Person? Der unrepräsentativ aus dem Hintergrund hervorstolpernde Hauslehrer oder die würdevoll sitzende Domina? Man kann davon ausgehen, dass der krüppelhafte Alte die verstorbene Person ist.

Ist die Darstellung richtig interpretiert? Ist die kleine Figur etwa misslungen? Ist die Szene ernst gemeint und sollte auf eine bestimmte Person angespielt werden? Wem sollte eine Karikatur gegolten haben? Dass die Figur auch auf den antiken Betrachter komisch wirkte, ist anzunehmen. Dass sie aber im Rahmen eines Grabreliefs ernst genommen wurde, befremdet den modernen Betrachter doch.

\section{Die Inschriften der Grabstelen}

Katalog der Personennamen

\author{
'Aiveos: 2. Jh. v. Chr. $($ Kat. 4) $=$ PM $1 \times 2$. Jh. v. Chr. $=$ Łajtar \\ $2000,1 \times 2 . / 1$. Jh. v. Chr. \\ 'A $\lambda \dot{\varepsilon} \xi \alpha v \delta \varrho o \varsigma$ (außer Könige): 2. Jh. v. Chr. (Kat. 6. 26) = PM \\ $49 \times 2$. Jh. v. -4 . Jh. n. Chr. $=$ Wagner 1976, $1 \times 3$. Jh. n. Chr. \\ $=$ Strubbe - Schuddeboom 2005, $7 \times$ Kaiserzeit -4 . Jh. $\mathrm{n}$. \\ Chr. $=$ Byrne - Labarre 2006, $3 \times 3$. Jh. n. Chr. $=$ Canali De \\ Rossi 2004, $1 \times 3$. Jh. v. Chr. = Dreyer - Engelmann 2003, \\ $2 \times 2$. Jh. v. Chr. $=$ Jonnes $2002,1 \times 3$. Jh. n. Chr. $=$ Corsten \\ $2002,2 \times 1$. Jh. v. -2 . Jh. n. Chr. $=$ Corsten $1991,7 \times 1$. Jh. v. \\ Chr. -2 . Jh. n. Chr. $=$ Kearsley 2001, $2 \times 2 .-3$. Jh. n. Chr. $=$ \\ Lajtar 2000, $3 \times 2$. -3. Jh. n. Chr. $=$ Nollé $2001,3 \times 2 . J$ J. n.
}

Chr. - spätantik $=$ Ameling - Jonnes 1994, $3 \times 2$. Jh. n. Chr. $=$ Ricl 1997, $2 \times 1 .-2$. Jh. n. Chr. $=$ Blümel 1988, $7 \times 1$. Jh. v. - 1. Jh. n. Chr./Kaiserzeit/byzantinisch $=$ Blümel 1991, $4 \times$ 3. Jh. v. Chr. -1 . Jh. n. Chr. $=$ Blümel $1985,14 \times 3 . / 1$. Jh. v. Chr. -1 . Jh. n. Chr. $=$ Nollé - Schindler 1991, $1 \times 2 .-3$. Jh. n. Chr. $=$ Ameling 1985, $7 \times 2 .-3$. Jh. n. Chr./byzantinisch $=$ Corsten 1987, $3 \times 1$ 1./2./6. Jh. n. Chr. = Schwertheim 1987, $14 \times$ gesamte Kaiserzeit.

'Avtiyovos: 1. Jh. n. Chr. (Kat. 18) = PM $2 \times 1$. Jh. n. Chr. = Canali De Rossi 2004, $1 \times$ 2. Jh. v. Chr. $=$ Lajtar 2000, $1 \times$ 1. -2 . Jh. n. Chr. $=$ Berges - Nollé $2000,1 \times$ hellenistisch $=$

\footnotetext{
${ }^{35}$ PM S. 45.
} 
Blümel 1988, $1 \times$ Kaiserzeit $=$ Blümel 1991, $3 \times 3 .-2$. Jh. v. Chr. $=$ Blümel 1985, $6 \times$ hellenistisch - Kaiserzeit $=$ Corsten $1985,3 \times 2$. Jh. n. Chr. $=$ Délos $10 \times 100$ v. Chr.

'Aло $\lambda \lambda \omega \dot{v i o s: ~ 1 . ~ J h . ~ v . ~ C h r . ~(K a t . ~ 12) ~}=$ PM $77 \times 3$. Jh. v. 4. Jh. n. Chr. $=$ Canali De Rossi 2004, $3 \times 3 .-2$. Jh. v. Chr. $=$ Byrne - Labarre 2006, $1 \times$ ohne Dat. $=$ Strubbe - Schudde boom 2005, $2 \times$ Kaiserzeit/5. Jh. n. Chr. $=$ Dreyer - Engelmann 2003, $3 \times 2$. Jh. v. Chr. $=$ Corsten $1997,3 \times 2 .-3$. Jh. n. Chr. $=$ Corsten 2002, $16 \times 1$. Jh. v. -3. Jh. $\mathrm{n}$. Chr. $=$ Corsten 1991, $11 \times 1$. Jh. v. -3 . Jh. n. Chr. $=$ Lajtar 2000, $28 \times 3$. Jh. v. - 2. Jh. n. Chr. $=$ Ricl 1997, $3 \times 4 . / 2 .-1$. Jh. v. Chr. $=$ Berges - Nollé $2000,7 \times 2$. Jh. n. Chr. $/$ Kaiserzeit $=$ Horsley - Mitchell 2000, $3 \times 3$. Jh. n. Chr. $=$ Nollé 2001, $4 \times$ hellenistisch $/$ 2. Jh. n. Chr. $=$ Blümel $1988,60 \times 2$. Jh. v. Chr. $=$ Blümel 1991, $8 \times$ 3.-1. Jh. v./3. Jh. n. Chr. $=$ Nollé - Schindler 1991, $1 \times 1$. Jh. v. Chr. $=$ Blümel $1985,34 \times 2$. Jh. v. -1 . Jh. n. Chr. $/$ Kaiserzeit $=$ Corsten 1987, $2 \times 1$. Jh. n. Chr. $=$ Corsten 1985, $4 \times 2$. -3 . Jh. n. Chr. $=$ Schwertheim 1987, $7 \times 1$. -3 . Jh. n. Chr. $=$ Délos $16 \times 100$ v. Chr.

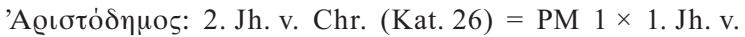
Chr. $=$ Byrne - Labarre 2006, $1 \times 2$. Jh. v. Chr. $=$ Blümel 1988, $1 \times$ 2. Jh. v. Chr. $=$ Blümel 1991, $4 \times$ 'A -2 . Jh. v. Chr.

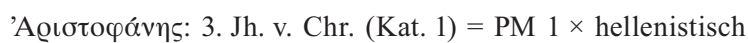
$=$ French 2004, $1 \times$ 5. -4 . Jh. v. Chr. $=$ Canali De Rossi 2004, $1 \times 4$. Jh. v. Chr. $=$ Corsten $2002,1 \times 1$. Jh. v. -1 . Jh. n. Chr. $=$ Blümel 1988, $1 \times 1$. Jh. n. Chr. $=$ Blümel 1985, $2 \times 200 \mathrm{v}$. Chr.

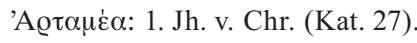

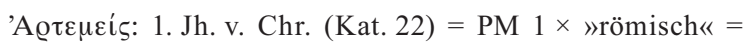
Horsley - Mitchell 2000, $2 \times 1$. -2 . Jh. n. Chr.

'A $\tau \dot{\varepsilon} \mu \omega v$ : 2. Jh. v. Chr. (Kat. 29) $=$ PM $9 \times 2$. Jh. v. 2. Jh. n. Chr. $=$ Canali De Rossi 2004, $4 \times 1$. Jh. v. -1 . Jh. n. Chr. $=$ Corsten 2002, $3 \times$ Kaiserzeit $=$ Corsten 1991, $1 \times$ 2. Jh. n. Chr. $=$ Ricl 1997, $1 \times 1$. Jh. v. Chr. $=$ Nollé 2001, $5 \times 3$. Jh. v. -1 . Jh. n. Chr. $=$ Ameling - Jonnes $1994,1 \times$ Kaiserzeit $=$ Blümel 1988, $12 \times 2$. Jh. v. -2 . Jh. n. Chr. $=$ Blümel 1991, $1 \times 1$. Jh. v. Chr. = Ameling 1985, $2 \times 2$. Jh. n. Chr. $=$ Blümel 1985, $9 \times$ 4. Jh. v. Chr. $=$ Corsten 1987, $1 \times$ 3. Jh. v. Chr. $=$ Schwertheim $1987,1 \times 2$. Jh. v. Chr. $=$ Délos $1 \times 100$ v. Chr.

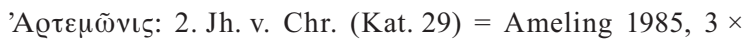
1.-2. Jh. n. Chr.

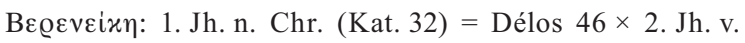
Chr.

'Eлirovos: 1. Jh. n. Chr. (Kat. 18) = PM $2 \times 2$. Jh. v. Chr./ Kaiserzeit $=$ Strubbe - Schuddeboom 2005, $1 \times$ Kaiserzeit $=$ Kearsley 2001, $1 \times 1$. Jh. n. Chr. $=$ Corsten 2002, $1 \times 1$. Jh. n. Chr. $=$ Corsten 1997, $1 \times 1$. Jh. v. Chr. $=$ Blümel 1988, $3 \times$ Kaiserzeit $=$ Blümel 1991, $4 \times$ 3. -1 . Jh. v. Chr. $=$ Ameling 1985, $1 \times$ 3. Jh. n. Chr. $=$ Blümel 1985, $6 \times 1$. Jh. v. Chr. $=$ Délos $1 \times 100$ v. Chr.

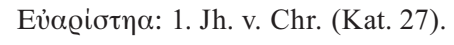

'H $\lambda$ ıódwoos: 2. Jh. v. Chr. (Kat. 6) $=$ PM $1 \times 3$. Jh. n. Chr. $=$ Canali De Rossi 2004, $2 \times 3 .-2$. Jh. v. Chr. $=$ Strubbe - Schuddeboom 2005, $2 \times$ Kaiserzeit $=$ Kearsley 2001, $1 \times$ 2. Jh. n. Chr. $=$ Corsten 1997, $1 \times 3$ 3. Jh. n. Chr. $=$ Blümel 1991, $1 \times 3$. Jh. n. Chr. $=$ Nollé - Schindler 1991, $1 \times 1$. Jh. v. Chr. $=$ Ameling 1985, $1 \times$ 3. Jh. n. Chr. $=$ Blümel 1985, $1 \times$ ohne Dat. $=$ Délos $3 \times 2$. Jh. v. Chr.

'Hvódw@os: 1. Jh. v. Chr. (Kat. 15).

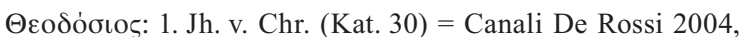
$1 \times 1$. Jh. v. Chr. $=$ Berges - Nollé $2000,1 \times 4$. Jh. n. Chr. $=$ Corsten 1987, $1 \times 2$. Jh. v. Chr. $=$ Corsten $1985,1 \times$ mittlere Kaiserzeit.

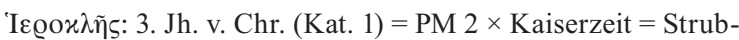
be - Schuddeboom 2005, $1 \times$ Kaiserzeit $=$ Corsten 1997, $1 \times$ frühe Kaiserzeit $=$ Blümel 1988, $22 \times 3$. Jh. v. - Kaiserzeit $=$ Blümel 1991, $6 \times$ 3. -2 . Jh. v. Chr./3. Jh. n. Chr. $=$ Blümel 1985, $17 \times$ 4./3./1. Jh. v. -1 . Jh. n. Chr. = Délos $1 \times 100 \mathrm{v}$. Chr.

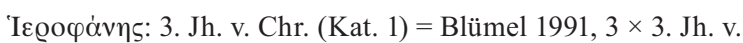
Chr.

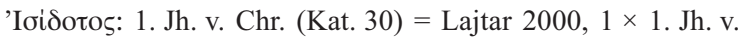
Chr. $=$ Blümel 1988, $1 \times$ ohne Dat. $=$ Blümel $1985,1 \times$ ohne Dat. $=$ Délos $1 \times 100 \mathrm{v}$. Chr.

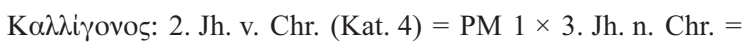
French 2004, $1 \times 3$. Jh. n. Chr.

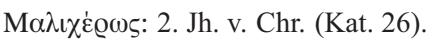

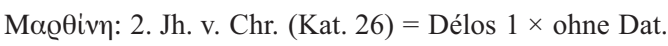

Mixxos: 2. Jh. v. Chr. (Kat. 26) $=$ PM $1 \times 1$. Jh. v. Chr. $=$ French 2004, Mixos $2 \times 5$. -4 . Jh. v. Chr. = Lajtar 2000, $2 \times$ 2. Jh. v. Chr.

Nixaıs: 1. Jh. v. Chr. $($ Kat. 22) $=$ PM $1 \times$ Kaiserzeit $=$ Blümel 1991, $1 \times 3$. -2 . Jh. v. Chr.

$\Xi \dot{\varepsilon} v v \varepsilon \alpha:$ 1. Jh. v. Chr. (Kat. 12).

По $\dot{\varepsilon} \mu[\omega v]:$ 2. Jh. v. Chr. (Kat. 2) $=$ PM $4 \times$ späte Kaiserzeit; davon einmal auf lanzenschwingende Krieger bezüglich = Corsten 2002, $20 \times$ Kaiserzeit $=$ Nollé $2001,2 \times 200$ n. Chr. $=$ Corsten 1991, $1 \times 1$. Jh. n. Chr. $=$ Nollé - Schindler 1991, $2 \times$ 1. Jh. v. /2. - 3. Jh. n. Chr. $=$ Blümel 1985, $1 \times$ 4. Jh. v. Chr.

$\Sigma \varepsilon 0 \varepsilon \pi i \omega v: 1$. Jh. v. Chr. (Kat. 15) wohl Verschreibung für $\Sigma \varepsilon \varrho \alpha \pi i \omega v=$ PM $2 \times 2 .-1$. Jh. v. Chr. $=$ Blümel 1988, $1 \times$ ohne Dat.

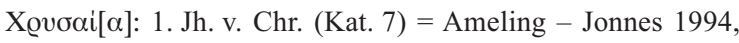
$2 \times$ X 
Unter der geringen Anzahl von 32 Grabstelen in Antiochia am Orontes, die sich im Hatay Museum von Antakya befinden, lassen sich 28 inschriftlich wiedergegebene Namen fassen. Diese wurden im Katalog der Personennamen einer repräsentativen Anzahl publizierter Inschriften des kleinasiatischen Raumes gegenübergestellt. Dabei zeigten sich erwartete Koinzidenzen, aber auch eine Reihe sowohl singulär abgewandelter Namensformen als auch unbekannter Namen. Letztere scheinen einen Zugewinn von fünf hier erstmals do-

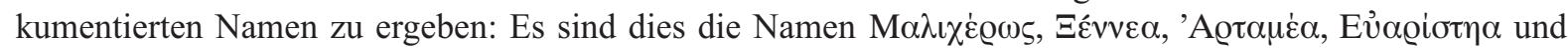
'Hvódw@os.

Der sehr geläufige Name 'A $\lambda \dot{\varepsilon} \xi \alpha v \delta \varrho o s$ tritt im 2. Jahrhundert v. Chr. zweimal auf, anderweitig ist er vom 3. Jahrhundert v. bis in das 6. Jahrhundert $\mathrm{n}$. Chr. durchgehend belegt, allein 49-mal bei E. Pfuhl und H. Möbius. Noch beliebter scheint nach Aussage der Literatur 'Aло $\lambda \lambda \omega$ óvı und H. Möbius 77-mal, in Iasos 34-mal vertreten, in Antiochia indessen nur einmal im 1. Jahrhundert v. Chr.; sonst ist der Name zwischen dem 3. Jahrhundert v. und dem 5. Jahrhundert n. Chr. üblich. Beliebt

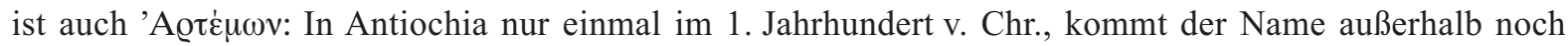
vom 4. Jahrhundert v. bis in das 2. Jahrhundert n. Chr. vor. 'Avtiyovos, einmal im 1. Jahrhundert $\mathrm{n}$. Chr. in Antiochia, begegnet außerhalb weniger häufig vom 3. Jahrhundert v. bis in das 2. Jahrhundert n. Chr. Auch 'Eлiүovo5, in Antiochia einmal im 1. Jahrhundert n. Chr. belegt, findet sich des Weiteren vom 3. Jahrhun-

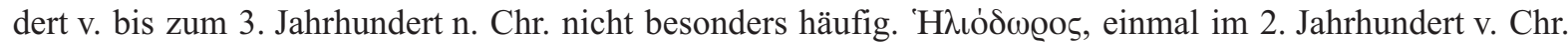
in Antiochia bezeugt, gibt es vom 3.-1. Jahrhundert v. sowie im 2. und 3. Jahrhundert n. Chr. außerhalb; der

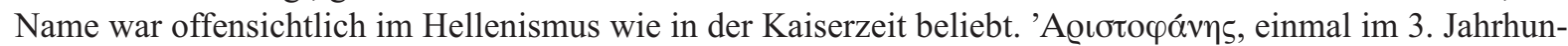
dert v. Chr. in Antiochia belegt, ist sowohl klassisch griechisch als auch hellenistisch, vom 5. Jahrhundert v. bis zum 1. Jahrhundert n. Chr. gebräuchlich, später aber nicht mehr üblich. Im 1. und 2. Jahrhundert v. Chr.

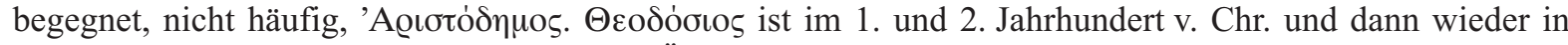

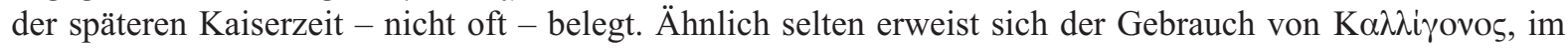
2. Jahrhundert v. und im 3. Jahrhundert n. Chr. Пo $\lambda \dot{\varepsilon} \mu \omega v$, ein sprechender Name, kommt öfter vor, im 4. und

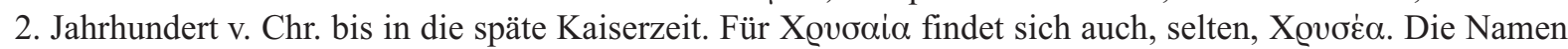

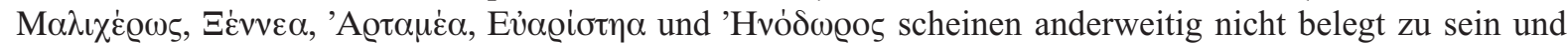
sind als Zugewinn zu verbuchen.

\section{Formular}

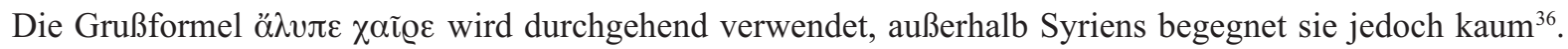
G. Klaffenbach ${ }^{37}$ und M. Couilloud ${ }^{38}$ betonen ihre aktive Bedeutung im Sinne von, »der du keinen Kummer verursacht hast, der du immer ein lieber Mensch gewesen bist«. Die passive Übersetzung indessen im Sinne von, »der du heiter, ohne Kummer sein mögest«, entspricht einem Abschiedsgruß besser. Dieselbe Interpre-

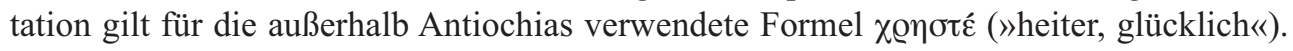

\section{Zusammenfassung}

In Antiochia und Daphne sind überwiegend Giebelstelen, seltener auch einfachste Leistenstelen gearbeitet worden. Die Bildtypik reicht von einfigurigen Darstellungen bis zu Totenmahl-Szenen von sieben Personen. Unter den Grabreliefs finden sich künstlerisch hervorragende (Kat. 1. 11. 17), aber auch bescheidene Arbeiten. Die Typologie der Themen entspricht etwa dem Standard der ostgriechischen Grabreliefs, einige Exemplare aber haben einen ganz untypischen Bildcharakter (Kat. 1. 10. 14. 24. 28). Sie fallen durch singuläre Personendarstellungen bzw. Kombinationen auf, die anderweitig nicht belegt sind. Kompositorisch und motivisch herausragend, scheinen sie persönliche Käuferwünsche widerzuspiegeln und sind als Auftragswerke zu interpretieren.

\footnotetext{
${ }^{36}$ Délos S. 256.

${ }^{37}$ G. Klaffenbach, Griechische Epigraphik (Göttingen 1966) 58.

${ }^{38}$ Délos S. 255.
} 
Kat. $1-13$

An der spätklassischen Kriegerstele Kat. 1 ist die lebhaft differenzierende Bildhauerarbeit des Vorhangstoffes ohne Parallele. Die üblicherweise quer gespannten Parapetasmata anderer Stelen geben nur grob linear vereinfachte Faltenbögen wieder (Kat. 18. 19). Stand- und Spielbein, die Drehung des Kopfes, die Position von Lanze und Schild erzeugen eine natürliche Tiefenillusion. Angesichts der besonderen künstlerischen Qualität des Reliefs ist kaum anzunehmen, dass die Kriegerstele Kat. 1 in der Werkstatt auf Vorrat gearbeitet zur Auswahl bereit lag. Die unaufdringliche Eleganz der Komposition ist kein zweites Mal in dieser Form überliefert. Sie zeugt von Anspruch und Geschmack und wohl auch von der sozialen Bedeutung des Auftraggebers. In schwungvoller Ausfallstellung mit abgespreiztem, schildhaltendem Arm und über das Bildfeld ausholendem rechtem Arm mit Schwert ist das Relief der Kriegerstele Kat. 2 mit ihr in keiner Weise vergleichbar. Das Relief Kat. 2 in frontaler Wiedergabe ist hart und flach. Die gewaltig ausgreifende Kampfhaltung geht auf die Kunst des 2. Jahrhunderts v. Chr. zurück. Die Ausführung dürfte frühestens dem 1. Jahrhundert v. Chr. angehören. Die linke, weibliche Figur auf Kat. 5 steht neben zwei schmalen männlichen Mantelfiguren in Frontansicht ins Profil gedreht. Ist ihr abstehender Mantelrand der aufgestützten Muse verwandt? Ohne Parallele ist das lange Podest auf Kat. 8, das links bis an den Bildrand reicht, rechts aber vor diesem endet. Auf ihm stehen frontal ein Mann und eine Frau sowie ein kleiner Opferaltar. Das Grabrelief mit Podest, Altar und ausführlich ausgearbeiteter Girlande ist eine bescheidene Arbeit mit besonderem Anspruch. Das schlichte Motiv einer jungen Frau mit Handspiegel auf Kat. 10 überrascht in seiner Thematik nicht. Dennoch ist es in der vorliegenden Form ein Hapax. Wer erfand das Motiv? Man mag spekulieren, ob eine Werkstatt es als geschmackvolle Erfindung von sich aus anbot, oder ob die Idee auf einen hinterbliebenen Käufer zurückgeht. Die Haltung der Frau wirkt aus der Situation heraus echt und lebendig. Der Faltenwurf ihres Chitons und durchsichtigen Mantels spiegelt hochhellenistische Formensprache, etwa der zweiten Hälfte des 2. Jahrhunderts v. Chr. An Feinheit und Schwung der Faltenwiedergabe wird er noch übertroffen von der Stele Kat. 11, einer Mutter zweier Kinder. Tatsächlich wiederholt sich das Motiv mit hochgehaltenem Handspiegel an untergeordneten, kleinen Dienerinnenfiguren kaiserzeitlicher Grabstelen aus dem westlichen Schwarzmeergebiet Thrakiens ${ }^{39}$. Ein typologischer Zusammenhang zwischen dem Hauptmotiv der hellenistischen Stele Kat. 10 in Antiochia und den stereotypen Dienerinnenfigürchen aus Odessos und Mesembria aus dem 2. Jahrhundert n. Chr. ist nicht zu erkennen. An Kat. 13 scheint der Mann an das Knie der sitzenden Frau zu greifen. Beide Gestalten wirken wie aus Musterbüchern unverstanden kombiniert.

Kat. 14. 24. 28

Als Karikatur ist das Fragment Kat. 14 zu verstehen. Das Schema der am rechten Stelenrand auf die sitzende Frau zuschreitenden Figur ist beispiellos. Das Motiv der Dexiosis von sitzender Frau und stehendem Mann wird hier für einen verwachsenen Krüppel benutzt. Sicher ist die Darstellung komisch gemeint. Umso erstaunlicher ist ihre Verwendung für ein Grabrelief, dessen links sitzende Frauengestalt den Rahmen des Üblichen nicht sprengt. Eine persönliche Absprache steht offensichtlich hinter der Komposition von Kat. 24. Dem geläufigen Schema ist eine weitere Frau zugeordnet, die eine gänzlich unübliche, emotional zu verstehende Haltung einnimmt. Ihre enge Verbundenheit mit dem Toten auf der Kline wird auf ungewöhnliche, aber überzeugende Weise deutlich gemacht. Der aus ihrer Haltung abzuleitende Käuferwunsch ist offensichtlich. Das eigenartigste Relief ist wohl die auf einem Architekturfragment wiedergegebene Mahlszene Kat. 28. So stereotyp die Reihe der sechs gelagerten Frauen und Männer wiedergegeben ist, so originell und einmalig ist die Figürchenreihe zwischen den drei sichtbaren Klinenbeinen. Schon der Umstand einer sechsbeinigen Kline ist ungewöhnlich. Will man nicht einen Scherz der Werkstatt annehmen, so liegt hier ein seltsamer, höchst individueller Auftrag vor, den anhand von bekannten Bildtypen zu verstehen nicht möglich ist. Weder handelt es sich um Dienerfiguren, noch findet sich eine Erklärung für ihre unregelmäßige Anordnung.

${ }_{39}$ PM 1453. 1416 b. 1693. 1698. 1729. 2008 Taf. 247. 248. 251. 301. 


\section{Mutter und Kind}

Gruppen von Mutter und Kind treten mit sechs Szenen unter den 32 überlieferten Exemplaren Antiochias verhältnismäßig häufig auf. Zwei unterschiedlich große Kinder begleiten die stehende Mutter auf Kat. 11. Die schlichte Darstellung hat künstlerischen Anspruch. Emotionale Werte wie auf Kat. 17 treten hier in den Hintergrund. Vier Stelen (Kat. 17-19. 22) geben die Mutter mit Kleinkind auf dem Schoß wieder. Unter ihnen erstaunt Kat. 17 durch die Innigkeit, mit der Mutter und Kind aneinander geschmiegt sind. Die Führung der Arme, auch die sorgfältig unter dem Mantel ausgearbeiteten Beine und besonders der angelehnte Kopf des Kindes vermitteln dem kleinen Werk eine zu Herzen gehende Atmosphäre. Die Stelen Kat. 11 und 17 fallen zwar nicht durch außergewöhnliche Thematik auf, sind aber so gute Arbeiten, dass man sie sich kaum als Massenware, auf Vorrat angefertigt, vorstellen möchte. Sie strahlen warmen Stimmungsgehalt aus und sprechen für das Können des Steinmetzen, der den Käuferwunsch einfühlsam umsetzte. Die übrigen vier Reliefs selber Thematik (Kat. 18-20. 22) sind von minderwertiger Qualität. Der große Abstand zur künstlerischen Wiedergaben auf Kat. 11 und 17 ist keine Frage der Produktion auf Vorrat oder privater Bestellung. Es mögen auch Aufträge billig ausgeführt worden sein, wie letztlich auch umgekehrt qualitätsvolle Arbeiten vorrätig gewesen sein mögen, sofern das Thema häufig gewünscht wurde. Kat. 20 bereichert die Typik von Mutter und Kind durch das stehend angelehnte Kind. Einmal sitzt ein Kind am Fußende auf der Totenkline (Kat. 27).

\section{Bildungsanspruch, Diener}

$\mathrm{Zu}$ registrieren ist das Fehlen aller Hinweise auf Bildungsanspruch. Buchrollen oder Handschriftenbündel finden sich nicht, sieht man auf das dünne Gebilde in der linken Hand des Mannes auf Kat. 18 ab. Was es mit den vier Mantelstatuen von Kat. 28 auf sich hat, ist noch erklärungsbedürftig. Möglicherweise ist die komische Groteske auf Kat. 14 eine Ausnahme. Hier wird der Gegenstand im Arm des Krüppels als Diptychon mit zwei Griffeln gedeutet. Eine derartige Interpretation relativiert das oben registrierte Fehlen von Bildungsanspruch und geistiger Tätigkeit in exzeptioneller Weise. Aufgrund der Dexiosis mit der Sitzenden ist die Groteske nicht als Dienerfigur einzustufen. Dienerfiguren werden auf neun Stelen in die Szene einbezogen, wo ihre Proportionen aber ohne groteskes Miniaturformat bleiben. An Kat. 6 und 12 werden sie als vollwertiger Bestandteil der Szene behandelt. Beide Male stehen die Diener mit überkreuzten Beinen. An den übrigen sieben Stelen sind die Diener stereotype Versatzfiguren. Es gibt keine Dienerin, die etwa der Herrin ein Attribut reicht, oder Diener, die eine Handlung ausführen.

\section{Ortstypischer Stil}

Die Antiochener Grabstelen verzichten auf Anhäufungen von Ausstattungsluxus und demonstrativ ins Bild gesetzten Reichtum. Sie fesseln vielmehr durch Originalität im Umgang mit konventionell tradierten Szenen. Zweimal werden die an der linken Seite des Bildfeldes Sitzenden ganz locker in halbfrontaler, dem Betrachter zugewandter Pose gezeigt (Kat. 9. 26), die Frau sogar mit leger übergeschlagenem Bein. So schlecht der Erhaltungszustand ist, so eindeutig ist das unübliche - man möchte fast sagen: unziemliche Sitzmotiv. Der Eingriff in traditionelle Schemata schafft eine intime Atmosphäre. Die Bilder strahlen eine Stimmung aus, die für den Betrachter spürbar wird. Die Gruppe mit eng an die Mutter geschmiegtem Kind auf Kat. 17 ist nachhaltig mit Leben und Sentiment erfüllt und weit entfernt, ein stereotypes Muster zu wiederholen. Die innige Umarmung von Mutter und Kind, die dicht an den Gelagerten gelehnt stehende Frau auf Kat. 24, eine andere in ihrer weiblichen Beschäftigung mit dem Spiegel auf Kat. 10, ebenso wie auch der kämpfende Krieger Kat. 2 oder die sich würdevoll präsentierende Kriegerstatue Kat. 1 sind Dokumente, die eine unmittelbare persönliche Aussage wiedergeben. Auf die Charakterisierung einer Situation oder Aktion konzentriert sich der Bildgehalt. Statt überladener Zurschaustellung von Mobiliar, Dienern und Berufsutensilien spricht die schlichte Person oder Gruppe für sich. In diesem Geist treffen sich die so unterschiedlichen Kriegerstelen Kat. 1 und 2. Als anspruchsvoll und subjektiv geprägtes Motiv gibt sich der mächtig ausho- 
lende Krieger von Kat. 2, dessen Schwert den Bildrand überschneidet. Eine Reihung von Personen wie auf Kat. 5 - zwei Männer frontal und eine Frau im Profil - ist zwar nicht absolut außergewöhnlich, zeugt aber vom Wunsch nach Auflockerung der Aktion und Leben der Bildaussage. Schließlich wirkt die eng zusammengerückte Position von Mutter und stehendem Kind auf Kat. 20 in ihrer Schlichtheit echt und natürlich. Abgewandelte Schemata dienen der Vermittlung unmittelbaren Erlebens. Der trauende Mann (Kat. 23), der frivole (Kat. 13, überinterpretiert?), die Sitzgruppe von Mann und Frau (Kat. 9) sprechen ihre persönliche, unverschlüsselt verständliche Sprache. Die intime Alltagsszene der Frau mit Spiegel (Kat. 10) begegnet in ihrer natürlichen Anmut hier das erste und einzige Mal im Rahmen des hellenistischen Reliefs; das Thema wird in der Kaiserzeit aufgegriffen oder neu entdeckt für kleine Dienerinnenfiguren in Thrakien ${ }^{40}$. Die drei Stelen (Kat. 14. 24. 28) erweisen sich als völlig singuläre Motivkombinationen. Sie folgen keinem bekannten Typus und schaffen auch keine einsetzende Tradition. Ihnen liegt ein sehr individuelles Konzept zugrunde. Das von Kat. 28 kann heute nicht mehr, das von Kat. 14 und 24 nur mühsam erklärt werden.

\section{Gesellschaft}

Breiten Raum nehmen Frauenthemen ein. Viermal liegen Frauen auf der Kline, zweimal allein, zweimal zu zweit neben Männern (Kat. 23. 26. 28. 29). Die mit steil aufgerichtetem Oberkörper liegende Frau mit unansehnlich kleiner Dienerin und der trauernde männliche Hinterbliebene im >Pudicitia<-Motiv auf Kat. 23 stellen eine ungewöhnliche Personenkombination dar. Nur wenige männliche Figuren erscheinen mit der Armhaltung der Pudicitia. Der auf niedrigem Hocker sitzende Mann von Kat. 23 wiederholt sich einmal auf Délos 316. Ein trauernder Mann sitzt hier an der linken Seite der Kline, der Hinterbliebene der liegenden Toten, denn die delische Parallele nennt die Frau im Formular. Liegende Frauen gibt es im Corpus von PM auf 18 Reliefs. Diese wenigen Beispiele kommen aus Bithynien, Paphlagonien, Isaurien, Pontos sowie drei aus Rhodos. Alle sind von recht bescheidener Qualität. Sie gehören der mittleren bis späten Kaiserzeit an; nur die rhodischen Beispiele werden von Pfuhl und Möbius in das 2. Jahrhundert v. Chr. datiert. Auf der Kline liegende Frauen sind in Antiochia keine Seltenheit. Allein mit Dienerin erscheint sie auf Kat. 29. Auf den mit mehreren Personen belegten Klinen von Kat. 26 und 28 liegen jeweils auch zwei Frauen. Auf Kat. 26 nimmt die links Sitzende eine lockere Haltung mit übergeschlagenem Bein ein. Eine derartig souveräne Einstellung gegenüber traditionellen Verhaltensmustern konnte wohl in der syrischen Metropole leichter Raum greifen als etwa in feudal geprägten Rückzugsgebieten. Eine vergleichbare Entwicklung zur Aufwertung der Rechte und Befugnisse von Frauen findet sich indessen in Rhodos und Byzantion ${ }^{41}$.

So spiegeln die 32 Grabstelen aus dem Raum Antiochia und Daphne eine Gesellschaft, die sich nicht unbedingt an Konventionen gebunden fühlt. Mit Kat. 24 ist eine Stele überliefert, deren handwerkliche Qualität als bescheiden zu gelten hat. Individuelle Käuferwünsche und deren Umsetzung waren also keine Frage einer besonders einflussreichen Klientel. Die Stele spiegelt vielmehr einen Werkstattbetrieb, der mit seinen Auftraggebern in lebhaftem Austausch stand. Diese Werkstatt mag ein mittleres oder auch kleines Unternehmen gewesen sein. Wohl kaum gingen aus ihr so repräsentative Werke wie Kat. 1 und 11 hervor. Die Anzahl an typologischen Varianten ist groß. Mit den Kriegerstelen Kat. 1 und 2, den Frauenmotiven Kat. 10 und 11, der Mutter-Kind-Gruppe Kat. 17 und auch dem variiert gemischten Totenmahl Kat. 26 und 28 sind Produkte für eine anspruchsvolle Klientel dokumentiert. Kaum, dass diese Stelen ohne Einflussnahme ihrer Besteller gearbeitet wurden oder gar in der Bildhauerwerkstatt vorrätig waren.

\section{Kunstgeschichte}

Der Antiochener Bestand umfasst neben überkommenen und wenig reflektierten Schemata einige Exemplare hoher künstlerischer Qualität. Außerdem finden sich Szenen, deren Typik weit außerhalb des geläufigen Standards angesiedelt ist. Das disparate, nicht aus systematischen Grabungen, sondern aus Zufallsfunden im

\footnotetext{
40 s. o. Anm. 39.

${ }^{41}$ Fabricius 1999, 338 Taf. 17 a; 18 a. b; 19 b; 20 a.
} 
modernen Stadtbereich stammende Material deckt in kontinuierlicher Folge eine Epoche von mehr als vier Jahrhunderten ab. Von dieser insgesamt dürftigen Überlieferung ist weder eine stilistische Kontinuität noch eine Unterscheidung von Werkstattgruppen zu erwarten. Die wenigen Grabreliefs, die Beachtung im Rahmen der hellenistischen Kunstgeschichte erfordern (Kat. 1. 10. 11. 17), wurden hier mehrfach hervorgehoben. Sie gehören dem hohen Hellenismus an. Nicht so sehr ihre Motivik als ihre künstlerische Durchführung geht über den überlieferten Standard hellenistischer Grabreliefs deutlich hinaus. Wo genau die herausragenden Stücke geschaffen wurden, ist nicht zu bestimmen, keinesfalls ausgeschlossen ist ihre Herkunft aus Antiochia selbst. Ihre künstlerisch ausgewogene Bildkomposition präsentiert beide einzeln stehende Figuren und auch die Mutter zweier Kinder wirkungsvoll in charakteristischer Pose. Eigenwillig gibt sich die Komposition der Stele Kat. 17. Eine tiefe quadratische Nische bleibt zur Hälfte ohne Relief, das Relief der Sitzenden mit Fußbank und Kind füllt die linke Seite in diagonaler Begrenzung aus und umschreibt so ein Dreieck. An den drei Personenreliefs wird der symmetrische Bezug von figürlicher Darstellung und räumlichem Hintergrund berücksichtigt. Symmetrisch ist auch die figurenreiche Stele Kat. 26 komponiert; Abweichungen vom symmetrischen Gesamteindruck im Detail sind beabsichtigt. Außergewöhnlich ist die Bildkomposition von Kat. 28. Während oben schönste Symmetrie in der Reihenfolge der Gelagerten herrscht, wird eine solche unterhalb der Gelagerten vor den Klinenbeinen bewusst umgangen, zumal sich für die vier Figürchen eine symmetrische Anordnung zwischen den drei Klinenbeinen mühelos ergeben hätte. Dergleichen lockere, wie zufällige, undurchdachte Platzierung von Figuren findet unter den antiken Reliefbildern kaum eine Parallele. Die Absicht, mit dieser Aufmerksamkeit provozierenden Bildordnung ganz persönliche Thematik zu beleuchten, wird sehr deutlich.

\section{Abgekürzt zitierte Literatur}

Ameling 1985

Ameling - Jonnes 1994

Berges - Nollé 2000

Blümel 1985

Blümel 1988

Blümel 1991

Byrne - Labarre 2006

Canali De Rossi 2004

Corsten 1985

Corsten 1987

Corsten 1991

Corsten 1997

Corsten 2002

Cremer 1991

Délos

Dreyer - Engelmann 2003

Fabricius 1999
W. Ameling, Die Inschriften von Prusias ad Hypium, Inschriften griechischer Städte aus Kleinasien 27 (Bonn 1985).

W. Ameling - L. Jonnes, The Inscriptions of Heraclea Pontica, Inschriften griechischer Städte aus Kleinasien 47 (Bonn 1994).

D. Berges - J. Nollé - R. Barcsay-Regner u. a., Tyana. Archäologisch-historische Untersuchungen zum südwestlichen Kappadokien, Inschriften griechischer Städte aus Kleinasien 55 (Bonn 2000).

W. Blümel, Die Inschriften von Iasos I. II., Inschriften griechischer Städte aus Kleinasien 28, 1. 2 (Bonn 1985).

W. Blümel, Die Inschriften von Mylasa II. Inschriften aus der Umgebung der Stadt, Inschriften griechischer Städte aus Kleinasien 34/35 (Bonn 1987/1988).

W. Blümel, Die Inschriften der rhodischen Peraia, Inschriften griechischer Städte aus Kleinasien 38 (Bonn 1991).

M. A. Byrne - G. Labarre, Nouvelles inscriptions d'Antioche de Pisidie d'après les note-books de W. M. Ramsay, Inschriften griechischer Städte aus Kleinasien 67 (Bonn 2006).

F. Canali De Rossi, Iscrizioni dello Estremo Oriente greco. Un repertorio, Inschriften griechischer Städte aus Kleinasien 65 (Bonn 2004).

T. Corsten, Die Inschriften von Kios, Inschriften griechischer Städte aus Kleinasien 29 (Bonn 1985).

T. Corsten, Die Inschriften von Apameia, Inschriften griechischer Städte aus Kleinasien 32 (Bithynien und Pylai) (Bonn 1987).

T. Corsten, Die Inschriften von Prusa ad Olympum I, Inschriften griechischer Städte aus Kleinasien 39 (Bonn 1991).

T. Corsten, Die Inschriften von Laodikeia am Lykos I, Inschriften griechischer Städte aus Kleinasien 49 (Bonn 1997).

T. Corsten, Die Inschriften von Kibyra I. Die Inschriften der Stadt und ihrer näheren Umgebung, Inschriften griechischer Städte aus Kleinasien 60 (Bonn 2002).

M. Cremer, Hellenistisch-römische Grabstelen im nordwestlichen Kleinasien I. Mysien, AMS 4, 1 (Bonn 1991).

M. T. Couilloud, Les monuments funéraires de Rhénée, Délos 30 (Paris 1974).

B. Dreyer - H. Engelmann, Die Inschriften von Metropolis I. Die Dekrete für Apollonios. Städtische Politik unter den Attaliden und im Konflikt zwischen Aristonikos und Rom, Inschriften griechischer Städte aus Kleinasien 63 (Bonn 2003).

J. Fabricius, Die hellenistischen Totenmahlreliefs (München 1999). 
French 2004

Horsley - Mitchell 2000

Jonnes 2002

Kearsley 2001

Łajtar 2000

Nollé 2001

Nollé - Schindler 1991

Özgan 1999

Parlasca 1982

PM

Ricl 1997

Schwertheim 1987
Jalabert - Mouterde 1950

D. H. French (Hrsg.), The Inscriptions of Sinope, Inschriften griechischer Städte aus Kleinasien 64 (Bonn 2004).

G. H. R. Horsley - S. Mitchell, The Inscriptions of Central Pisidia, Inschriften griechischer Städte aus Kleinasien 57 (Bonn 2000).

L. Jalabert - R. Mouterde, Inscriptions grecques et latines de la Syrie III 1 (Paris 1950).

L. Jonnes, The Inscriptions of the Sultan Dağ1 I, Inschriften griechischer Städte aus Kleinasien 62 (Bonn 2002).

R. Kearsley, Greeks and Romans in Imperial Asia (Bonn 2001).

A. Łajtar, Die Inschriften von Byzantion I, Inschriften griechischer Städte aus Kleinasien 58, 1 (Bonn 2000).

J. Nollé, Side im Altertum. Geschichte und Zeugnisse II, Inschriften griechischer Städte aus Kleinasien 44 (Bonn 2001).

J. Nollé - F. Schindler, Die Inschriften von Selge, Inschriften griechischer Städte aus Kleinasien 37 (Bonn 1991).

R. Özgan, Die Skulpturen von Stratonikeia, AMS 32 (Bonn 1999).

K. Parlasca, Die syrischen Grabreliefs hellenistischer und römischer Zeit, 3. TrWPr (Mainz 1982).

E. Pfuhl - H. Möbius, Die ostgriechischen Grabreliefs I. II (Mainz 1977-1979).

M. Ricl, The Inscriptions of Alexandreia Troas, Inschriften griechischer Städte aus Kleinasien 53 (Bonn 1997).

E. Schwertheim, Die Inschriften von Hadrianoi und Hadrianeia, Inschriften griechischer Städte aus Kleinasien 33 (Bonn 1987).

Strubbe - Schuddeboom 2005 J. Strubbe - F. Schuddeboom (Hrsg.), The Inscriptions of Pessinous, Inschriften griechischer Städte aus Kleinasien 66 (Bonn 2005).

Wagner 1976 J. Wagner, Seleukeia am Euphrat-Zeugma (Wiesbaden 1976).

Doç. Dr. Ergün Laflı

Dokuz Eylül Üniversitesi, Fen-Edebiyat Fakültesi, Arkeoloji Bölümü, Tınaztepe/Kaynaklar Yerleşkesi, Buca, TR-35160 İzmir

E-Mail: elafli@yahoo.ca

Dr. Jutta Meischner

Philipp Franck-Weg 8, D-14109 Berlin

E-Mail:meijut@t-online.de

Abbildungsnachweis: Kat. 1-9. 11. 12. 14.-22. 25. 27. 29-32: E. Lafli; Kat. 10. 13. 23. 24. 26. 28: J. Meischner. 
